\title{
AJUSTE E ENSAIO DE SISTEMAS DE PROTEÇÃO DE GERADORES SÍNCRONOS
}

Dissertação apresentada à Escola Politécnica da Universidade de São Paulo para obtenção do Título de Mestre em Ciências.

São Paulo 


\title{
AJUSTE E ENSAIO DE SISTEMAS DE PROTEÇÃO DE GERADORES SÍNCRONOS
}

\author{
Dissertação apresentada à Escola \\ Politécnica da Universidade de São \\ Paulo para obtenção do Título de \\ Mestre em Ciências.
}

Área de concentração:

Sistemas Elétricos de Potência

Orientador:

Prof. Dr. Eduardo César Senger

São Paulo

2015 
Catalogação - na - publicação

Chayña Velásquez, Omar

Ajuste e ensaio de sistemas de proteção de geradores síncronos / O. Chayña Velásquez. -- São Paulo, 2015. $139 \mathrm{p}$.

Dissertação (Mestrado) - Escola Politécnica da Universidade de São Paulo. Departamento de Energia e Automação Elétrica

1. Geração de energia elétrica. 2. Proteção de sistemas elétricos. 3. Proteção de geradores síncronos. 4. Faltas internas I. Universidade de São Paulo.

Escola Politécnica. Departamento de Energia e Automação Elétrica. II. t. 


\section{AGRADECIMENTOS}

A Deus pela oportunidade deste aprendizado. Expresso os meus agradecimentos à Escola Politécnica da Universidade de São Paulo por ter proporcionado a oportunidade de evolução pessoal, professional e acadêmica, decorrentes da pesquisa e elaboração deste trabalho de mestrado.

Ao professor Dr. Eduardo César Senger, pela dedicação, incentivo, apoio, diretrizes e orientação durante a pesquisa, desenvolvimento e elaboração deste trabalho.

Aos professores do Departamento de Engenharia de Energia e Automação Elétricas (PEA), Dr. Dorel Soares Ramos, Dr. Silvio Ikuyo Nabeta, Dr. Giovanni Manassero Junior, Dr. Eduardo Lorenzetti Pellini, pelo profissionalismo e dedicação na transmissão de conhecimentos nas disciplinas cursadas na pós-graduação em engenharia elétrica da Escola Politécnica da Universidade de São Paulo.

Ao Dr. Carlos Alberto Febres Tapia e ao engenheiro Leonardo Ramos Pereira, cujo auxilio viabilizou a conclusão desta dissertação. Aos colegas do Laboratório de Pesquisa em Proteção de Sistemas Elétricos (L-PROT).

A todos os professores do departamento de Engenharia Elétrica, da Escola de Engenharia de São Carlos (EESC-USP), em especial ao professor Dr. Mário Oleskovicz, Dr. Denis Vinicius Coury, pelo apoio e incentivo.

Ao Conselho Nacional de Desenvolvimento Científico e Tecnológico (CNPq) pela apoio financeiro para realização desta pesquisa.

Aos meus pais Dionisio e Teonila e aos meus irmãos Leonardo e Sixto pelo apoio incondicional. À Diana por suas palavras de apoio, carinho, compreensão e estímulo durante todo o período de elaboração deste trabalho. 


\section{RESUMO}

Os sistemas de proteção dos elementos da rede elétrica desempenham um papel de fundamental importância na segurança e confiabilidade dos sistemas de potência. A não atuação ou a atuação incorreta dos relés de proteção durante uma falta localizada em um componente da rede pode transformar-se em um evento sistêmico de grandes proporções (blecaute). Esses eventos trazem riscos e elevados prejuízos econômicos à sociedade.

A proteção dos geradores síncronos, apesar do alto custo e complexidade deste tipo de equipamento, não recebe a mesma atenção na literatura que a dedicada à proteção de outros elementos da rede, como, por exemplo, a das linhas de transmissão. Isso decorre do menor número de geradores existentes na rede e também da ideia que as faltas neste tipo de equipamento são menos frequentes.

Este trabalho aborda os principais aspectos envolvidos com o projeto de um sistema de proteção para geradores síncronos de grande porte. Incialmente, discutese os principais conceitos associados com os geradores, de interesse para a tarefa de proteção. Particular atenção é dedicada às formas de aterramento e aos critérios adotados para projeto do resistor de aterramento utilizado nesse equipamento.

Em seguida, apresentam-se as principais funções de proteção aplicáveis aos geradores, particularmente aquelas voltadas para a detecção de faltas nos enrolamentos do estator. Discute-se também os critérios de ajustes dos parâmetros dessas funções.

Descreve-se o uso de uma plataforma laboratorial, baseada em simulador de tempo real (RTDS), para ensaio e análise do sistema de proteção visando validar seu correto desempenho frente às possíveis condições operativas que podem ser encontradas em campo.

Finalmente, utilizando os conceitos desenvolvidos ao longo do trabalho, desenvolve-se um estudo de caso, onde é realizado o projeto e implementação do sistema de proteção dos geradores de uma usina hidrelétrica hipotética. Para avaliar e analisar o desempenho do sistema de proteção dessa rede exemplo, parametrizou-se o IED G60 (GE) e realizou-se inúmeras simulações na plataforma de testes proposta.

Palavras chaves: Geração de Energia Elétrica, Proteção de Sistemas Elétricos, Proteção de Geradores Síncronos, Proteção Digital, Relé Microprocessado, Faltas Internas, Real Time Digital Simulator. 


\begin{abstract}
Protection systems play a critical role in the safety and reliability of electric power systems. The non-operation or wrong operation of protective relays during a fault in a network element can evolve to a systemic event in large scale (blackout). These events bring risks and high economic losses to society.

Despite the high cost and complexity, the protection of synchronous generators has not received much attention in the literature devoted to protection of other network elements, such as transmission lines. This stems from the smaller number of generators in the network and also the idea that the faults in this type of equipment are less frequent.

This research discusses the main aspects involved in the design of a protection system for large synchronous generators. Initially, it discusses the key concepts of interest to the generation protection. Particular attention is given to grounding techniques and the criteria adopted for the design of grounding resistors used in those equipment. Then the main protection functions applicable to generators are presented, particularly those related to fault detection in the stator windings. The criteria for setting the parameters of these functions are also discussed.

After that, the use of a laboratory shelf, based on Real-Time Digital Simulator (RTDS) for testing and analysis of the protection system, is described in order to validate the correct performance in face of possible operating conditions in the field.

Finally, a study case is developed using the concepts developed throughout the research. Then, the design and implementation of the protection system of generators of a hypothetical hydroelectric plant are carried out. To evaluate and analyze the performance of this example network protection system, parameterized up IED G60 (GE) and held numerous simulations in the proposed test platform.
\end{abstract}

Keywords: Electric Power Generation, Power System Protection, Synchronous Generator Protection, Digital Relay, Microprocessor Relay, Internal Fault, Real Time Digital Simulator 


\section{LISTA FIGURAS}

Figura 2.1 - Máquina síncrona.

Figura 2.2 - Gerador ligado a um barramento infinito e diagrama fasorial correspondente.

Figura 2.3 - Diagrama fasorial para o gerador no limite de estabilidade.

Figura 2.4 - Diagrama fasorial do gerador em operação potência ativa variável e de excitação constante.

Figura 2. 5 - Diagrama fasorial de um gerador de polos salientes representação dois eixos.

Figura 2.6 - Curva carasterística de $\mathrm{P}=\mathrm{f}(\delta)$ de um gerador de polos salientes.

Figura 2.7 - Curva carasterística de $\mathrm{Q}=\mathrm{f}(\delta)$ de um gerador de polos salientes.

Figura 2.8 - Curva típica de capacidade de um gerador de polos salientes.

Figura 2.9 - Curva V d e um gerador de polos salientes.

Figura 2.10 - Aterramento de baixa impedância.

Figura 2.11 - Aterramento de alta impedância.

Figura 3.1 - Diagrama de blocos de um relé digital ou microprocessado.

Figura 3.2 - Sistema de proteção de um gerador síncrono e transformador.

Figura 3.3 - Proteção diferencial de um gerador síncrono.

Figura 3.4 - Falta externa com relé diferencial.

Figura 3.5 - Falta interna com relé diferencial.

Figura 3.6 - Proteção diferencial tipo autobalanço. 
Figura 3.7 - Proteção diferencial porcentual.

Figura 3.8 - Curva característica diferenciais percentuais de relés.

Figura 3.9 - Multiplicador da corrente de pick up em função da tensão terminal em relés da série UR da GE.

Figura 3.10 - Proteção retaguarda de um gerador síncrono.

Figura 3.11 - Configuração de um sistema com alimentação múltiplo.

Figura 3.12 - Esquema de proteção de sobretensão no nuetro.

Figura 3.13 - Representação típica de terceiro harmônico.

Figura 3.14 - Esquema de subtensão de terceiro harmônico.

Figura 3.15 - Injeção de tensão subharmônico.

Figura 3.16 - Característica do relé Mho - Offset de uma zona.

Figura 3.17 - Proteção contra sobreexcitação.

Figura 3.18 - Proteção contra correntes desbalanceadas.

Figura 4.1 - Simulador de tempo real utilizado nos ensaios.

Figura 4.2 - Simulação em tempo real em laço fechado com RTDS.

Figura 4.3 - Rede exemplo utilizado neste trabalho.

Figura 4.4 - Esquema simulado no RTDS.

Figura 4.5 - Configuração do modelo de máquina síncrona no incorporado no RTDS.

Figura 4.6 - Circuito para geração da componente de terceira harmônica das tensões. 
Figura 4.7 - Soma das tensões de $60 \mathrm{~Hz}$ e $180 \mathrm{~Hz}$ para as tensões de neutro.

Figura 4.8 - Tensões de fase e neutro para gerador operando com carga pesada.

Figura 4. 9 - Tensões de fase e neutro para gerador operando com carga leve.

Figura 4.10 - Lógica de controle de máquina no RTDS.

Figura 4.11 - Lógica de faltas no RTDS.

Figura 4.12 - Lógica de falta externa no RTDS.

Figura 4.13 - Lógica do relé no RTDS.

Figura 4.14 - Logica do disjuntor.

Figura 4.15 - Diagrama de blocos do sistema de excitação e controle de tensão.

Figura 4.16 - Diagrama de blocos para turbina e regulador de velocidade.

Figura 4.17 - Rede simulada no RTDS.

Figura 4.18 - Controle do sistema simulado.

Figura 5.1 - Diagramas sequênciais para a rede exemplo.

Figura 5.2 - Forma de aterramento do gerador G1.

Figura 5.3 - Diagramas sequenciais reduzidos.

Figura 5.4 - Correntes para curto circuito trifásico interno.

Figura 5.5 - Correntes para fase-terra interna nos terminais do gerador.

Figura 5.6 - Característica diferencial percentual ajustada para função 87G.

Figura 5.7 - Resposta da função $87 G$ para curto circuito trifásico e fase terra 
nos terminais do gerador.

Figura 5.8 - Rede simulada no Matlab.

Figura 5.9 - Corrente e impedância medida durante curto circuito trifásico no final da linha.

Figura 5.10 - Localização da impedância medida durante o curto circuito trifásico no final da linha.

Figura 5.11 - Associação dos diagramas sequênciais para falta fase-terra dos terminais do gerador.

Figura 5.12 - Diagrama de sequência zero considerando-se a componente de $180 \mathrm{~Hz}$ nas tensões de fase.

Figura 5.13 - Detalhes da função implementada no IED G60 da GE.

Figura 5.14 - Curto dupla - fase $(A B)$ nos terminais do gerador, interno à zona de proteção do $87 \mathrm{G}$.

Figura 5.15 - Curto fase-terra (AN) nos terminais do gerador, interno à zona de proteção do 87G.

Figura 5.16 - Curto fase-terra (NA) nos terminais do gerador, externo à zona de proteção do $87 \mathrm{G}$.

Figura 5.17 - Curto circuito fase - terra no estator a $15 \%$ do centro estrela.

Figura 5.18 - Curto circuito fase - terra no estator a $15 \%$ do centro estrela.

Figura 5.19 - Curto circuito fase - terra no estator a $5 \%$ do centro estrela carga pesada.

Figura 5.20 - Curto circuito fase - terra no estator a 5\% do estrela - carga pesada.

Figura 5.21 - Curto circuito fase - terra no estator a $5 \%$ do centro estrela - 
carga leve.

Figura 5.22 - Curto circuito fase - terra no estator a $5 \%$ do centro estrela carga leve.

Figura 5.23 - Curto circuito dupla - fase (AB) no final da linha de transmissão $R_{F A L L A}=0,5$ ohms.

Figura 5.24 - Curto - circito dupla - fase (AB) no linha LT ( $R_{F A L L A}=0,5$ ohms).

Figura 5.25 - Perda de excitação do gerador.

Figura 5.26 - Motorização do gerador. 


\section{LISTA DE TABELAS}

Tabela 2.1 - Perturbações no gerador síncrono.

Tabela 2.2 - Pertubações no gerador síncrono.

Tabela 2.3 - Falha dos equipamentos de uma usina hidrelétrica.

Tabela 3.1 - Funçoes de proteção aplicáveis a geradores síncronos.

Tabela 4.1 - Características elétricas do gerador síncrono.

Tabela 4.2 - Constantes do sistema de excitação e controle do gerador síncrono.

Tabela 43 - Constantes dos reguladores e turbina a vapor do sistema RTDS.

Tabela 4.4 - Dados constructivos das linhas d etransmissão no RTDS. 


\section{LISTA DE SÍMBOLOS E ABREVIATURAS}

\begin{tabular}{ll} 
FMM & Forçã magneto motriz \\
F & Enrolamento de campo \\
Q & Eixo direto \\
$\omega_{r}$ & Eixo de quadratura \\
$\theta_{r}$ & Velocidade angular \\
$\omega_{A}$ & Deslocamento angular \\
$\omega_{B}$ & Velocidade angular máquina A \\
\hline
\end{tabular}

$E_{R A}, E_{R B}, E_{S A}, E_{S B}, E_{T A}, E_{T B}$ Diferencia potencial entre os terminais da chave.

$S$

Potência

V

Tensão

f

Frequência

$\mathrm{R}_{\mathrm{T}}$

Resistência de aterramento

$V_{\text {prim }}$

Tensão no primário

$\mathrm{V}_{\mathrm{sec}}$

Tensão no secundário

$I_{N}$

Corrente de falta

$\mathrm{V}_{\mathrm{NF}}$

Tensão fase neutro

$\mathrm{P}_{\mathrm{RT}}$

Potência da resistência de aterramento

StRAFO

Potência nominal do transformador 
$T_{C S}$

TPS

$\mathrm{S} / \mathrm{H}$

RAM

SDRAM

EEPROM

RTDS

RAT

$\mathrm{I}_{0}$

$I_{R}$

$\mathrm{L}_{\text {atf }}$

$\mathrm{K}_{\mathrm{f}}$

$\operatorname{lng}$

$\mathrm{R}_{\mathrm{TC}}$

$\mathrm{l}_{\text {actf }}$

$\mathrm{T}_{\mathrm{pm}}$

$\mathrm{T}_{\mathrm{acr}}$

$\mathrm{K}_{\mathrm{n}}$

$I_{m}$
Transformadores de corrente

Transformadores de potencial

Sample and hold

Read only momery

Synchronous dinamics access memory

Electrically erasable programable read only memory

Real time digital simulator

Automatic voltage regulator

Corrente de operação

Corrente de restrição

Corrente de ajuste da unidade temporizada de fase

fator de sobrecarga admissível

Corrente nominal do gerador

Relação de transformação de corrente do

transformador de corrente

Corrente de acionamento da unidade temporizada fase

Tempo de partida do motor

Tempo de acionamento da unidade temporizada fase

Fator de desequilíbrio de corrente admissível

Corrente máxima 
$\mathrm{I}_{\mathrm{atm}}$

Ing:

$\mathrm{l}_{\mathrm{actm}}$

27TH

$\mathrm{A} 1, \mathrm{~A} 2$

NA1, NB1, NC1

TL21

TL22

TL6

$\mathrm{H}$

D

$X_{a}$

$X_{d}$

$X_{d}^{\prime}$

$\mathrm{X}^{\prime \prime}$

$X_{q}$

$X_{q}^{\prime}$

$\mathrm{X}_{\mathrm{q}}$

$\mathrm{R}_{\mathrm{a}}$
Corrente de ajuste da unidade temporizada de neutro

Corrente nominal do transformador

Corrente de acionamento da unidade temporizada de neutro

Relé de subtensão de terceiro harmônico

Subenrolamentos da bobina na fase $\mathrm{A}$

Nós de tensão no terminal da máquina

Trecho da linha de circuito simples

Trecho da linha de circuito simples

Trecho da linha de circuito duplo

Constante de inércia (MW/MVA)

Amortecimento (pu/pu)

Reatância do estator (pu)

Reatância síncrona de eixo d (pu)

Reatância transitória de eixo d (pu)

Reatância sub-transitória de eixo d (pu)

Reatância síncrona de eixo q (pu)

Reatância transitória de eixo q (pu)

Reatância sub-transitória de eixo q (pu)

Resistência do estator (pu) 
$T^{\prime}$ do

T"do

$\mathrm{T}_{\mathrm{qo}}{ }^{\prime}$

$\mathrm{T}{ }_{\mathrm{q} o}$

$X_{s 1}$

$X_{\text {mdo }}$

$X_{2 d}$

$X_{3 d}$

$X_{m q}$

$X_{2 q}$

$\mathrm{R}_{\mathrm{s} 1}$

$\mathrm{R}_{2 \mathrm{~d}}$

$\mathrm{R}_{3 \mathrm{~d}}$

$\mathrm{R}_{2 \mathrm{q}}$

$M_{x z r o}$
Constante de tempo transitória de circuito aberto no eixo $d(p u)$

Constante de tempo sub-transitória de circuito aberto no eixo d (pu)

Constante de tempo transitória de circuito aberto no eixo q (pu)

Constante de tempo sub-transitória de circuito aberto no eixo $\mathrm{q}(\mathrm{pu})$

Reatância do estator

Reatância de dispersão não saturado de eixo direto (pu)

Reatância de dispersão de campo de eixo direto (pu)

Reatância de dispersão de amortecedor de eixo direto (pu)

Reatância de magnetização de eixo de quadratura (pu)

Reatância de dispersão de campo de eixo de quadratura (pu)

Resistência do estator (pu)

Resistência de campo (pu)

Resistência de amortecedor de eixo direto (pu)

Resistência de amortecedor de eixo de quadratura (pu)

Reatância de sequência zero da máquina (pu) 


\section{SUMÁRIO}

CAPITULO 1

1.1 INTRODUÇÃO

1.2 ORGANIZAÇÃO DO TRABALHO

CAPITULO 2

CARACTERISTICAS GERAIS E APLICAÇÕES DE GERADORES

SINCRONOS

INTRODUÇÃO

2.1 GERADORES SÍNCRONOS

2.2 PERTURBAÇÕES NO GERADOR SÍNCRONO

2.3 OPERAÇÃO DE GENERADORES SÍNCRONOS NO SISTEMA ELÉTRICO

2.4 GERADORES DE POLOS SALIENTES

2.5 LIMITES OPERACIONAIS DOS GERADORES SÍNCRONOS

2.6 MÉTODOS DE ATERRAMENTO

2.6.1 ATERRAMENTO SÓLIDO

2.6.2 ATERRAMENTO DE BAIXA IMPEDÂNCIA

2.6.3 ATERRAMENTO DE ALTA IMPEDÂNCIA

CAPITULO 3

PROTEÇÃO DE GERADORES SINCRONOS

3.1 INTRODUÇÃO

3.2 EVOLUÇÃO DE TECNOLOGIAS DE PROTEÇÃO

3.3 ARQUITETURA DO RELÉ DIGITAL 42

3.4 FUNÇÕES DE PROTEÇÃO APLICADAS AOS GERADORES SÍNCRONOS

3.5 PROTEÇÃO DIFERENCIAL DO GERADOR SÍNCRONO __ 49

3.5.1 PROTEÇÂO DIFERENCIAL DO TIPO AUTOBALANÇO _—

3.5.2 PROTEÇÃO DIFERENCIAL PERCENTUAL__ 53

3.6 PROTEÇÃO DE RETAGUARDA _ 56

3.6.1 PROTEÇÃO DE SOBRECORRENTE SUPERVISIONADA POR TENSÃO

3.6.2 PROTEÇÃO DE DISTÂNCIA DE FASE (FUNÇÃO 21)

3.7 PROTEÇÃO CONTRA FALTAS FASE-TERRA NO ESTATOR 61

3.7.3 SUBTENSSÃO DE TERCEIRA HARMÔNICA NO NEUTRO $(2 \overline{7 \mathrm{H}})-64$

3.7.4 ESQUEMA DE INJEÇÃO DE TENSÃO SUBHARMÔNICA — 66

3.8 PROTEÇÃO CONTRA FALTAS ENTRE ESPIRAS —_ 67

3.9 PROTEÇÃO CONTRA SOBRE E SUBTENSÃO_ 68

3.10 PROTEÇÃO CONTRA PERDA DA EXCITAÇÃO__ 69

3.11 PROTEÇÃO CONTRA SOBREEXCITAÇÃO 71

3.12 PROTEÇÃO CONTRA CORRENTES DE DESEQUILÍBRIO NO ESTATOR

3.13 PROTEÇÃO CONTRA MOTORIZAÇÃO __ 75

CAPITULO 4 77

PLATAFORMA PARA ENSAIOS E VALIDAÇÃO DE SISTEMAS DE PROTEÇÃO 
4.1 ENSAIOS DE SISTEMAS DE PROTEÇÃO DE GERADORES EM SIMULADOR DE TEMPO REAL

- $\quad$ Cartões de entradas analógicas (GTAI) - total de 24 canais para entrada de sinais analógicos.

4.2 DESCRIÇÃO DO SISTEMA SIMULADO 78

4.3 GERADOR SÍNCRONO 80

4.5. TURBINA E REGULADOR DE VELOCIDADE ___ 93

4.6 LINHAS DE TRANSMISSÃO__ 94

CAPITULO 5 98

ESTUDO DE CASO: AJUSTE E ENSAIO DE SISTEMA DE PROTEÇÃO DE GERADORES 98

Na base 160 MVA, as impedâncias mostradas na figura 5.1, assumem os seguintes valores:

5.1.1 DEFINIÇÃO DO TRANSFORMADOR DE CORRENTE (TC) 100

5.1.2 DEFINIÇÃO DO TRANSFORMADOR DE POTENCIAL (TP) 103

5.1 .3 AJUSTE DAS FUNÇÕES DE PROTEÇÃO PARA FALTAS ENTRE FASE NO ESTATOR

5.1.4 AJUSTE DA FUNÇÃO DE DISTÂNCIA (21) __ 107

5.1.5 FUNÇÃO DESBALANÇO DE CORRENTE ___ 116

5.1.6 FUNÇÃO PERDA DE EXCITAÇÃO____ 116

5.1.7 FUNÇÃO ANTI-MOTORIZAÇÃO 117

5.2.1 SIMULAÇÃO DE FALTAS NOS TERMINAIS DO GERADOR 119

5.2.2 SIMULAÇÃO DE FALTAS INTERNAS AO ESTATOR ___ 124

5.2.3 SIMULAÇÃO DE FALTAS NAS LINHAS DE $345 \mathrm{KV} \_130$

5.2.4 SIMULAÇÃO DE PERDA DE EXCITAÇÃO____ 131

5.2.5 SIMULAÇÃO DE MOTORIZAÇÃO DO GERADOR ___ 132

CAPITULO $6 \_133$

CONCLUSÕES E CONSIDERAÇÕES FINAIS __ 133

REFERENCIAS BIBLIOGRÄFICAS _ 136 


\section{CAPÍTULO 1}

\subsection{INTRODUÇÃO}

Os sistemas de proteção da rede elétrica de potência têm como principal função a detecção da ocorrência de faltas nos equipamentos primários visando desconectá-los da rede, de forma rápida e automática, evitando, assim, que uma falta localizada evolua para um evento sistêmico (blecaute).

A ocorrência de blecautes em um sistema elétrico de potência de grandes dimensões, como é caso do sistema interligado brasileiro, acarreta sérios riscos e prejuízos econômicos à sociedade. Por essas razões, os técnicos responsáveis pelo planejamento, projeto e operação da rede elétrica têm de tomar todas as providências e precauções para minimizar ao máximo a possibilidade de ocorrência desse tipo de evento

Dentre as principais causas de faltas nos equipamentos primários, que se não forem prontamente isolados podem levar a falhas sistêmicas de grandes proporções, estão os curtos circuitos, normalmente produzidos por descargas atmosféricas, surtos de chaveamentos e falhas de isolação.

Nesse contexto, os sistemas de proteção devem operar para atenuar os efeitos provocados por situações anormais e evitar danos irreversíveis nos equipamentos. Para realizar essa tarefa os sistemas de proteção estão baseados fundamentalmente na operação de relés de proteção, componentes capazes de acionar a isolação de elementos ou zonas que estejam sendo afetadas quando ocorrem faltas que possam provocar explosões, incêndios e, em situações extremas, comprometer a estabilidade do sistema elétrico.

São esses motivos que destacam a importância dos relés nos sistemas de proteção e suas notáveis mudanças em razão do avanço da tecnologia. Inicialmente, os relés de proteção utilizavam tecnologia eletromecânica, na maioria dos casos baseado no princípio Ferraris, para produzir movimentos mecânicos. Estes relés praticamente não são mais comercializados. 
Com o decorrer dos anos foram introduzidos os relés de estado sólido, cujo funcionamento é caracterizado pela ausência de movimentos mecânicos, dado que, utilizam dispositivos semicondutores e, por esse motivo, são também chamados relés estáticos.

No final dos anos sessenta apareceram os primeiros artigos investigando a aplicação de um minicomputador, utilizados na época para o controle de processos industriais, para implementar as funções de proteção dos vários equipamentos de uma subestação elétrica. Era o início da tecnologia digital sendo aplicada à proteção de sistemas elétricos de potência.

Entre as principais limitações enfrentadas nessas aplicações estavam o preço, tamanho e a baixa capacidade computacional dessas máquinas, além do elevado consumo de potência para seu funcionamento. No entanto essas tentativas foram bem aproveitadas no desenvolvimento dos algoritmos para as funções de proteção.

A partir do final dos anos setenta houve significativo avanço no desenvolvimento do hardware digital e as limitações do passado começaram a ser superadas gradativamente.

A partir das décadas de 80 e 90, o hardware digital passa a substituir de forma mais sistemática as tecnologias anteriores (eletromecânica e estática) na implementação dos relés de proteção. A partir desse período, duas importantes mudanças tecnológicas ocorreram:

Começa uma tendência no sentido de incentivar o desenvolvimento de protocolos de comunicação abertos e padronizados em substituição aos protocolos proprietários utilizados, até então, na automação das instalações elétricas de potência. Dois marcos dessa tendência foram a IEC 60870-5 (1995), protocolo para sistema SCADA orientado a lista de pontos, e a IEC 61850(2004), primeiro protocolo SCADA orientado a objeto. Em paralelo, a tecnologia de redes de comunicação avança de forma significativa, alcançando-se altas velocidades de transmissão de dados e redução nos custos dos equipamentos de rede. 
Com o crescente poder computacional dos processadores, os relés tornam-se equipamentos multifuncionais, englobando funções de proteção, controle, medição, oscilografia, registro de eventos e localização de faltas e passam a ser denominados IEDs (Inteligente Electronic Devices). Com o uso da proteção digital, diversas funções de proteção antes desempenhadas por diferentes relés passaram a ser agregadas em um mesmo hardware, reduzindo o número de equipamentos necessários para implementar o sistema de proteção.

Dentre os equipamentos do sistema elétrico de potência, o gerador síncrono, apesar de sua alta complexidade e custo, em termos de proteção, recebe pouca atenção quando comparado com as numerosas linhas de transmissão e transformadores também presentes nesse sistema. Isso decorre do menor número de geradores existentes na rede de potência e da ideia de que os geradores apresentam uma frequência de faltas bastante inferior à verificada em outros componentes da rede. $\mathrm{Na}$ realidade, os geradores síncronos também estão continuamente sujeitos às faltas $e$ as suas consequências podem ser muito severas, gerar elevados custos de reparo e, em casos extremos, danos irreversíveis.

Um estudo de proteção cuidadoso deve ser executado antes de se considerar que um gerador está devidamente protegido. No tutorial sobre proteção de geradores, apresentado na referência [28], descrevem-se diversos esquemas que tem o propósito de proteger os enrolamentos dos geradores síncronos.

Visando garantir que o sistema de proteção seja suficientemente seguro e eficaz, é conveniente simular e avaliar através de modelos matemáticos adequados o funcionamento dos geradores síncronos em diversas situações de operação e de ocorrência de faltas, com a finalidade de testar se a solução de proteção adotada evita potenciais danos. Para realizar essas simulações uma representação convencional de geradores síncronos está baseada na teoria dq0, a qual é bastante utilizada e tem gerado inúmeros trabalhos que analisam o comportamento transitório e de regime permanente do gerador. 
Nesta teoria é assumido que os enrolamentos, tanto os não defeituosos como os defeituosos, em casos de falhas, criam ondas de força magnetomotriz no entreferro perfeitamente senoidais [15]. Uma desvantagem da teoria dq0 é a impossibilidade de mostrar os componentes harmônicos produzidos pela distribuição não senoidal dos enrolamentos e da permeância.

Durante a ocorrência de faltas nos enrolamentos do estator dos geradores síncronos a FMM torna-se menos senoidal e gera divergência com a hipótese de FMM perfeitamente senoidal considerada na teoria dq0.

Na tecnologia atual, o RTDS "Real Time Digital Simulator" (Simulador Digital em Tempo Real) é um hardware de elevada capacidade computacional para simulação em tempo real de sistemas elétricos de potência capaz de avaliar o desempenho de sistemas de proteção de equipamentos e dispositivos de controle de forma bastante eficiente.

Nos próximos capítulos deste trabalho discute-se, principalmente as funções de proteção aplicáveis à detecção de faltas nos enrolamentos do estator, os procedimentos para ajuste dos parâmetros dessas funções e as técnicas disponíveis de ensaios em laboratório visando avaliar a eficácia do sistema de proteção projetado.

\subsection{ORGANIZAÇÃO DO TRABALHO}

O trabalho está estruturado da seguinte forma:

No capítulo 1, discute-se a importância do sistema de proteção para a detecção e eliminação de faltas em geradores síncronos. Apresenta-se uma visão geral dessa área de pesquisa e também a estrutura na qual este trabalho de pesquisa foi elaborado.

No capítulo 2 descreve-se os aspectos da operação dos geradores de interesse para a tarefa de proteção. A seguir apresenta-se a modelagem dos geradores síncronos a partir da teoria dq0. Finalmente descrevem-se as formas de aterramento dos geradores e os critérios para dimensionamento do resistor de aterramento. 
No capítulo 3, discute-se a evolução das tecnologias utilizadas na implementação dos relés de proteção e as funções aplicáveis à proteção dos geradores síncronos. Ênfase especial é colocado na proteção de $100 \%$ do enrolamento do estator para faltas fase-terra.

No capítulo 4 é apresentado uma plataforma laboratorial para realizar ensaios de sistemas de proteção com a utilização de um simulador de tempo real. Neste trabalho, essa plataforma é baseada na utilização do simulador RTDS, o qual é uma ferramenta para simulação em tempo real de sistemas elétricos de potência com um funcionamento tipo hardware-in-loop. Com a utilização dessa plataforma é possível avaliar o desempenho do sistema de proteção projetado para todas as possíveis condições operativas do sistema e tipos de falta. Como os modelos de geradores síncronos disponíveis no RTDS baseiam-se na teoria dq0, os quais não disponibilizam informações sobre o conteúdo harmônico das tensões de fase, nesse capítulo é apresentada uma solução para viabilizar a realização de ensaios das funções de proteção que monitoram a terceira harmônica presente nas tensões do neutro e dos terminais do gerador (funções de $100 \%$ de proteção do estator).

Os conceitos desenvolvidos ao longo desses capítulos são aplicados a um estudo de caso, o qual é apresentado no capítulo 5. Nesse estudo é realizado o ajuste dos parâmetros das principais funções aplicáveis à proteção dos geradores de uma rede exemplo. Discute-se também os resultados das simulações realizadas na plataforma de ensaios para avaliar o desempenho do sistema projetado. Finalmente, no capítulo 6 são apresentadas as conclusões. 


\section{CAPÍTULO 2}

\section{CARACTERÍSTICAS GERAIS E APLICAÇÕES DE GERADORES SÍNCRONOS}

\section{INTRODUÇÃO}

Pela sua importância para um sistema elétrico de potência e principalmente pela gravidade dos danos que faltas ou mesmo a operação em condições anormais podem produzir, os geradores devem ser convenientemente protegidos, visando garantir a integridade de suas partes elétricas e mecânicas. Assim, é importante e fundamental que estas faltas e condições anormais de operação sejam prontamente reconhecidas e rapidamente eliminadas, evitando a extensão dos danos. Para atender esses requisitos, as proteções aplicadas aos geradores devem ser acima de tudo rápidas, confiáveis e seletivas [40]. Neste capítulo são apresentadas as características gerais dos geradores síncronos, incluindo a descrição matemática para modelagem dos circuitos do estator e rotor da máquina síncrona por meio de suas equações representativas. Discutem-se também os tipos de perturbações, às quais o gerador está sujeito durante sua operação. Finalmente se dá ênfase aos métodos de aterramento do estator, o qual tem um papel importante no desempenho da proteção contra faltas nos enrolamentos do estator.

\subsection{GERADORES SÍNCRONOS}

Os geradores síncronos são máquinas elétricas dinâmicas destinadas à geração de energia elétrica, através da conversão de energia mecânica rotacional por meio da utilização de turbinas instaladas em usinas hidrelétricas e termelétricas dentre outras. São chamados de síncronos em razão da existência de sincronismo devido à velocidade elétrica de giro do rotor ser a mesma do campo magnético. Estes geradores podem ser de polos salientes ou de polos lisos. 
Os geradores de polos salientes possuem alto número de polos e são comumente utilizados em usinas hidrelétricas e acionadas por turbinas que operam com baixas velocidades, já os geradores de polos lisos possuem baixo número de polos e são empregados em usinas termelétricas acopladas com turbinas que giram com altas velocidades. A seguir é apresentado na figura 2.1 o esquema de um gerador síncrono elementar com rotor de dois polos, onde consideram-se três enrolamene fase na armadura do estator ( $a, b, c)$, um enrolamento de campo ( $F$ ) e dois enrolamentos amortecedores (um de eixo direto (D) e outro de eixo em quadratura $(\mathrm{Q})$ ), nessa figura pode-se considerar a distribuição de cada enrolamento de fase deslocado de $120^{\circ}$ dos outros. A velocidade angular e o deslocamento angular do rotor (entre o eixo direito $\mathrm{e}$ eixo da fase a) são definidos como $\omega_{r}$ e $\theta_{r}$ respectivamente. A descrição matemática para o modelo de gerador síncrono mostrado na figura 2.1.

Figura. 2.1 - Máquina Síncrona.

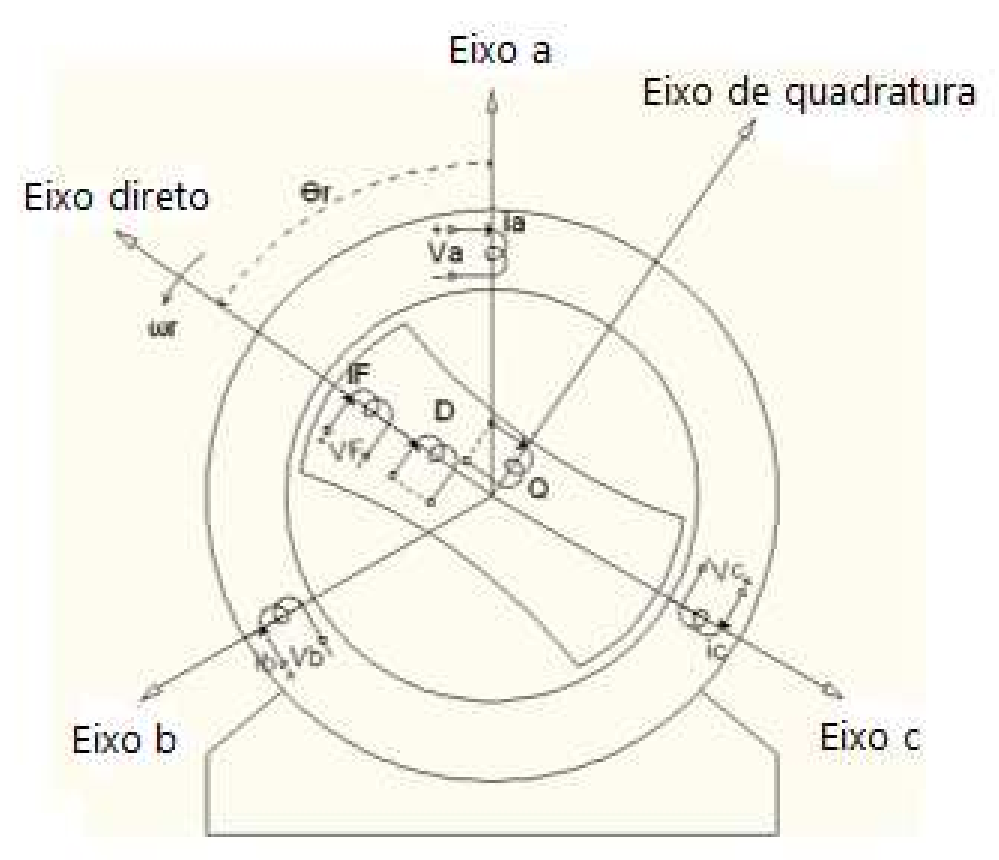

Fonte - Dehkordi A. B. Thesis University of Manitoba Winnipeg - 2010.

As abordagens para estudos de geradores síncronos podem exigir informação muito detalhada de todas suas partes (formato do entreferro distribuição dos enrolamentos, etc). Nesse sentido, a escolha de uma modelagem, que alie simplicidade e resultados realistas, é fundamental.

Os principais elementos que compõem o gerador síncrono são: 
- Estator ou Armadura: Parte que corresponde ao estator, onde se encontram os enrolamentos das fases. Estes enrolamentos estão distribuídos com defasagem de $120^{\circ}$ entre eles. Deste modo nos enrolamentos serão induzidas tensões elétricas defasadas em 120ํำ elétricos.

- Rotor: Peça constituída por um núcleo magnético girante, envolvido pelo enrolamento de campo magnético, o qual é alimentado em corrente contínua proveniente da excitatriz para criação de um campo magnético necessário para induzir tensões nos enrolamentos do estator.

- Excitatriz: É a fonte de excitação em corrente contínua necessária para alimentar o enrolamento de campo magnético no rotor através da corrente de excitação. Existem esquemas de excitatriz com escovas e sem escovas ("brushless").

Durante a conversão, os geradores síncronos operam na geração de energia elétrica ativa, enquanto há também uma geração de energia elétrica reativa segundo o controle do nível de excitação. O funcionamento de geradores síncronos está baseado na lei de Faraday, isto significa que tensões são induzidas nos enrolamentos do estator (armadura) a partir do giro de um campo magnético criado no rotor por uma fonte excitatriz em corrente continua. Os geradores de energia elétrica revelam sua importância como elementos fundamentais para conversão de energia tão necessária na atualidade nos grandes centros de consumo pertencentes aos setores industrial, comercial e residencial.

\subsection{PERTURBAÇÕES NO GERADOR SÍNCRONO}

Um gerador síncrono está sujeito a uma série de faltas ou condições anormais durante sua operação, para as quais são requeridas medidas de proteção, visando preservar o equipamento e o sistema elétrico. Algumas dessas faltas podem ser produzidas por falhas construtivas ou de materiais como mostrado na tabela 2.1 
Tabela 2.1 - Perturbações no gerador síncrono [8].

\begin{tabular}{|c|}
\hline FALHAS CONSTRUTIVAS E DE MATERIAIS \\
\hline Falha nos materiais isolantes e não isolantes \\
\hline Envelhecimento precoce ou não dos enrolamentos \\
\hline Introdução de corpos extranhos no interior do gerador, em ambientes poluídos \\
\hline
\end{tabular}

Já com relação à origem, as faltas podem ser classificadas em internas: nos equipamentos agregados e externas, como detalhado na tabela 2.2.

Tabela 2.2 - Perturbações no gerador síncrono [8].

\begin{tabular}{|l|}
\hline ORIGEM EXTERNA \\
\hline Sobrecargas continuas \\
\hline Curtos circuitos nas linhas de transmissão \\
\hline Rejeição de carga \\
\hline Sobretensões de origem atmosférica \\
\hline Sobretensões por manobra no sistema de potência \\
\hline Perda de excitação \\
\hline Desequilíbrio de carga entre as fases \\
\hline Sobrevelocidade causada por perda de carga \\
\hline Perda de sincronismo \\
\hline Vibração do eixo do conjunto máquina primária gerador \\
\hline Temperatura externa elevada \\
\hline Deficiência do meio refrigerante \\
\hline Instalação do gerador em superfície inadequada \\
\hline ORIGEM INTERNO \\
\hline Curto circuito no rotor \\
\hline Curto circuito no estator \\
\hline Curto circuito nos terminais \\
\hline ORIGEM NOS EQUIPAMENTOS AGREGADOS \\
\hline Curto circuito nos transformadores de corrente \\
\hline Curto circuito nos transformadores de potencial \\
\hline Curto circuito no transformador elevador \\
\hline Curto circuito no circuito auxiliar \\
\hline Defeito na máquina primária (acionados por turbinas: hidráulicas, vapor, gás natural, eólicas) \\
\hline
\end{tabular}

Algumas funções de proteção de geradores se confundem com tarefas de controle, nas quais são requisitadas as intervenções do operador ou ações de controle automático, com respostas mais lentas que os relés. Alguns exemplos dessas funções são as proteções de potência reversa, falta à terra no rotor, sobrecarga (capabilidade), perda de campo, energização acidental, sobre-excitação e perda de sincronismo. 
Outros tipos de perturbações podem estar associadas a problemas com equipamentos agregados que compõem os serviços auxiliares, e cuja operação e regulagem afetam as condições de operação do gerador síncrono. Na tabela 2.3, apresenta-se um levantamento estatístico das taxas de falhas mais comuns nos equipamentos de uma usina hidrelétrica.

Tabela 2.3 - Falhas dos equipamentos de uma usina hidrelétrica [39]

\begin{tabular}{|c|c|}
\hline \multicolumn{2}{|c|}{ USINA HIDRELÉTRICA } \\
\hline EQUIPAMENTO & PERCENTUAL DE FALHAS \\
\hline Gerador & $28,72 \%$ \\
\hline Regulador de Velocidade & $21,28 \%$ \\
\hline Turbina Hidráulica & $12,23 \%$ \\
\hline Excitação & $10,10 \%$ \\
\hline Adução/Sucção & $8,51 \%$ \\
\hline Mancal & $13,30 \%$ \\
\hline Servicio Auxiliar & $4,25 \%$ \\
\hline Quadro de Comando & $1,60 \%$ \\
\hline
\end{tabular}

\subsection{OPERAÇÃO DE GENERADORES SÍNCRONOS NO SISTEMA ELÉTRICO}

Uma das condições mais frequentes de funcionamento de uma máquina síncrona é a operação em paralelo com os demais geradores que alimentam um grande sistema de potência. Quando o conjunto de máquinas ligadas em paralelo tem a capacidade tal que a inserção de uma máquina nova, independente de variações impostas à sua excitação e ao conjugado aplicado ao eixo de um particular gerador, não irá modificar a tensão e frequência do sistema, diz-se que aquele conjunto constitui um sistema de barramento infinito, isto é, um sistema infinito de geração. Essa constância de $V$ e $f$ é garantida pelos reguladores automáticos de tensão dos demais geradores e de velocidade das turbinas [6].

A figura 2.2 ilustra a conexão de uma máquina síncrona em paralelo com um sistema de potência (barramento infinito), onde desprezou-se a resistência dos enrolamentos do gerador. 
Figura. 2.2 - Gerador ligado a um barramento infinito e diagrama fasorial correspondente.
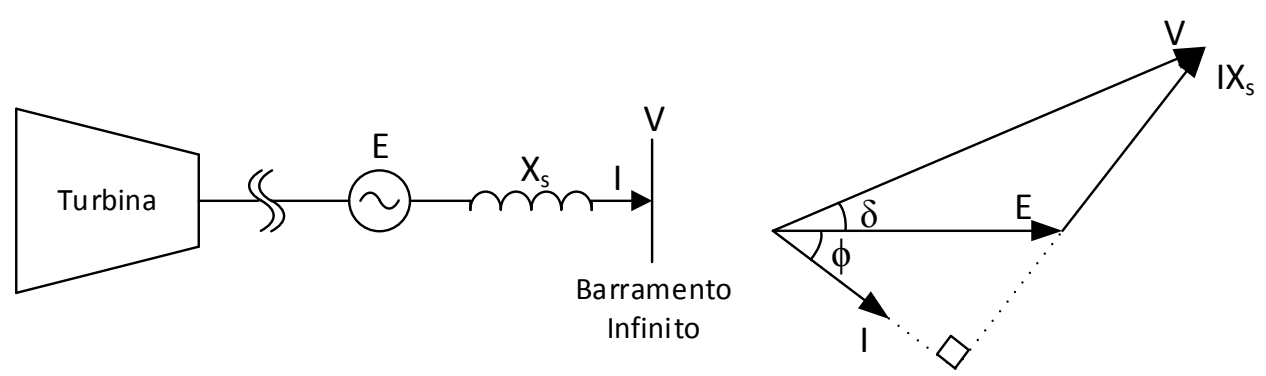

Fonte - IJB Proteção de geradores síncronos - 2012

Desprezando-se as perdas, a potência mecânica fornecida pela turbina é igual à potência elétrica fornecida pelo gerador. $O$ ângulo $\delta$ entre os fasores $E$ e $V$ é definido como ângulo de carga e é função da potência transferida da turbina para o gerador. Variando-se a potência de saída da turbina, e em consequência o ângulo $\delta$, é possível impor ao gerador qualquer carga que se deseja, dentro dos limites da máquina. Do diagrama de fasores da figura 2.2, a potência fornecida por fase ao barramento infinito é dada por VI $\cos \emptyset$ mas:

$$
\frac{E}{\operatorname{sen}(90+\emptyset)}=\frac{I X_{s}}{\operatorname{sen} \delta}
$$

Da equação acima e lembramos que $\operatorname{sen}(90+\emptyset)=\cos \emptyset$, concluímos que:

$$
I \cos \emptyset=\frac{E}{X_{s}} \operatorname{sen} \delta
$$

Logo a potência fornecida será:

$$
P=\frac{E V}{X_{S}} \operatorname{sen} \delta
$$

Esta equação é conhecida como a equação de transferência de potência e se reveste de grande importância, uma vez que se aplica amplamente nos conceitos de operação do sistema de potência. Aumentando-se gradativamente a potência fornecida pelo gerador, por meio de pequenos acréscimos, e mantendo-se constante a tensão em seus terminais, o limite de estabilidade ocorre para $\delta=90^{\circ}$, valor conhecido como limite de estabilidade de regime 
permanente. A figura 2.3 mostra um diagrama de fasores na condição limite da estabilidade de regime permanente.

Figura. 2.3 - Diagrama fasorial para o gerador no limite de estabilidade.

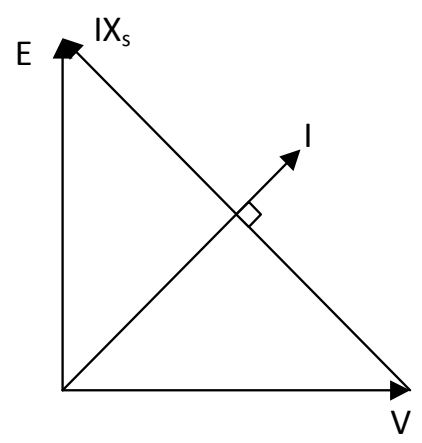

Fonte - Fonte - IJB Proteção de geradores síncronos - 2012

Há outro limite que determina a estabilidade do sistema quando ocorre uma variação brusca e de magnitude significativa nas condições de operação, como por exemplo, a ocorrência de um curto-circuito na rede. A manutenção ou não do sincronismo neste segundo caso é denominado estabilidade transitória.

Ainda usando o modelo simplificado de máquina operando em barramento infinito, a figura 2.4. mostra outra condição importante: operação com potência ativa variável e excitação constante. Neste caso como $V$ e $E$ são constantes, aumentando-se a potência ativa fornecida pela turbina, aumenta 0 valor de $\delta$ e o fator de potência varia. É conveniente resumir as condições de operação acima num diagrama único, que permita ao operador visualizar imediatamente quando a máquina está funcionando em seus limites de estabilidade ou limites de valores nominais.

Figura 2.4 - Diagrama fasorial do gerador em operação potência ativa variável e excitação cte.

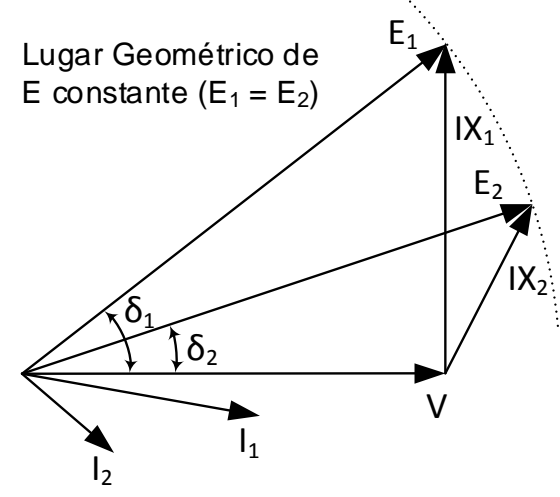

Fonte - IJB Proteção de geradores síncronos - 2012. 


\subsection{GERADORES DE POLOS SALIENTES}

Até este ponto, a reatância do eixo direto foi considerada igual à do eixo em quadratura. No caso de turbogeradores, esta hipótese é razoavelmente precisa para operação em condições de regime permanente.

Para máquinas de polos salientes, outro eixo, conhecido como eixo de quadratura, situado entre os polos principais, deve ser considerado para se obter uma representação exata da máquina. O diagrama fasorial para este caso é mostrado na figura 2.5 .

Figura 2.5 - Diagrama fasorial de um gerador de polos salientes - representação de dois eixos.

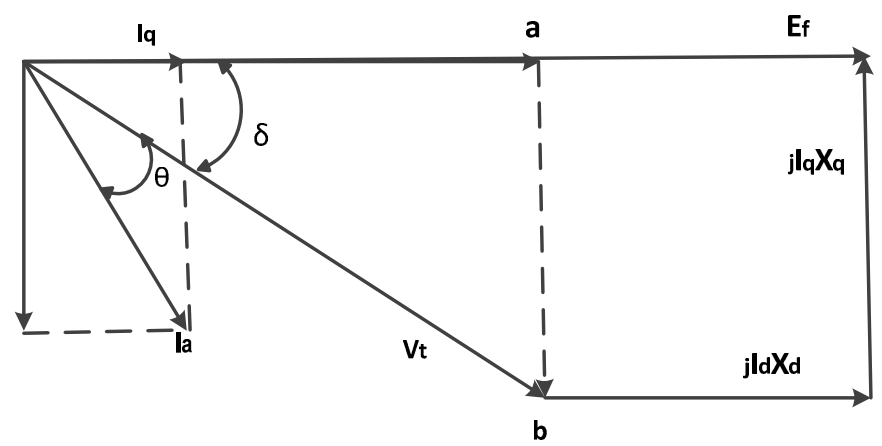

Fonte - Bimbhra P.S. - 2013

Um gerador de polos salientes que está ligado a uma barra infinita, como mostrado na figura 2.6, sua característica de potência ativa é composto de um componente senoidal principal, sobreposto por segundo componente de forma senoidal de dupla frequência.

Note-se que o aumento de potência é importante, quando a magnitude da energia característica fundamental $\left(\frac{V t E f}{X_{d}}\right)$ tem a mesma ordem que a magnitude da segunda harmônica $\left(\frac{v t^{2}\left(X_{d}-X_{q}\right)}{2 X_{d} X_{q}}\right)$. Nolmalmente, quando a fem $E_{f}$ tem um valor considerável grande, a magnitude da segunda harmônica é inferior a $10-15 \%$ da magnitude fundamental e, consequentemente, a sua influência sobre a magnitude caracterítica de energia é muito pequena.

$$
V t \operatorname{sen} \delta=a b=d c=I_{q} X_{q}
$$




$$
I_{q}=\frac{V t \operatorname{sen} \delta}{X_{q}}
$$

$$
V t \cos \delta=o a=o d-a d=o d-b c=E f-I_{d} X_{d}
$$

$$
I_{d}=\frac{E f-V t \cos \delta}{X_{d}}
$$

$$
P=\frac{V t E f}{X_{d}} \operatorname{sen} \delta+\frac{V t^{2}\left(X_{d}-X_{q}\right)}{2 X_{d} X_{q}} \operatorname{sen} 2 \delta
$$

A taxa de variação de $\mathrm{P}$ em relação ao ângulo $\delta$ é o coeficiente de sincronização de potência, é dado pela equação a seguir:

$$
\frac{d P}{d \delta}=\frac{V t E f}{X_{d}} \cos \delta+\frac{V t^{2}\left(X_{d}-X_{q}\right)}{X_{d} X_{q}} \cos 2 \delta
$$

A curva $\mathrm{P}$ em função de $\delta$ está representado na figura 2.6, donde se observa que o limite de estabilidade de regime permanente ocorre para um valor de $\delta$ menor que $90^{\circ}$.

Figura 2.6 - Curva característica de $\mathrm{P}=\mathrm{f}(\delta)$ de um gerador de pólos salientes.

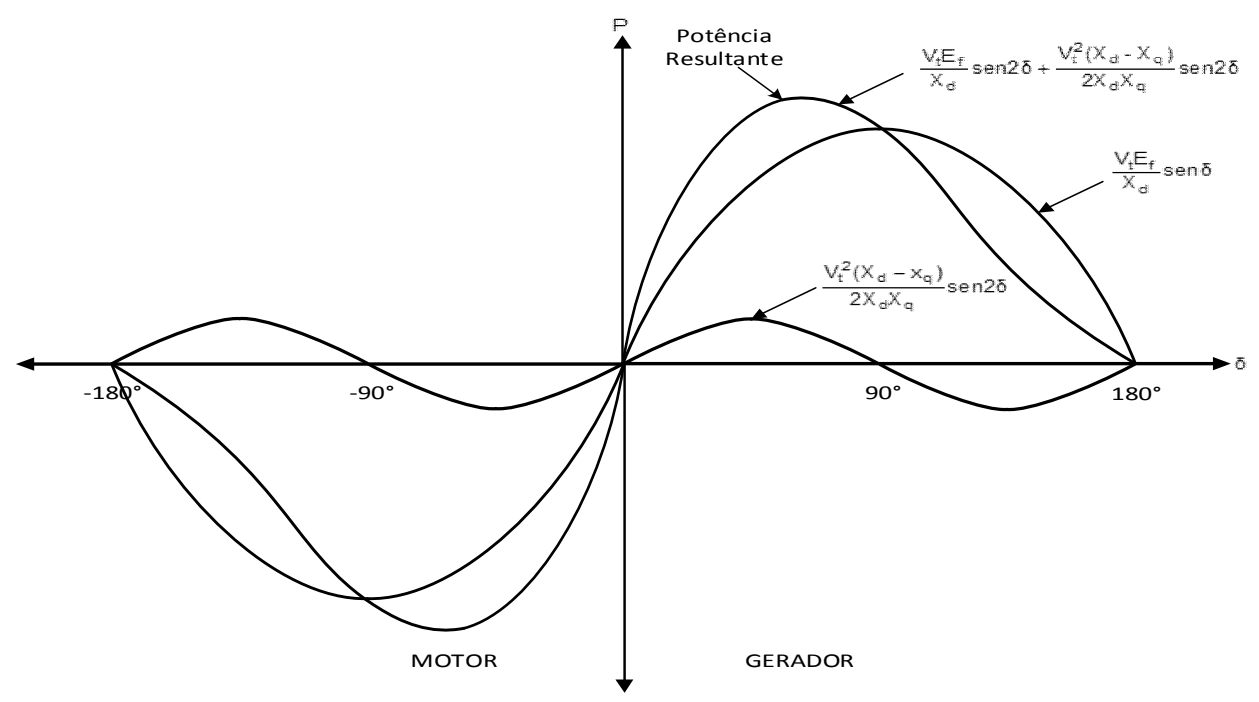

Fonte - Bimbhra P. S. - 2013 
Nos cálculos de estabilidade de regime permanente, os efeitos da saliência são usualmente desprezados, especialmente comparando-os com os da saturação.

Aplicando uma análise matematicamente semelhante ao que foi apresentado para a potência ativa, obtém-se que a potência reativa entregue à barra terminal é dada por:

$$
Q=V_{t} \cos \delta I_{d}-V_{t} \operatorname{sen} \delta I_{q}
$$

$$
V t \operatorname{sen} \delta=a b=d c=I_{q} X_{q}
$$

$$
I_{q}=\frac{V t \operatorname{sen} \delta}{X_{q}}
$$

$$
E f-V t \cos \delta=a d=b c=I_{d} X_{d}
$$

$$
I_{d}=\frac{E f-V t \cos \delta}{X_{d}}
$$

$$
Q=\frac{V t E f}{X_{d}} \operatorname{sen} \delta-\frac{V_{t t}^{2}}{X_{d}}+\frac{V t^{2}\left(X_{d}-X_{q}\right)}{2 X_{d} X_{q}} \operatorname{sen} 2 \delta
$$

\subsection{LIMITES OPERACIONAIS DOS GERADORES SÍNCRONOS}

Cada gerador tem seus limites operacionais, os quais devem ser respeitados para que o gerador opere em regime permanente de forma segura conforme sua curva de capacidade. Assim, os geradores síncronos têm limites de capacidade de geração de potência ativa e reativa.

Para um funcionamento seguro, os lugares geométricos dos pontos de operação são fornecidos pela curva de capacidade, sendo que os limites apresentados nessa curva estão baseados nas características de projeto e 
construção da máquina. Os diversos trechos que formam a curva de capacidade correspondem a uma determinada limitação operativa da máquina em regime permanente e sob condições pré-determinadas [46].

$\mathrm{Na}$ figua 2.8 mostra-se a curva de capacidade de operação para o gerador de pólos salientes em termos de potência ativa e reativa, para o limite térmico do rotor, limite da turbina, limite térmico do estator, limite de estabilidade e limite de mínima excitação, como visto a seguir.

Figura 2.8 - Curva típica de capacidade de um gerador de polos salientes.

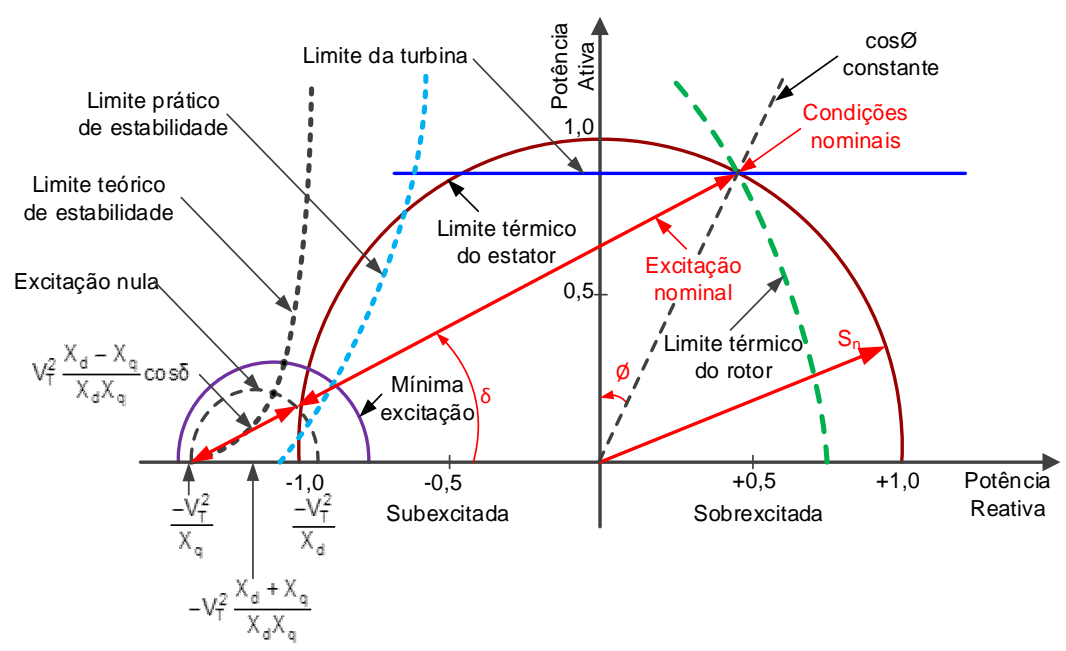

Fonte - Grimarães, Rangel Ricardo D. - 2009.

Limite térmico do rotor: Correspondente à máxima corrente que pode circular pelo enrolamento de campo, dado que existe um valor máximo de corrente que pode circular pelo enrolamento de armadura sem exceder as limitações de perdas no cobre por efeito térmico.

Limites da turbina: Existe uma limitação imposta à potência primária que o gerador pode receber da turbina. Dependendo das características do gerador, esse limite poderá ser mais ou menos restritivo que o limite imposto pelo aquecimento da armadura. No caso de turbinas hidráulicas esse limite é determinado pela vazão máxima e pela pressão da agua, as quais limitam a máxima potência mecânica disponível no eixo do rotor.

Limite térmico do estator: A corrente produzida na armadura do gerador provoca o aquecimento dos enrolamentos do estator e danos 
significativos podem ocorrer caso essa corrente supere os limitesespecificados no projeto. Dessa forma, o valor de corrente nos enrolamentos do estator deve ser limitado para operação segura [48].

Limite de estabilidade: Outro limite para a potência ativa fornecida pelo gerador síncrono é a estabilidade do sistema. Um sistema de energia que mantem a condição de operação normal perante pequenas mudanças de carga consegue garantir a estabilidade de estado estacionário. Nessas condições, há um equilíbrio entre a potência ativa gerada e consumida em condições de operação normal do sistema de potência. Este limite está definido pela curva $\mathrm{P}$ $=\mathrm{f}(\delta)$ para máquinas de polos lisos e salientes.

Limite de mínima excitação: A fixação de um nível mínimo de excitação aceitável evita que as condições de operação com fatores de potência altamente capacitivos. Esse limite previne que o gerador seja levado a operar próximo dos pontos inferiores do limite teórico de estabilidade, o que pode provocar a perda de controle, bem como sobreaquecimento do estator do gerador.

Para una máquina síncrona operando com uma dada potência ativa de carga, o fator de potência e sua corrente de armadura, podem ser controlados ajustando a excitação de campo. A curva que mostra a relação entre as correntes de armadura e de campo, para uma tensão nos terminais e uma potência ativa constante, são conhecidas como curvas V. Essas curvas características para um gerador de polos salientes são mostradas na figura 2.9. As curvas $V$ são expressados para vários fatores de potência, mantendo a tensão terminal e velocidade com os valores nominais. 
Figura 2.9 - Curva $V$ de um gerador de polos salientes.

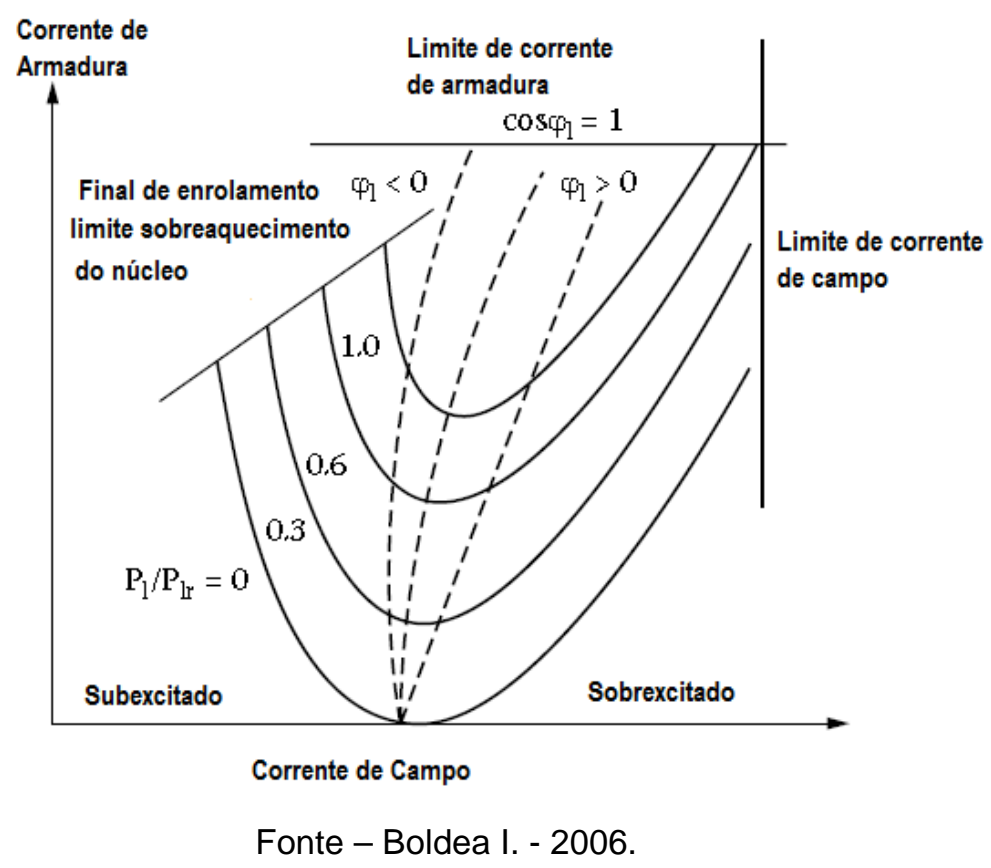

\subsection{MÉTODOS DE ATERRAMENTO}

O comportamento das correntes de um gerador durante uma falta à terra nos enrolamentos do depende fortemente do método de aterramento utilizado e determina a escolha do tipo de proteção de falta à terra a ser aplicada [2].

A maioria das falhas que ocorrem no enrolamento do estator são faltas à terra, isso é verdade por que os enrolamentos estão sempre em contato próximo com as ranhuras de aço que estão no potencial de terra. As falhas fase - fase são menos graves, por que os danos devidos a estas falhas podem ser resolvidos reparando somente $\mathrm{o}$ isolamento danificado. Para falhas à terra, os danos podem ser bem maiores, em razão da fundição de laminas de aço, com danos que repercutem em longos períodos de interrupção, para sua reconstrução [5].

Devido a isso, na maioria das aplicações, os neutros de grandes geradores são conectados à terra utilizando uma impedância para limitar drasticamente as correntes de falta à terra em seus terminais, assim, reduzir o poder destrutivo desse tipo de falta. As correntes e tensões de falta, no entanto, devem proporcionar meios suficientes para o sistema de proteção detectar a 
falta em um pequeno intervalo de tempo, evitando o aquecimento do ferro.

Se o gerador é solidamente aterrado, o que é raro, uma falta à terra em seus terminais implicará em uma corrente elevada, acompanhada de uma redução de cerca de $42 \%$ nas tensões de fase-fase que envolvem a fase faltosa (caem para 58\%) e de um pequeno deslocamento da tensão de neutro [38]. Por outro lado, se o gerador não é aterrado, o que também é raro, a corrente de curto circuito fase-terra em seus terminais será desprezível, não haverá redução nas tensões fase-fase, mas ocorrerá deslocamento na tensão de neutro. As altas correntes resultantes de faltas fase-terra num gerador solidamente aterrado são inaceitáveis devido ao dano que podem causar. $O$ desligamento do gerador através do disparo do disjuntor principal, do disjuntor de campo e da turbina não é suficiente para que a corrente de falta se reduza imediatamente a zero. O fluxo residual no campo manterá uma corrente de falta (diminuindo lentamente) por alguns segundos depois os disjuntores forem abertos, o que aumenta substancialmente o dano.

Por outro lado, quando um gerador sem aterrar, está em operação, as correntes de faltas à terra tornam-se desprezíveis, mas as tensões transitórias nas fases não faltosas podem se elevar durante as faltas com arco a níveis altamente perigosos.

Os sistemas não aterrados têm como característica principal a ausência de uma conexão física entre o neutro do gerador e terra. No entanto, uma pequena corrente de falta à terra irá fluir como resultado da capacitância parasita à terra existente nos de componentes do sistema. Dos componentes do sistema, o enrolamento do estator é em grande parte a fonte dessa capacitância em paralelo. Outros componentes, como: barras, cabos, pararaios, transformadores auxiliares, etc., podem ainda incrementar essa capacitância.

A corrente de falta entre fase e terra num sistema não aterrado é uma função dessa capacitância paralela do sistema e normalmente é menor que 10 A [2]. Atualmente, geradores não aterrados, não são utilizados e dentre as razões, para tal escolha, menciona-se a alta susceptibilidade deste sistema a 
danos ocasionados por sobre tensões produzidas durante faltas a terra.

\subsubsection{ATERRAMENTO SÓLIDO}

Neste caso, os enrolamentos do estator são ligados em estrela e o neutro é solidamente ligado à malha de terra. A corrente de falha fase - terra para um sistema efetivamente aterrado é muito alta. Em muitos casos maiores que a corrente de falha trifásica.

Este método em geral é utilizado somente para pequenas máquinas, quando se têm muitos geradores operando numa barra comum, compartilhando o transformador elevador, ou ligados diretamente à barra de carga, de modo a proporcionar a fonte de terra para o sistema.

\subsubsection{ATERRAMENTO DE BAIXA IMPEDÂNCIA}

Neste caso, o método de ligação à terra emprega um resistor ou um reator entre o neutro do gerador e a terra ou a instalação de um transformador de aterramento. $O$ resistor ou reator é dimensionado para limitar a corrente de falta à terra a um valor entre $200 \mathrm{~A}$ e $150 \%$ da corrente nominal do gerador [38].

De modo geral, o aterramento de baixa impedância mostrado na Figura 2.10 é utilizado quando duas ou mais unidades são conectadas juntas, sem a interposição de transformadores, ou quando os geradores estão diretamente conectados a um sistema de distribuição aterrado em baixa impedância.

Em instalações onde esquemas de aterramento de baixa impedância são projetados para fornecer altas correntes de falta à terra, a instalação de um disjuntor a neutro pode ser necessária. O disjuntor de neutro seria disparado quando os disjuntores do gerador e de campo são disparados. Isto instantaneamente reduz a magnitude da corrente de falta para alguns amperes, que circulam através das capacitâncias parasitas em paralelo. 
Figura 2.10 - Aterramento de baixa impedância.

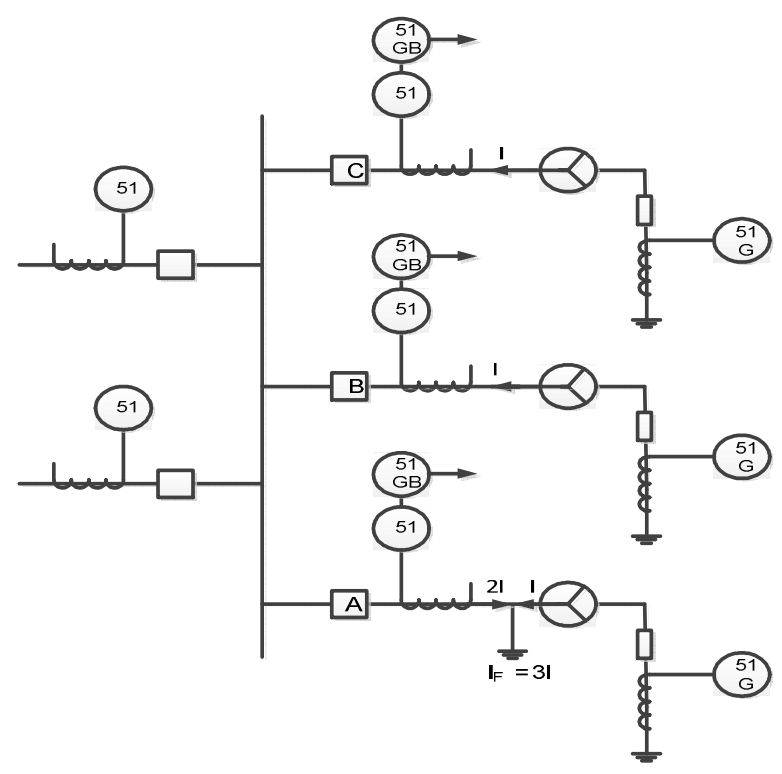

Fonte - Reimert D. - 2006.

\subsubsection{ATERRAMENTO DE ALTA IMPEDÂNCIA}

Este método de aterramento é aplicado a grandes geradores conectados individualmente ao sistema através de um transformador elevador. $O$ aterramento do neutro é feito normalmente através de um transformador de distribuição com um resistor no secundário como mostrado na figura 2.11. A utilização do transformador de distribuição com o resistor de aterramento instalado no lado de baixa tensão facilita dimensionamento e construção desse resistor.

Figura 2.11 - Aterramento de alta impedância.

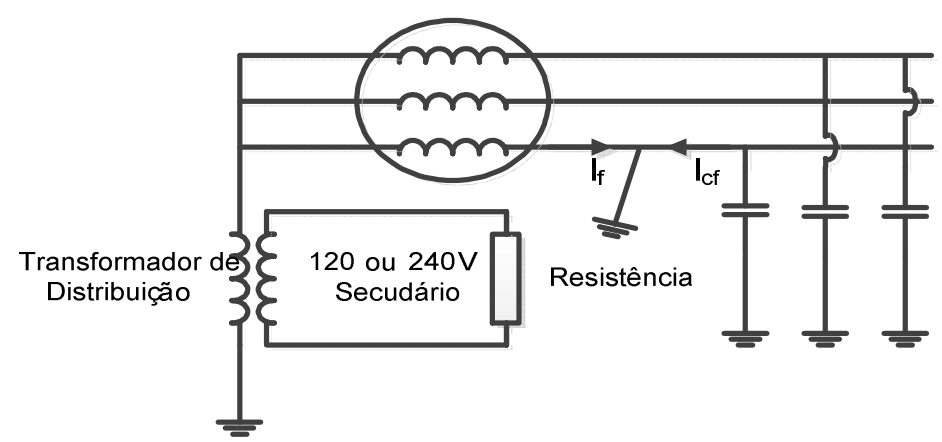

Fonte - Reimert D. - 2006 
Nesta solução o valor do resistor de aterramento é escolhido para limitar severamente as correntes de falta fase-terra, eliminando assim os danos causados por essas falhas.

Embora não exista um consenso geral quanto ao melhor valor para esta impedância limitadora de corrente, cr [10]. A tensão nominal do primário do transformador de aterramento deve ser maior ou igual à tensão nominal de fase-neutro do gerador, e a tensão secundária deve situar-se na faixa de 120 a 240 V. Quando eventualmente acontece uma falha à terra durante a operação do gerador a $105 \%$ de tensão nominal, o sistema de aterramento do transformador deve ser capaz de suportar sobre tensões para evitar fenômenos de saturação [2].

\subsubsection{DIMENSIONAMENTO DA RESISTÊNCIA DE ATERRRAMENTO}

Como já comentado, normalmente as faltas fase-terra originam-se de uma falha de isolamento que acarreta o contato entre o condutor do enrolamento do estator e o aço das ranhuras que se encontra no potencial da terra. Se o valor da corrente de falta for elevado, sérios danos serão produzidos no circuito magnético do gerador e tanto o custo quanto o tempo de reparo da máquina serão consideráveis. Desse ponto de vista, quanto mais elevado o valor da resistência de aterramento menor será a magnitude da corrente de curto fase-terra e, portanto, menor os riscos de danos que o gerador estará sujeito durante esse tipo de ocorrência.

Por outro lado, caso seja utilizado uma resistência de neutro elevada, existe o risco de criação de um circuito ferro-ressonante entre as indutâncias do gerador e a capacitância parasita presente nos terminais do gerador. Caso isso ocorra, poderão surgir elevadas sobretensões transitórias nos terminais da máquina com potencial para danificar 0 isolamento dos condutores. Este aspecto impõe um limite superior para o valor desse resistor. A pratica demostra que um valor seguro para esse limite é dado pela expressão (2.16) [5]. 


$$
R \leq \frac{1}{3 \omega C} \quad \Omega
$$

Onde C é a capacitância parasita total, por fase, presente nos terminais do gerador.

Adotar o valor do resistor de aterramento igual ao limite dado pela expressão (2.16) significa que, durante o curto fase-terra nos terminais do gerador, a potência ativa dissipada no resistor será numericamente igual à potência reativa dissipada nas capacitâncias parasitas [5].

Nesse caso, para uma capacitância parasita de alguns décimos de $\mu \mathrm{F}$, resultará em uma resistência de aterramento, conectada diretamente no neutro, de alguns poucos milhares de ohms. Como, no entanto, é mais conveniente implementar esse aterramento com a utilização de um transformador de distribuição, onde o enrolamento de média tensão do transformador é conectado com o neutro do gerador e o resistor é instalado no enrolamento de baixa tensão, mostrada na figura 2.12, o valor do resistor deve ser refletido a esse enrolamento, dividindo-o pelo quadrado da relação de espiras $(n)$.

Figura 2.12 - Transformador de distribuição no aterramento do gerador síncrono.

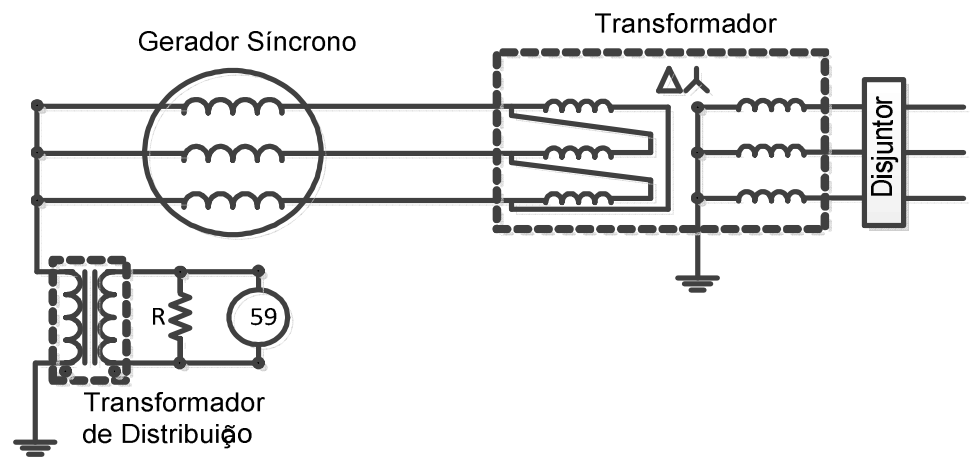

Fonte - Kindermann G. - 2008. 


\section{CAPÍTULO 3}

\section{PROTEÇÃO DE GERADORES SÍNCRONOS}

\subsection{INTRODUÇÃO}

Como discutido no capítulo 2, o gerador é periodicamente, submetido a faltas ou condições anormais de operação, que podem ter origem no próprio gerador, nos equipamentos agregados ou ainda na rede externa do sistema interligado. Devido a isso, é fundamental a utilização de um sistema de proteção que rapidamente detecte e isole a falta, evitando danos de elevada monta ao gerador e, possivelmente, a evolução de uma falta local para um evento sistêmico de grandes proporções.

No atual estágio tecnológico dos sistemas de proteção, um único relé de proteção, baseado em um hardware microprocessado, oferece todas as funções necessárias para proteger adequadamente 0 gerador dos eventos/perturbações elétricas que ele está sujeito. As principais características dos modernos sistemas de proteção de geradores são discutidas nos itens a seguir.

Nesse sentido, os sistemas de proteção numéricos permitem proteger esses geradores perante diversos eventos, como falhas que poderiam implicar graves danos ou apenas causar perturbações, não só para o gerador, mas também para todo o sistema elétrico da usina [3], [4].

\subsection{EVOLUÇÃO DE TECNOLOGIAS DE PROTEÇÃO}

Os dispositivos de proteção de geradores síncronos mudaram de acordo às necessidades encontradas durante sua operação e deram origem aos avanços tecnológicos voltados para relés com tecnologia eletromecânica, de estado sólido e digital. 
Em muitas usinas, os geradores síncronos ainda utilizam sistemas de proteção baseados em relés eletromecânicos ou de estado sólido, os quais estão direcionados à proteção do estator além de várias outras funções de proteção e alarme que são mais próximas de funções de controle [4].

$\mathrm{Na}$ atualidade os sistemas de proteção de novas subestações de geração de energia elétrica utilizam tecnologia com relés digitais. Nesse contexto de modernidade, subestações antigas com relés eletromecânicos e de estado sólido, vêm também, gradativamente, sendo substituídos por relés digitais [22].

Os relés digitais foram projetados para operar com desempenho superior aos relés de estado sólido e relés eletromecânicos [26].

Os relés digitais foram desenvolvidos por G. D. Rockfeller em 1969, como uma aplicação de um computador digital para realizar funções de proteção de todos os equipamentos de uma subestação [24] [25].

Ao longo de vários anos houve um avanço da tecnologia de microprocessadores e na atualidade esses relés digitais são capazes de executar novos algoritmos para proteção de diversos elementos de sistemas elétricos de potência, além de geradores síncronos.

Enquanto ao funcionamento dos relés digitais, estes convertem os sinais analógicos em sinais digitais por meio de conversores analógicos digitais, para depois processar numericamente as quantidades binárias utilizando algoritmos computacionais [4]. Esses algoritmos são os encarregados de detectar as falhas e controlar os sinais de disparo ("tripping") de circuitos de comando para atuação dos sistemas de proteção.

Uma vantagem destes relés está relacionada à capacidade de monitorar várias funções de proteção (sobre correntes, baixa tensão, distancia, etc.) a partir das características de hardware e software [23]. Os relés digitais são capazes de armazenar e enviar dados relativos aos ciclos de pré falta e falta para eventuais análises. Estas características incrementam sua confiabilidade de operação com maior precisão e rapidez. 
Dentre os elementos em um sistema de potência, que podem ser protegidos com relés digitais, os sistemas de proteção de geradores têm recebido pouca atenção, devido ao seu reduzido número, quando comparados com as numerosas linhas de transmissão, transformadores, etc. Enquanto aos relés com tecnologia digital, contínuos incentivos vêm a propiciar o incremento de suas aplicações para proteção de geradores síncronos, que eliminem a ocorrência de faltas, a fim de garantir um desempenho eficiente de sistemas elétricos de potência.

\subsection{ARQUITETURA DO RELÉ DIGITAL}

Os relés digitais ou microprocessados utilizados atualmente na proteção de geradores síncronos são equipamento multifuncionais que englobam recursos de proteção, controle, medição e análise pós-falta, tais como:

- Funções de proteção aplicáveis a geradores síncronos.

- Lógica programável.

- Medição de grandezas elétricas.

- Registro de eventos

- Oscilografia.

- Autosupervisão para detecção de falhas de hardware ou de software.

- Sincronismo.

- Comunicação de dados (atualmente baseado no protocolo IEC 61850).

O hardware do rele digital é constituído por subsistemas com funções bem definidas como mostrado na figura 3.1. A unidade central de processamento (CPU), juntamente com as memórias (RAM, SDRAM, EEPROM) e os dispositivos de entrada e saída (I/O) constituem o microcomputador, Além da CPU encontram-se presentes os seguintes subsistemas: sistema de entrada de dados analógicos destinado à medição das tensões e correntes alternadas a serem monitoradas; sistema de entrada de dados digitais; sistema de saída digitais (saídas a relé ou a estado sólido); portas de comunicação e IHM local [4] [27]. Na figura 3.1 mostra-se que o processador controla o funcionamento do relé, e faz filtragem digital dos sinais, na maioria dos casos, a extração da componente fundamental de tensões e correntes. 
Figura. 3.1 - Diagrama de blocos de um relé digital ou microprocessado.

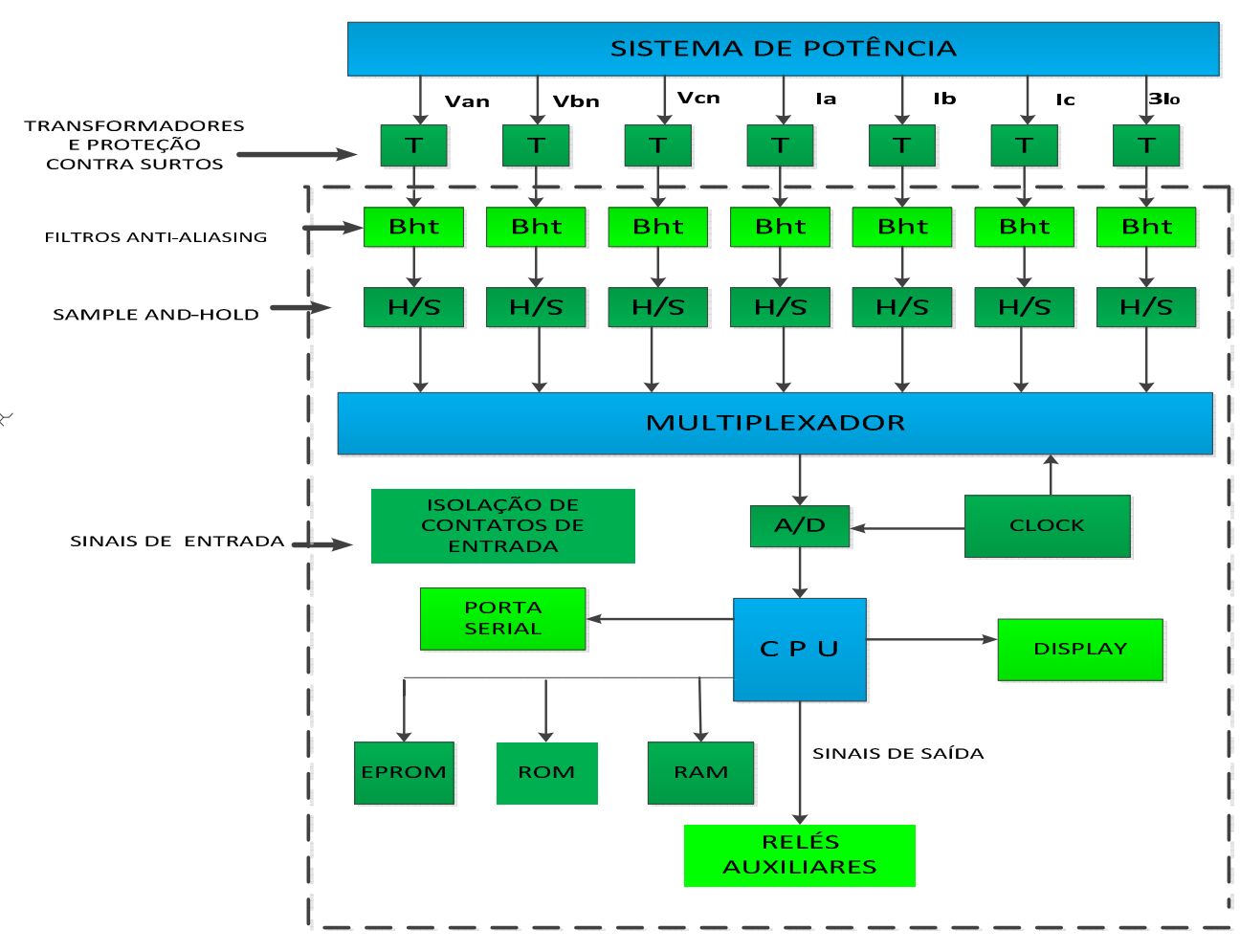

Fonte - Coury V. D; Oleskovicz M. - 2007

A seguir são descritos os principais componentes presentes nesses diversos subsistemas do relé digital:

- Os transformadores de entrada são módulos de interface que atenuam as tensões e correntes de entrada, para níveis de tensão adequados aos microprocessadores (por exemplo $\pm 10 \mathrm{~V}$ ). Esses transformadores permitem também fornecem a isolação galvânica entre os relés de proteção e os sinais provenientes dos transformadores de corrente (TCs) e transformadores de potencial (TPs) da subestação.

- Os filtros analógicos tipo passa-baixa são utilizados, com o objetivo de evitar erros de aliasing no processamento digital dos sinais.

- O multiplexador MXP permite que seja usado apenas um conversor A/D (Analógico-Digital) para os vários canais de entradas analógicas.

- No conversor A/D os sinais analógicos são convertidos para a forma digital, normalmente, utilizando-se uma taxa de amostragem na faixa de 16 a 64 amostras/ciclo e uma resolução entre 12 a 16 bits. 
- Os dispositivos Sample and Hold $(\mathrm{S} / \mathrm{H})$ mantém o sinal em sua saída em um valor constante e igual ao sinal presente em sua entrada no instante de recebimento do comando Hold, durante todo o ciclo de conversão analógica-digital. Dessa forma, o $\mathrm{S} / \mathrm{H}$ permite obter o valor digitalizado, em um instante de tempo $t_{0}$, para todos os canais analógicos, mesmo com a utilização de um único conversor $A / D$ amostrando sequêncialmente todos os canais.

- As rotinas do software embarcado, tais como os algoritmos de proteção, são gravados na memória de leitura ROM (Read Only Memory), enquanto a memória do tipo SDRAM (Synchronous Dynamics Random Access Memory) será utilizada para o armazenamento de dados temporários, tais como os valores digitalizados e cálculos intermediários executados pelos algoritmos de proteção e controle. Enquanto nas memórias EEPROM (Electrically Erasable Programable Read-Only Memory), são armazenados os ajustes e parametrizações das funções de proteção do relé.

\subsection{FUNÇÕES DE PROTEÇÃO APLICADAS AOS GERADORES SÍNCRONOS}

A maioria das funções de proteção de geradores síncronos utilizadas nos modernos IEDs originaram-se e estão baseadas, ainda hoje, nos esquemas e filosofias desenvolvidas, décadas atrás, para os relés implementados com as tecnologias eletromecânica e estática.

Apesar dessa origem comum, as técnicas de processamento digital de sinais permitem que essas funções de proteção sejam implementadas nos modernos IEDs de forma muito sofisticada, garantindo maior precisão e segurança de atuação.

O principal critério normalmente utilizado para selecionar as funções de proteção que serão utilizadas no esquema de proteção de um gerador síncrono é a potência nominal dessa máquina. As funções de proteção comumente utilizadas com os geradores são apresentadas na Tabela 3.1 
Tabela.3.1 - Funções de proteção aplicáveis a geradores síncronos.

\begin{tabular}{|c|c|}
\hline $\begin{array}{l}\text { FUNÇÃO } \\
\text { ANSI/IEEE }\end{array}$ & $\begin{array}{l}\text { DESCRIÇÃO DAS FUNÇÕES DE PROTEÇÃO } \\
\text { APLICÁVEIS A GERADORES SÍNCRONOS }\end{array}$ \\
\hline 27 & Subtensão \\
\hline 37 & Perda de excitação \\
\hline 21 & Distância \\
\hline $27 \mathrm{HT}$ & Subtensão sintonizado na frequência terceira harmônica \\
\hline 40 & Perda de excitação \\
\hline $87 \mathrm{G}$ & Diferencial do gerador \\
\hline $87 \mathrm{U}$ & Diferencial da unidade \\
\hline $87 \mathrm{~T}$ & Diferencial do transformador elevador \\
\hline $50 / 51 N$ & Sobrecorrente de neutro do gerador \\
\hline $50 / 51 \mathrm{~V}$ & Sobrecorrente de fase do gerador com restrição por tensão \\
\hline $64 G$ & Falhas à terra do estator (baseada em tensões $3^{\circ}$ ha rmônico) \\
\hline $64 \mathrm{R}$ & Falhas à terra do rotor \\
\hline $32 \mathrm{P}$ & Antimotorização (potência reversa) \\
\hline $32 Q$ & Direcional contra potência reativa \\
\hline 24 & Sobreexcitação do gerador (Voltz/Hertz) \\
\hline 46 & Correntes desbalanceadas no estator (sequência negativa) \\
\hline 59 & Sobretensão \\
\hline $59 G$ & Sobretensão no neutro do gerador \\
\hline 81 & Sub e Sobrefrequência \\
\hline 81 of & Acumuladores de freq. nominal. de tempo para turbinas a vapor \\
\hline 76 & Sobrecorrente no circuito de campo \\
\hline 78 & Perda de sincronismo \\
\hline 25 & Synchro-check elemento para supervisão disjuntor \\
\hline 60 & Balanço de tensão (perda de potencial por queima de fusíveis) \\
\hline 61 & Curto-circuito entre espiras do gerador \\
\hline 49 & Térmica do estator \\
\hline
\end{tabular}

Fonte - IEEE Guide for AC Generator Protection - 2012.

Na figura 3.2 está apresentado um sistema típico de proteção de um conjunto gerador síncrono e transformador elevador. 
Figura. 3.2 - Sistema de proteção de um gerador síncrono e transformador.

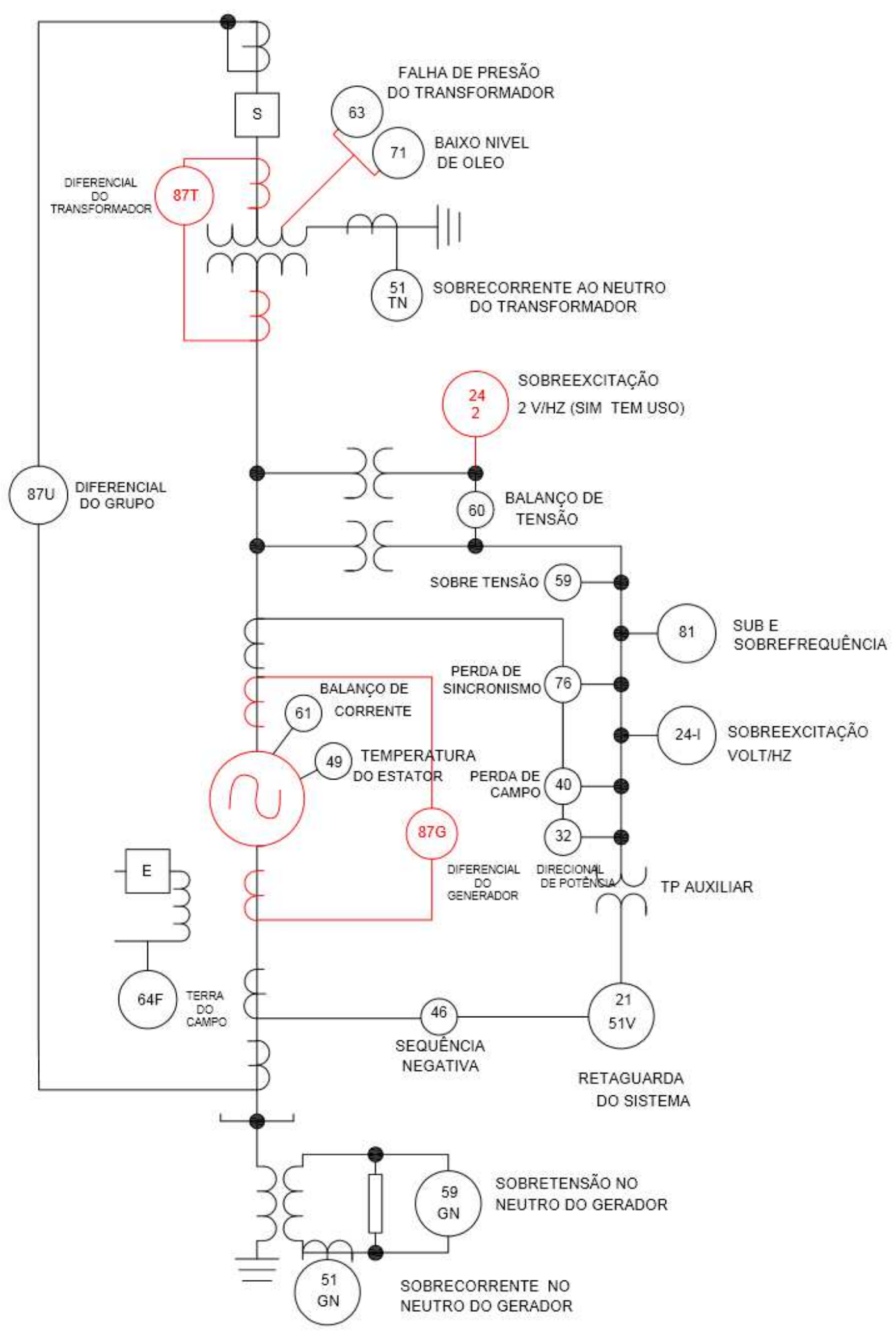

Fonte - The power engineering education comittee, power power system relaying.- tutorial IEEE de protección de generadores síncronos. 


\subsection{PROTEÇÃO DIFERENCIAL DO GERADOR SÍNCRONO}

A proteção diferencial de geradores síncronos é uma função de proteção importante e muito empregada para detecção de faltas no estator do equipamento-

É uma alternativa simples e eficiente, muito sensível para detecção de defeitos entre fases nos enrolamentos do estator. As correntes diferenciais são obtidas pela utilização de transformadores de corrente instalados nas duas extremidades do enrolamento.

O esquema de proteção diferencial de geradores síncronos utiliza TCs com a mesma relação de transformação, o que diminui os erros de medição, que são maiores em TCs com diferentes relações de transformação, como ocorre com a proteção diferencial em transformadores de potência [45].

Proteção diferencial opera quando existe uma corrente diferencial, resultado da diferença entre as correntes nos dois extremos do elemento protegido, que supera o valor umbral ajustado para a corrente de de pick-up.Na figura 3.3 é mostrado o esquema de proteção diferencial para um gerador síncrono.

Figura. 3.3 - Proteção diferencial de gerador síncrono.

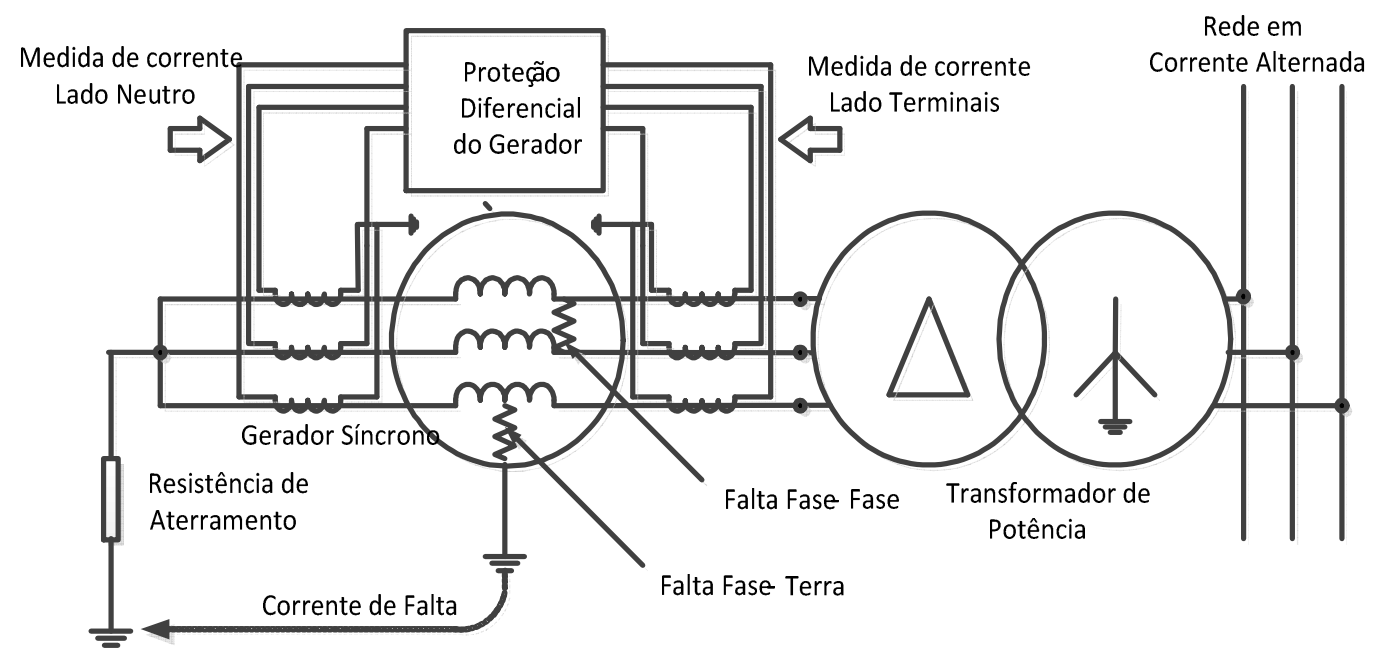

Fonte - Blánquez F.R - 2013.

A função diferencial (87) protege o gerador dos curtos circuitos ocorridos nos enrolamentos do estator, onde, produzem-se elevadas correntes durante 
faltas do tipo, fase-fase ou trifásicas. Os efeitos térmicos dessas correntes podem causar danos ao isolamento, ou ainda, as forças magnéticas associadas com essas correntes podem deformar os enrolamentos e submeter o rotor a choques mecânicos [2].

Já as faltas fase-terra, particularmente as que ocorrem próximas do centro estrela do enrolamento estator em geradores aterrados através de alta impedância, podem gerar correntes de falta com magnitude muito baixa, insuficientes para garantir a atuação segura da função diferencial.

Durante uma falha no enrolamento do estator, em qualquer fase, o sistema de proteção deve detectar as correntes diferenciais e quando essa corrente ultrapassa o valor de atuação ajustado, o disjuntor do gerador e o disjuntor de campo, serão acionados para sua desconexão.

Considerando a relevância da proteção diferencial, é sumamente importante evitar atuações indesejáveis do relé por meio de um ajuste conveniente.

A atuação da proteção diferencial está baseada na comparação de medições das correntes nos dois terminais dos enrolamentos. As medições são feitas a partir da aplicação das leis de Kirchhoff. Isto é, caso não exista uma falta interna aos dois TCs, a corrente entrando no primeiro TC é igual à corrente saindo no segundo, isto é, a soma dessas duas correntes é zero ou próximo de zero (devido aos erros dos TCs e erros de medição). [30].

$\mathrm{Na}$ figura 3.4 pode-se observar uma falta externa afetando o gerador síncrono, cuja configuração de proteção utiliza um relé diferencial de sobre corrente, onde o fluxo de corrente está saindo para a falha acontecida, fora da zona de proteção diferencial. 
Figura. 3.4 - Falta externa com relé diferencial.

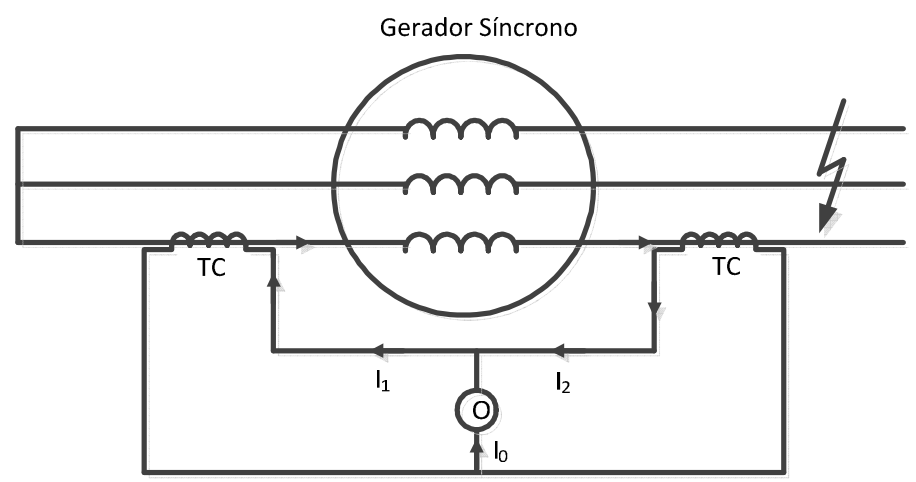

Fonte - Reimert D. - 2006.

Se o elemento protegido é um gerador, os TCs 1 e 2 têm relações de transformação iguais, nestas condições de operação normais ou de falta externa, as correntes $I_{1}$ e $I_{2}$ permanecem iguais entre si, portanto, $l_{1}=I_{2}$ e a corrente de operação $I_{0}$ no relé será zero $I_{0}=0$, cumpre-se a equação (3.1) [3], [30].

$$
I_{0}=\left|I_{1}\right|-\left|I_{2}\right|=0
$$

Neste caso, a corrente diferencial que circula pelo relé 87 é nula e o relé não opera.

$\mathrm{Na}$ figura 3.5 pode-se observar uma falta interna afetando o gerador síncrono, cuja configuração de proteção utiliza um relé diferencial de sobre corrente, onde o fluxo de corrente está entrando para a falha acontecida dentro da zona de proteção diferencial. 
Figura. 3.5 - Falta interna com relé diferencial.

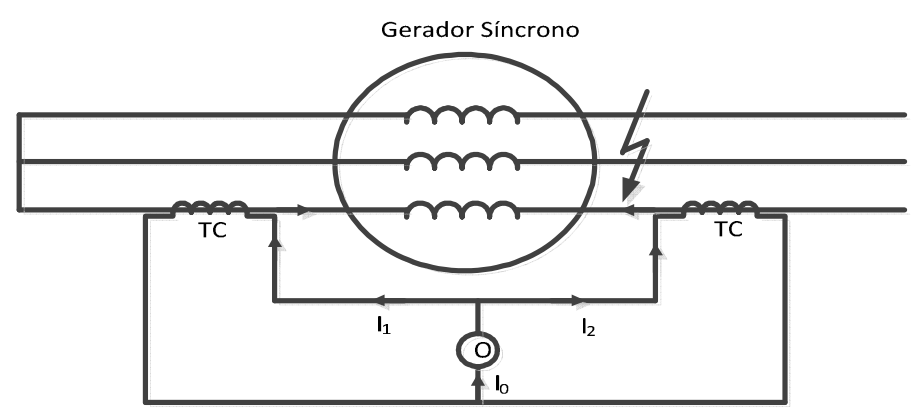

Fonte - Reimert D - 2006.

$\mathrm{Na}$ ocorrência de faltas internas, as correntes de entrada e saída deixam de ser iguais, resultando numa corrente diferencial não nula. Considerando-se que os transformadores de corrente são ideais, as correntes $I_{1}$ e $I_{2}$ deixam de ser iguais, portanto, $l_{1} \neq I_{2}$ e a corrente de operação $I_{0}$ no relé será diferente de zero $I_{0} \neq 0$ e muito grande, então: $I_{0}>0$, cumpre-se a equação (3.2) [3], [30].

$$
I_{0}=\left|I_{1}\right|+\left|I_{2}\right|>0
$$

Neste caso, o relé opera e isola o elemento protegido.

Devido ao seu princípio de funcionamento, a função diferencial é bastante precisa e seletiva. Na prática a maior ameaça a essa seletividade inerente é a possibilidade de saturação de um dos TCs durante a ocorrência de uma falta externa à zona de proteção primária do gerador. Essa saturação pode produzir uma considerável corrente diferencial e provocar a atuação indevida da proteção. Os dois esquemas particulares de proteção diferencial apresentados a seguir tornam essa função mais robusta a esse tipo de atuação incorreta.

\subsubsection{PROTEÇÃO DIFERENCIAL DO TIPO AUTOBALANÇO}

Este esquema de proteção diferencial é do tipo autobalanço, utilizado comumente em geradores síncronos de pequeno porte. Sua configuração é apresentada na figura 3.6 e nota-se o menor número de transformadores de corrente utilizados. 
Os três transformadores de corrente utilizados são do tipo janela com núcleo toroidal. Na ocorrência de algum defeito, há um desbalanço de corrente, tal que a diferença é superior ao ajuste da proteção, fazendo que o relé de sobrecorrente atue. As correntes de entrada e saída fluindo através dos transformadores são iguais durante a operação normal do gerador [29].

Figura 3.6 - Proteção diferencial tipo autobalanço.

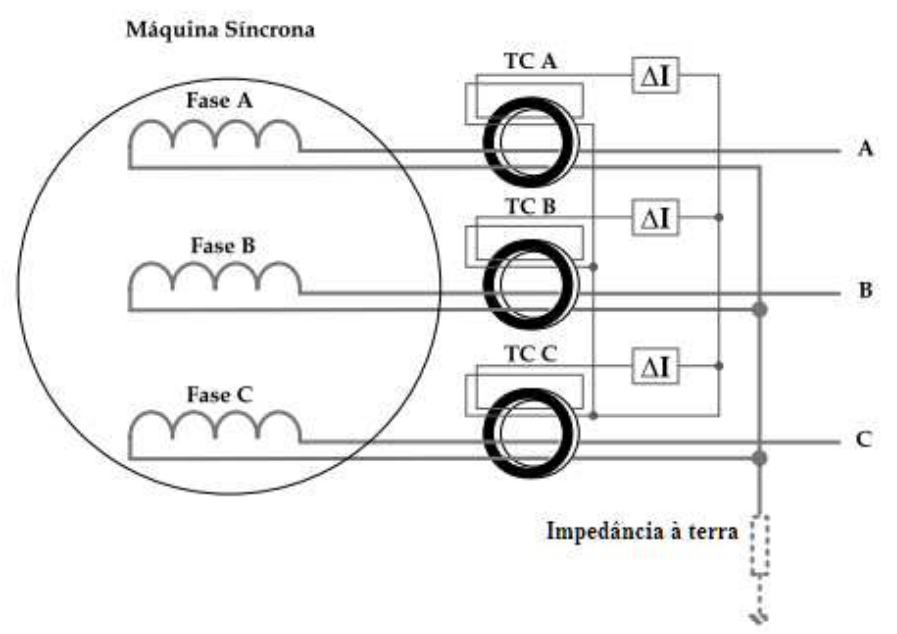

Fonte - Ziegler G. - 2005.

Neste esquema, uma falta externa, mesmo que produza corrente de elevada magnitude, não irá produzir fluxo interno no TC e, portanto, não haverá corrente diferencial e consequentemente não existirá possiblidade de atuação indevida.

\subsubsection{PROTEÇÃO DIFERENCIAL PERCENTUAL}

O relé diferencial percentual foi desenvolvido para superar as limitações de relés diferenciais ideais nos sistemas de proteção [2]. A proteção diferencial percentual com curvas características de inclinação variável é um método amplamente utilizado para proteção de geradores síncronos [10]. Esta proteção baseia-se no mesmo princípio da proteção diferencial, onde, são comparadas as correntes de entrada e saída do equipamento protegido e cuja operação se dá em função da diferença entre suas magnitudes, mas inclui um conjugado de restrição proporcional à média das correntes de entrada e saída. 
O relé é ajustado para operar quando a corrente diferencial ultrapassa uma determinada percentagem da corrente média de restrição. A figura 3.7 mostra a configuração típica desse tipo de sistema de proteção incluindo relés diferenciais percentuais compostos por bobinas operação $(0)$, bobinas de restrição $(R)$ e transformadores de corrente (TC) [2].

Figura. 3.7 - Proteção diferencial percentual

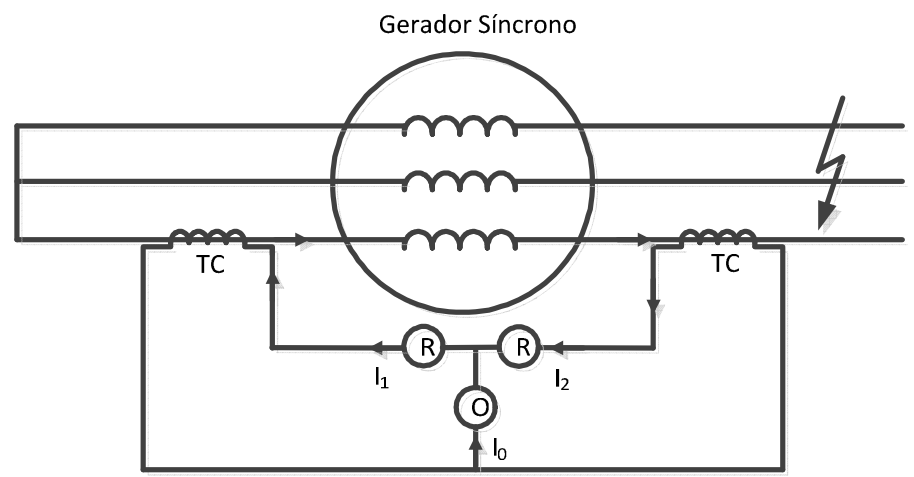

Fonte - Reimert. - 2006

Por meio dos transformadores de corrente são obtidas as correntes $I_{1} e$ $I_{2}$. Correntes que definem a corrente de restrição $I_{r}$ e a corrente de operação $I_{0}$, segundo as expressões (3.3), (3.4), (3.5) e (3.6) [2], [30].

$$
\begin{gathered}
I_{0}=\left|I_{1}-I_{2}\right| \\
I_{r}=\frac{\left|I_{1}\right|+\left|I_{2}\right|}{2}
\end{gathered}
$$

Onde, Io é muito pequeno ou igual a zero, para faltas externas.

$$
\begin{gathered}
I_{0}=\left|I_{1}+I_{2}\right| \\
I_{r}=\frac{\left|I_{1}\right|+\left|I_{2}\right|}{2}
\end{gathered}
$$

Onde, $I_{0}$ é grande ou diferente de zero, para faltas internas.

A corrente "pick up" ou menor corrente requerida para fazer operar o relé, é a corrente que entra em uma bobina de restrição e sai para bobina de operação. Este valor tende a ser pequeno para relés diferenciais de baixas 
percentagens e é tão baixo como 0,10 A para alguns deles.

Assim, na ocorrência de uma falta, a bobina de operação irá fechar o contato quando a corrente de operação exceder o valor de corrente de restrição, sendo esta útil para ativar a atuação do relé na eliminação da falta.

O relé diferencial percentual possui como vantagem a elevada sensibilidade para faltas dentro da zona de proteção e reduzida sensibilidade para faltas fora da zona de proteção, em que os transformadores de corrente podem produzir uma atuação intempestiva do relé, ocasionada por saturação às altas correntes de falta [2].

A relação existente entre as correntes de operação e de restrição pode ser determinada pela declividade (inclinação) da curva característica de operação do relé diferencial percentual e é definida em percentagem na expressão (3.7).

A percentagem $\mathrm{K}$ indica a diferença de corrente como uma percentagem da menor corrente de restrição requerida para operar o relé.

$$
\tan \theta=\frac{I_{0}}{I_{r}}=(K \%)
$$

Os relés diferenciais utilizados nos sistemas de proteção de geradores síncronos possuem diferentes curvas características de operação segundo seu tipo de funcionamento.

$\mathrm{Na}$ figura 3.8 estão mostradas as curvas características diferenciais percentuais para relés eletromecânicos, e microprocessados. 
Figura. 3.8-Curvas características diferenciais percentuais de relés.
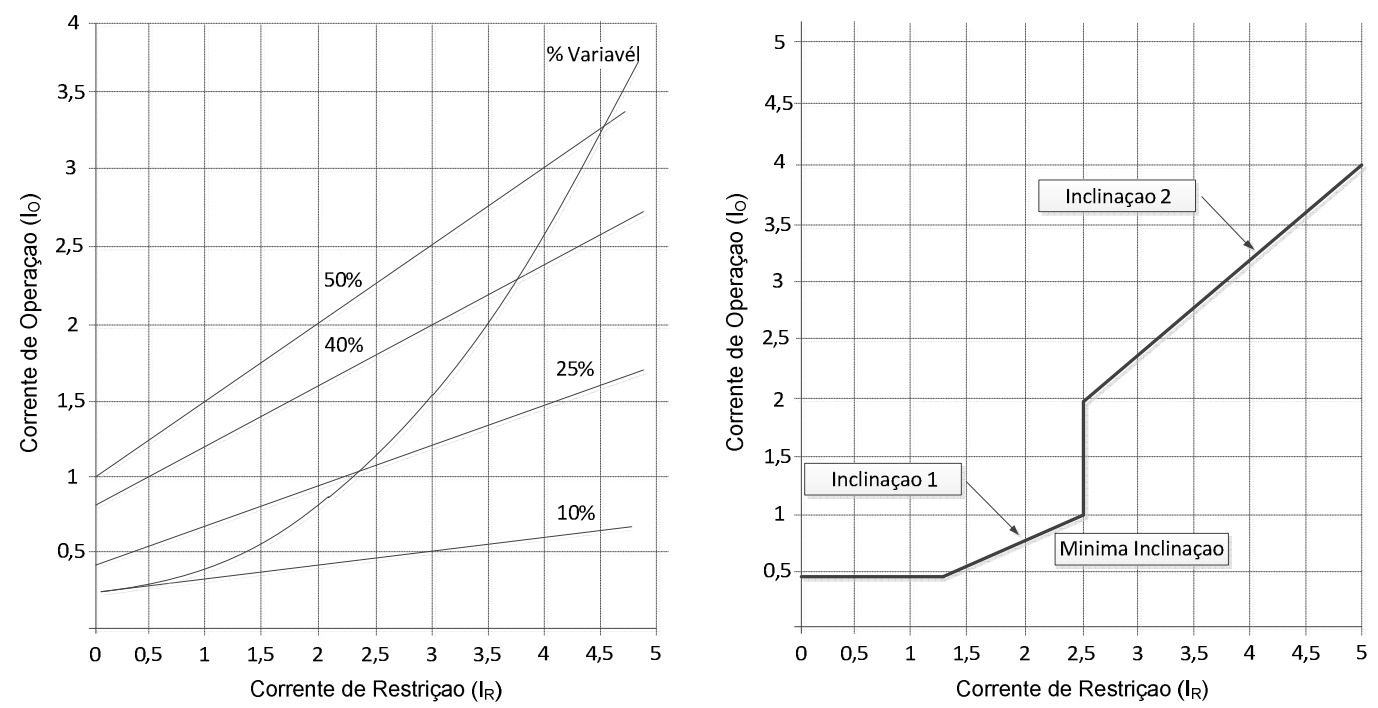

Fonte - Reimert D - 2006.

No caso de relés eletromecânicos podem-se encontrar inclinações para curvas características que variam entre $10 \%$ a $50 \%$ e não são ajustáveis. A mínima corrente de operação podem variar desde 0,2 A para $10 \%$ até 1 A para de $50 \%$. Os relés eletromecânicos atuam a partir de 80 ms a 165 ms [2].

Por sua vez, os relés de estado sólido ou também chamados relés estáticos, possuem semelhanças com curvas características para relés eletromecânicos, sendo também ajustáveis entre para inclinações de 10\%, $25 \%, 40 \%$ e $50 \%$. Os relés de estado sólido atuam a partir de $25 \mathrm{~ms}$ tempo reduzido quando comparados com relés eletromecânicos [2].

No caso de relés microprocessados encontram-se curvas características ajustáveis continuamente, em alguns casos variáveis entre $1 \%$ a $100 \%$. Os mínimos valores de corrente "pick up" também são ajustáveis na faixa de 0,1 A até $3 \mathrm{~A}$. Os valores de corrente de restrição e de operação são ser computados matematicamente pelo algoritmo de proteção [2].

\subsection{PROTEÇÃO DE RETAGUARDA}

Como discutido no item anterior, a proteção principal para detecção de faltas no estator do gerador é a função diferencial. 
É conveniente, ainda, a existência de uma proteção de retaguarda sensível às faltas no gerador, no transformador elevador ou no sistema de transmissão e que atue caso ocorra falha do sistema de proteção principal de qualquer um desses componentes do sistema elétrico.

Para essa proteção de retaguarda, comumente é utilizada a função de sobrecorrente supervisionada por tensão (51V) ou a função de distância (21).

A escolha por uma delas, para facilidade de coordenação, normalmente, é feita acompanhando o mesmo tipo de função principal utilizada para a proteção das linhas de transmissão.

A proteção de retaguarda é ajustada com um tempo de retardo, necessário para permitir a coordenação com as funções de proteção principal existentes no conjunto gerador-trafo elevador ou no sistema de transmissão.

Essas duas funções podem estar conectadas aos TCs nos terminais junto ao neutro do gerador ou podem estar ligadas aos TCs localizados nos terminais do gerador. A configuração no final do neutro apresenta a vantagem de permitir ao relé fornecer proteção quando a unidade estiver desconectada do sistema.

No outro caso, falhas internas não seriam detectadas nesta condição, dado que não haverá nenhuma corrente no relé [2]. Apesar disso, não é incomum se utilizar a função de distância energizada pelos TCs dos terminais do gerador. Nesta situação, são habilitadas duas zonas da função. A primeira fornece proteção de retaguarda para o sistema de transmissão e a segunda para o gerador.

Nos subitens a seguir discute-se o uso das funções $51 \mathrm{~V}$ e 21 como proteção de retaguarda para o gerador e sistema.

\subsubsection{PROTEÇÃO DE SOBRECORRENTE SUPERVISIONADA POR TENSÃO}

Dado que a reatância síncrona de eixo direto $\left(x_{d}\right)$ do gerador é maior que $1.0 \mathrm{pu}$ (nas bases nominais da máquina), a corrente de regime permanente durante um curto-trifásico nos terminais do gerador será inferior à sua corrente 
nominal. Considerando ainda que a proteção de retaguarda deve ser sensível à mínima corrente de falta, não é possível utilizar uma função de sobrecorrente convencional para essa finalidade, uma vez que a corrente de pick up da função de sobrecorrente teria de ser ajustada abaixo da corrente nominal do gerador.

A solução para essa situação pode ser encontrada lembrando-se que em operação normal, à plena carga, a tensão nos terminais do gerador encontra-se próximo do valor nominal (1.0 pu) e que, durante um curto trifásico, devido ao fato da impedância interna do gerador aumentar para o valor síncrono $\left(x_{d}\right)$, a tensão nos terminais entra em colapso.

Dessa forma, usando-se a informação de tensão e corrente, simultaneamente, é possível distinguir claramente as situações de curto-circuito trifásico e operação normal a plena carga. Isto é feito com o uso da função de sobrecorrente supervisionada por tensão (51V).

Existem basicamente dois tipos de relés de sobrecorrente supervisionados por tensão aplicáveis à proteção de retaguarda do gerador: a)sobrecorrente com restrição por tensão; b)- sobrecorrente controlado por tensão. Neste trabalho será considerado o primeiro tipo.

Seu princípio de funcionamento consiste em definir um valor para a corrente de pick-up, superior à corrente máxima do gerador, que permanece ativo enquanto a tensão nos terminais do gerador encontra-se próximo do valor nominal (máquina operando em condições normais). Quando a tensão terminal sofre uma redução significativa, como ocorre durante curtos-circuitos nos terminais do gerador, esse valor para a corrente de pick-up é reduzido dinamicamente, de forma automática, permitindo a atuação da função de sobrecorrente mesmo com corrente de falta inferior à corrente nominal da máquina.

A figura 3.9 mostra o multiplicador, menor que a unidade, que é aplicado à corrente de pick-up ajustada em função da tensão terminal do gerador. 
Figura 3.9 - Multiplicador da corrente de pick-up em função da tensão terminal em relés da série UR da GE.

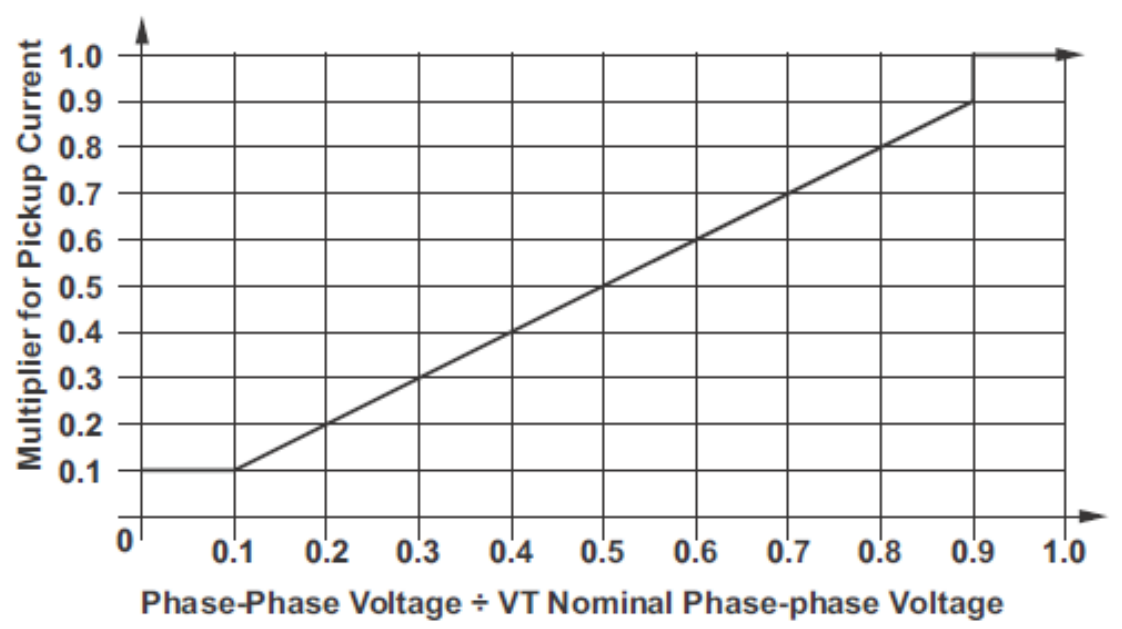

Fonte - Mozina, C. J. - 2012

A corrente de pick-up dessa função é normalmente configurada de 125 $175 \%$ da corrente de plena carga.

\subsubsection{PROTEÇÃO DE DISTÂNCIA DE FASE (FUNÇÃO 21)}

Quando a linha de transmissão é protegida por relé de distância, a utilização da função de sobrecorrente como proteção de retaguarda no gerador torna difícil a coordenação devido às mudanças no tempo de atuação da função de sobrecorrente para diferentes condições operativas do sistema. Por essas razões, a função de distância é proteção de retaguarda mais utilizada em geradores de grande porte.

Uma primeira forma de aplicação da função de distância, como proteção de retaguarda junto ao gerador, é a conexão com os TCs do lado do neutro e uso de uma única zona de proteção. Se o gerador é conectado ao sistema através de um transformador elevador delta/estrela, para detectar corretamente faltas nas linhas de transmissão, o algoritmo da função 21 deve ter capacidade de compensar a defasagem imposta por esse transformador ou, então, tornase necessário utilizar transformadores auxiliares de tensão para implementar essa compensação, como mostrado na figura 3.10. 
Nesse arranjo, a função 21 irá fornecer proteção de retaguarda para faltas entre fases no gerador, no trafo elevador e nas linhas de transmissão. Faltas no gerador serão detectadas mesmos nas situações em que o gerador encontra-se desconectado do sistema. Essa solução não é adequada para fornecer proteção de retaguarda para faltas fase-terra nas linhas de transmissão. Isso pode ser alcançado com o uso da função $51 \mathrm{~N}$ monitorando a corrente de neutro do trafo elevador.

Figura 3.10 - Proteção de retaguarda de um gerador síncrono.

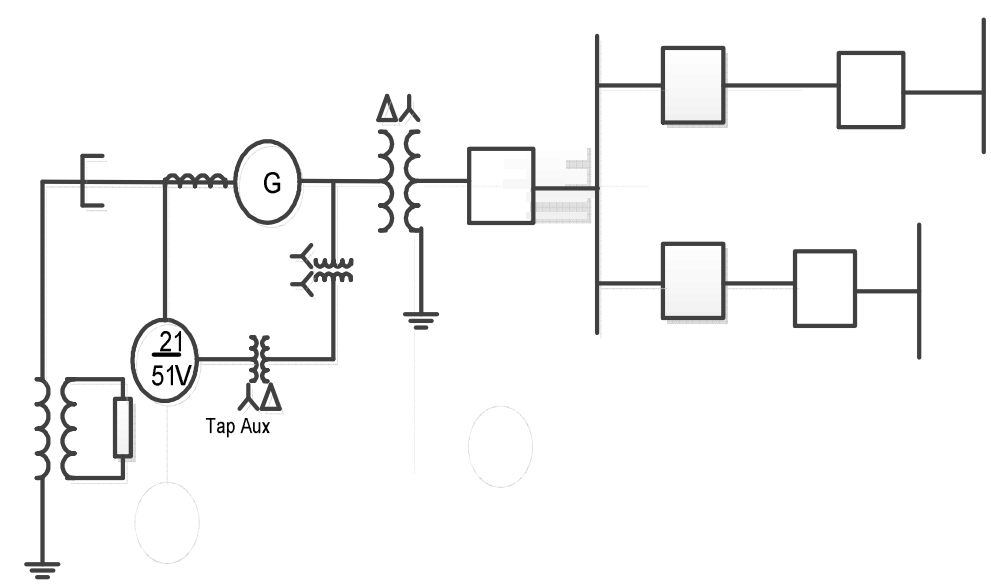

Fonte - Mozina, C.J. - 2012

A aplicação de relés de distância requer um ajuste com alcance suficiente para detectar falhas na linha mais longa que sai da subestação. Este ajuste pode ser dificultado pelo efeito de in-feed quando múltiplas linhas ligam o gerador ao sistema, como mostrado na figura 3.11. O efeito de in-feed requere que o ajuste seja muito maior que a impedância da linha. Além disso, o ajuste deve permanecer conservadoramente acima da capacidade da máquina para prevenir atuações inadvertidas durante oscilações do gerador e distúrbios severos de tensão. A coordenação com os dispositivos de proteção de linha é obtida impondo-se um tempo de atuação maior que o tempo de atuação da zona dois dos relé de distância da proteção principal da linha. 
Figura 3.11 - Configuração de um sistema com alimentação múltiplo.

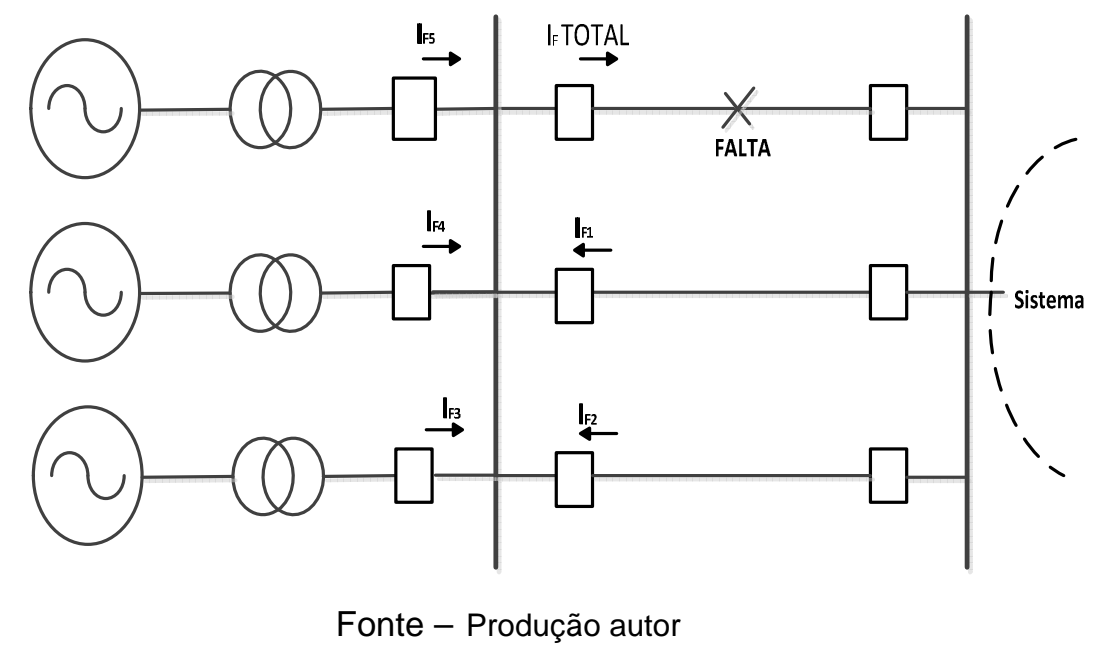

Uma segunda forma de aplicação da função 21 é sua conexão nos TCs dos terminais do gerador. Normalmente, uma zona Mho é ajustada para detectar faltas até o final da linha mais longa. Nesta situação, faltas internas ao gerador irão se localizar no terceiro quadrante do plano R-X e, dessa forma, não serão detectadas por essa zona. Para se conseguir de retaguarda também para o gerador existem duas soluções: a)- inserir um off-set a essa zona de proteção, normalmente com um alcance maior que $x_{d}^{\prime \prime}$ na direção reversa; b)utilizar uma segunda zona na direção reversa da primeira (monitorando o gerador). Deve-se ressaltar que, nesta forma de aplicação, a função 21 não irá fornecer proteção de retaguarda para o gerador quando este estiver desconectado do sistema.

\subsection{PROTEÇÃO CONTRA FALTAS FASE-TERRA NO ESTATOR}

As funções de proteção utilizadas para a detecção de faltas à terra no estator dependem fundamentalmente do esquema de aterramento empregado no gerador síncrono. Neste item será considerado somente o caso de aterramento através de alta impedância, que é o utilizado em máquinas de grande porte. Nesta situação, as funções de proteção de interesse são descritas nos subitens a seguir. 


\subsubsection{PROTEÇÃO DE SOBRETENSÃO DE NEUTRO (59GN)}

Este esquema tornou-se a proteção padrão para detecção de faltas à terra no estator de unidades gerador-transformador elevador aterrados através de alta impedância. Ele consiste na utilização de um relé de sobretensão de tempo inverso monitorando a tensão sobre o resistor de aterramento, como mostrado na figura 3.12. Quando ocorre uma falha à terra, a tensão no relé é uma função da relação de espiras do transformador. A tensão máxima aparece no relé para uma falta nos terminais do gerador. Por motivos de enrolamento do estator a tensão no relé diminui à medida que a falta se move direção do neutro do gerador. Para que o relé terra do gerador possa operar para faltas à terra no sistema, é necessário que o relé terra do gerador devem estar em coordenação com os outros relés de proteção para a mesma falta.

O gerador é aterrado através de alguma resistência para limitar a corrente de falta, porém, fornece suficiente corrente ou tensão para operar os relés. A resistência primária ou reator pode ser usado para limitar a corrente de falta à terra, mas por razões económicas é utilizado um transformador de distribuição em combinação de resistência. A avaliação de tensão primária do transformador de distribuição deve igual ou maior do que a classificação fase neutro de tensão do gerador, geralmente com uma classificação secundária de 120,240 ou 480 V. O transformador de distribuição deve ter a capacidade de sobretensão suficiente de modo que não se sature a $105 \%$ da tensão nominal. Um resistor secundário é escolhido de modo que, para única falha fase - terra nos terminais do gerador, a potência dissipada no resistor é igual à potência reativa que é dissipada na capacitância de sequência zero dos enrolamentos do estator. $O$ resistor no secundário é escolhido para limitar a corrente de falha primária para 10-35 $\mathrm{A}$. 
Figura 3.12 - Esquema de proteção de sobretensão de neutro.

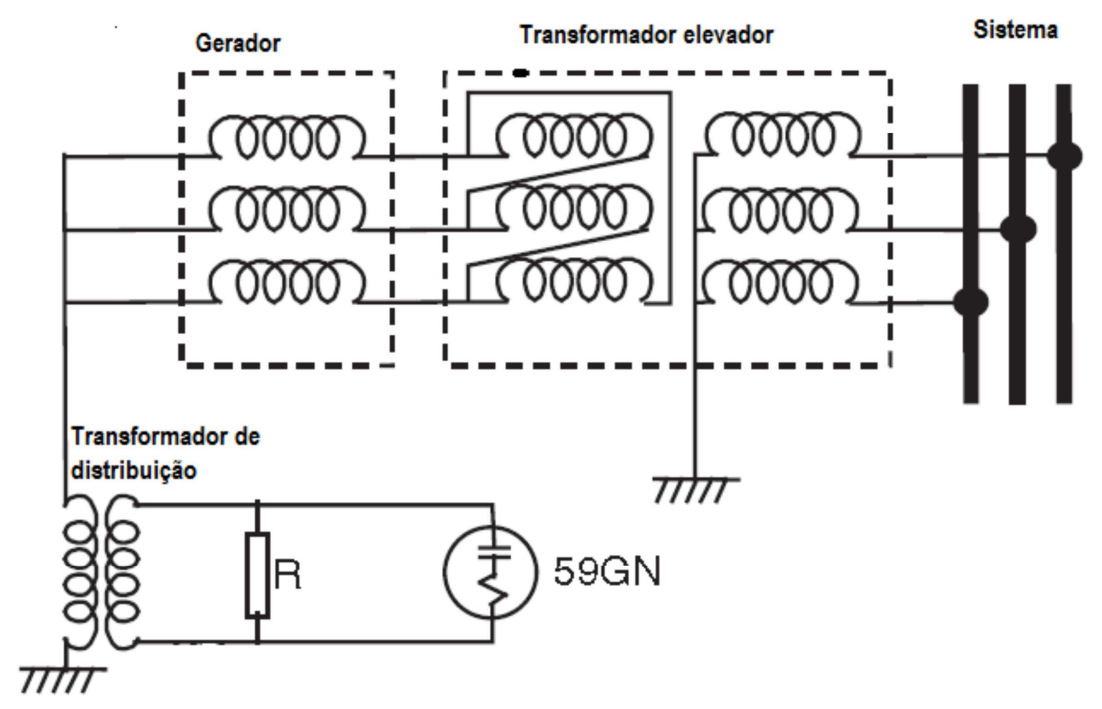

Fonte - Horowizt H. S; Phadke G.A. - 2006.

\subsubsection{PROTEÇÃO DE 100\% DO ESTATOR PARA FALTAS À TERRA}

O esquema de proteção contra faltas fase-terra apresentado no item anterior não consegue garantir uma proteção de $100 \%$ das espiras do enrolamento do estator. Visto que, na ocorrência de falhas fase-terra, os esquemas de proteção apenas conseguem garantir a proteção de aproximadamente $95 \%$ das espiras do enrolamento do estator.

Até alguns anos atrás, essa perda de proteção não era considerado um problema, dado que uma falta nessa região não produz dano significativo. Se uma segunda falta, no entanto, ocorrer na mesma fase, porem próximo dos terminais do gerador, ele irá experimentar uma falta com corrente muito elevada (não limitada pela impedância de aterramento) e não detectável pela função diferencial. Essa falta, com magnitude extremamente elevada, irá se manter até que ela evolua para uma falta fase-fase, a qual passa a ser detectavel pela função $87 \mathrm{G}$.

Devido a esse risco, os atuais relés digitais contam com algum tipo de algoritmo para detecção de faltas fase-terra em 100\% do enrolamento estator. 
Esses algoritmos podem ser agrupados em duas categorias: monitoramento da tensão de terceira harmônica no neutro; injeção de sinais no neutro. A seguir apresenta-se uma breve discussão sobre alguns desses algoritmos.

\subsubsection{SUBTENSÃO DE TERCEIRA HARMÔNICA NO NEUTRO (27H)}

As tensões de fase produzidas pelos geradores síncronos, obviamente, não são perfeitamente senoidais e, dessa forma, possuem harmônicas. $A$ componente de terceira harmônica dessas tensões comporta-se como uma grandeza de sequência zero, isto é, possui, aproximadamente, a mesma magnitude e fase.

Em operação normal, essa componente de terceira harmônica da tensão irá produzir uma corrente de $180 \mathrm{~Hz}$ que circula pela capacitância parasita total presente nos terminais do gerador (constituída pela soma das capacitâncias do enrolamento do estator, do barramento de média tensão, do para-raios do gerador, dos enrolamentos de baixa tensão do trafo elevador e do TP) e que retorna pela resistência de aterramento do gerador. Dessa forma, com o gerador operando em condições normais, existirá uma tensão de $180 \mathrm{~Hz}$, produzida pela circulação dessa corrente, que é monitorada pela função $27 \mathrm{H}$.

Os algoritmos desenvolvidos para implementar essa função nos modernos relés digitais, utilizando técnicas de filtragem, medem o valor RMS somente da componente de $180 \mathrm{~Hz}$, rejeitando eventuais componentes de 60 $\mathrm{Hz}$.

Quando ocorre uma falta à terra perto do neutro do gerador, o retorno da corrente de $180 \mathrm{~Hz}$ pela alta impedância de aterramento é reduzido de forma significativa, passando a ocorrer agora pelo ponto de falta. Dessa forma, a tensão de $180 \mathrm{~Hz}$ monitorada pela função $27 \mathrm{H}$ cai abaixo do valor de pick-up, provocando a atuação dessa função e indicando a ocorrência da falta

A principal dificuldade para aplicação dessa função decorre do fato da magnitude da componente de terceira harmônica presente nas tensões de fase variar de forma significativa com a situação de carregamento do gerador síncrono. Normalmente, a percentagem de terceira harmônica nas tensões de 
fase é máxima com o gerador operando a plena carga e mínima quando se encontra em vazio. Devido a essa variação, a tensão monitorada pela função $27 \mathrm{H}$, durante a operação normal do gerador operando em carga leve, pode cair abaixo do valor de pick-up, provocando uma atuação desnecessária da proteção.

Para reduzir o risco de atuações indevidas da função $27 \mathrm{H}$, alguns algoritmos, ao invés de responder somente à magnitude da tensão de $180 \mathrm{~Hz}$ do neutro, respondem à relação entre essa grandeza e a magnitude da componente de $180 \mathrm{~Hz}$ presente nas tensões terminais do gerador.

A figura 3.13 ilustra a variação da tensão de $180 \mathrm{~Hz}$ no neutro para as diversas situações. Já a figura 3.14 mostra o esquema baseado no uso das funções $27 \mathrm{TH}$ e $59 \mathrm{GN}$, que fornecem proteção de falta à terra para todo o enrolamento do estator.

Figura. 3.13- Representação típica de terceiro harmônico.

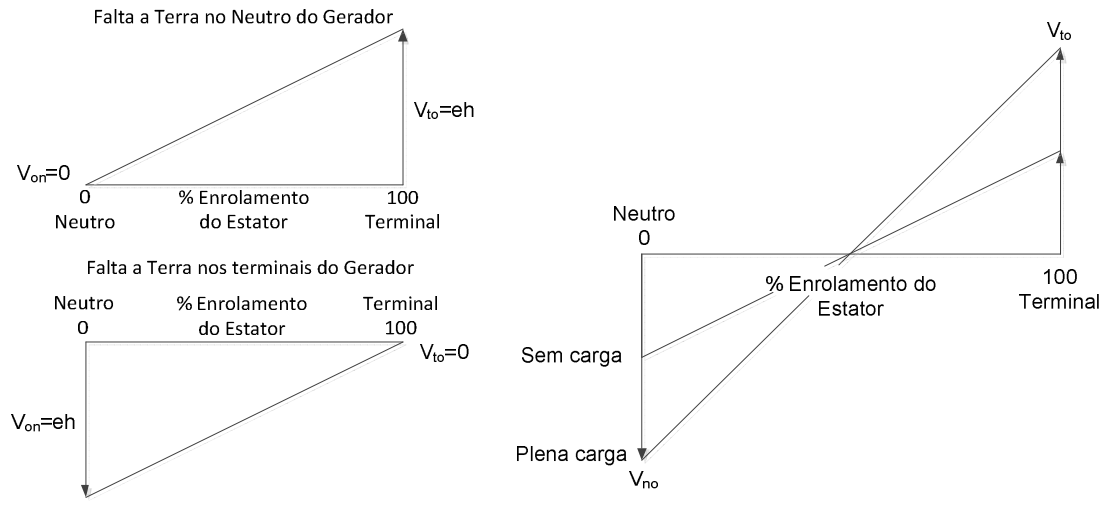

Fonte - Reimert D. - 2006. 
Figura 3.14 - Esquema de subtensão de terceiro harmônico.

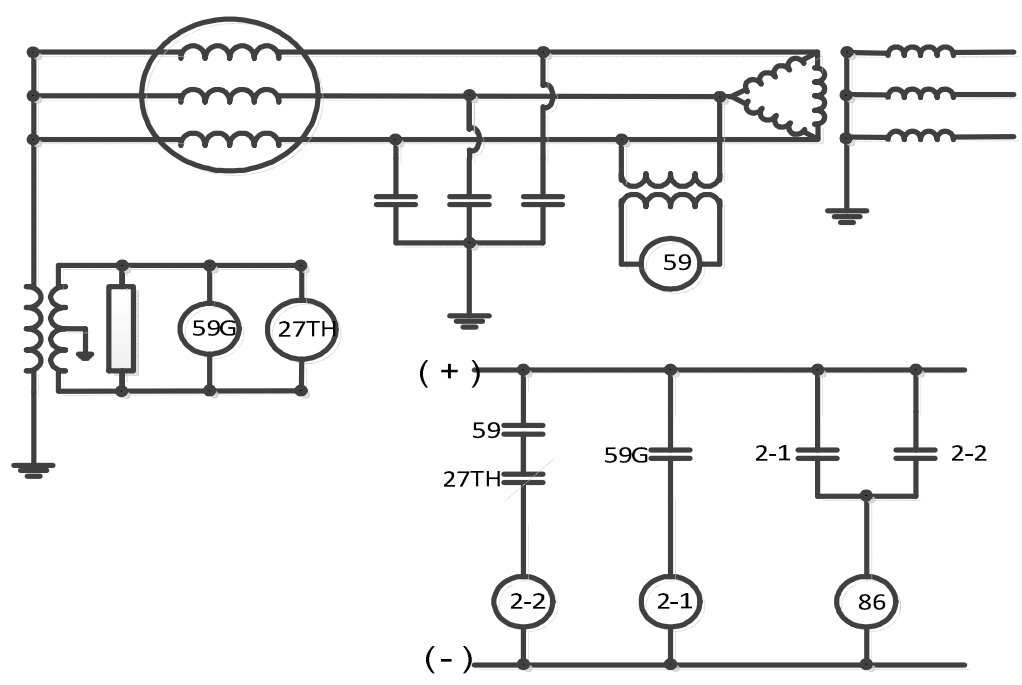

Fonte - Reimert D. - 2006.

\subsubsection{ESQUEMA DE INJEÇÃO DE TENSÃO SUBHARMÔNICA}

Um método capaz de assegurar a proteção para todo o enrolamento do estator contra faltas à terra, inclusive no trecho mais perto do neutro, é o processo de medida de impedância do enrolamento do estator para a terra.

Este método consiste basicamente em medir a corrente que circula pelo estator, produzida por uma tensão subharmônica de $20 \mathrm{~Hz}$ aplicada através do transformador de aterramento, como mostrado na figura 3.15.

Figura 3.15 - Injeção de tensão subharmônica.

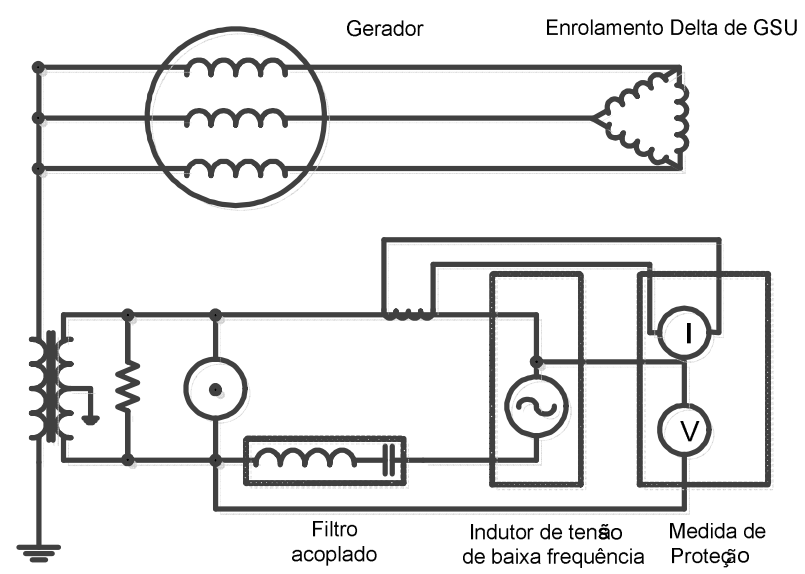

Fonte - Reimert D. - 2006. 
Como a tensão aplicada ao transformador de aterramento desloca o neutro do potencial de terra, surge uma corrente que irá circular entre a terra e os enrolamentos do estator, através das resistências e capacitâncias distribuídas.

O valor desta corrente determina a referência do nível de isolamento do gerador em relação à terra. Como a frequência da tensão aplicada é bem menor que a frequência nominal do gerador, não haverá influência significativa de correntes de desequilíbrio de carga que por ventura circulem pelo transformador de aterramento, uma vez que tanto o curto circuito de medição quanto o gerador de $20 \mathrm{~Hz}$ estão desacoplados para estas frequências por meio de filtros sintonizados em $20 \mathrm{~Hz}$. Em virtude disto, obtém-se uma proteção sensível para qualquer falha no isolamento do gerador em relação à terra, cobrindo assim, $100 \%$ do enrolamento do estator, mais o trecho entre os enrolamentos e o transformador de aterramento, [2] [38].

O esquema de injeção no neutro é um método alternativo para fornecimento de $100 \%$ de proteção de falta à terra. O sistema usa sinal subharmônica devido ao fato de que a frequência menor aumenta a impedância da reatância capacitiva do estator, o que melhora a sensibilidade do esquema. A principal desvantagem do sistema é o custo.

\subsection{PROTEÇÃO CONTRA FALTAS ENTRE ESPIRAS}

Problemas na isolação dos enrolamentos do estator ocorrem ao interior de máquinas síncronas e resultam em faltas entre espiras. Estas faltas na isolação originam-se a partir de falhas fase-terra, fase-fase ou trifásicas cuja duração é de alguns décimos de segundo até alguns minutos e resultam em danos severos.

Uma filosofia de proteção diferencial pode ser utilizada contra este tipo de faltas. Nesse sentido, algumas funções de proteção complementares são utilizadas para melhorar o desempenho da proteção diferencial.

Entre geradores que possuem dois ou mais circuitos em paralelo ou caminhos por fase, as correntes que circulam por cada um dos circuitos devem 
ser aproximadamente iguais em condições normais de operação. No caso de uma falta entre espiras em algum dos ramos (caminhos), a corrente que percorre os conjuntos será distinta. Medindo-se a diferença de corrente dos ramos, pode - se proteger os enrolamentos do estator contra faltas entre espiras [10].

\subsection{PROTEÇÃO CONTRA SOBRE E SUBTENSÃO}

Durante a operação normal de uma máquina, a tensão da unidade é controlada a partir do regulador de tensão. Porém, em casos excepcionais, a tensão pode subir acima dos limites máximos permitidos ou ajustados. Isto pode ocorrer em casos de defeitos no regulador automático de tensão ou rejeição de carga. A proteção contra sobretensões é recomendada especialmente para geradores sujeitos a sobrevelocidades. Uma sobretensão pode resultar, por exemplo, nos seguintes problemas:

- Arcos em linhas de transmissão.

- Excessiva corrente de fuga em para-raios.

- Esforços dielétricos em geradores e transformadores.

- Aquecimento excessivo do núcleo, acelerando a degradação do isolamento.

A proteção pode ser baseada em relés de sobretensão temporizados, com pick-up ajustado entre $105 \%$ e $110 \%$ da tensão nominal, e relés instantâneos, com pick up ajustado entre 130\% e 150\% da tensão nominal do gerador. A operação da proteção (sinal de saída dos relés) pode ter as seguintes aplicações:

- Desligamento do gerador do sistema, mantendo-o operando em vazio.

- Desligamento com parada total do gerador.

- Desligamento de linhas de transmissão para reduzir a geração de reativo.

Redução rápida da corrente de campo para tentar avaliar a sobretensão. 


\subsection{PROTEÇÃO CONTRA PERDA DA EXCITAÇÃO}

Quando um gerador síncrono opera conectado a um sistema elétrico, a transferência de energia é feita pelo acoplamento magnético do campo girante do rotor com o campo girante da armadura.

A excitatriz é a fonte de corrente contínua que gera uma corrente de campo necessária para a criação do campo magnético no rotor.

Os geradores síncronos possuem limites térmicos e de estabilidade para sua normal operação, esses limites são normalmente definidos no plano $\mathrm{P}-\mathrm{Q}$. Normalmente, o regulador automático de tensão RAT (Automatic Voltage Regulator AVR) do gerador possui funções, conhecidas como limitadores, que evitam que os geradores ultrapassem esses limites entrando na zona proibida. A combinação de limites térmicos, estabilidade e a natureza do próprio RAT terão impacto em algumas funções de proteção do gerador, tais como perda de excitação, ou perda de sincronismo [43].

Quando o gerador perde excitação a corrente do rotor diminui gradualmente e a tensão do campo decai lentamente como ditado pela constante de tempo de campo. Por tanto, o gerador passa a consumir potência reativa, em vez de fornecer. Esta perda de excitação pode ser causada por curto-circuito do enrolamento de campo, abertura do disjuntor de campo ou uma falha no sistema de excitação [42].

A proteção contra perda de excitação deve detectar confiavelmente a desconexão de excitação, sem responder às oscilações de carga, às falhas no sistema e outros transitórios que provoquem a instabilidade do gerador. Em situações mais complexas, se o gerador que sofreu a perda de campo não é isolado, as proteções das linhas de transmissão podem disparar devido às oscilações de potência ou devido ao fluxo de potência reativa em excesso para o gerador em falha.

Nesse sentido, a perda de excitação não detectada rapidamente poderia provocar um grave impacto no sistema de potência, criando um dreno de potência reativa devido à perda de campo, uma condição que poderia levar ao 
colapso da tensão, se os reativos requeridos para operação do gerador dentro de limites não são suficientemente fornecidos pelo sistema.

Durante a perda de excitação, o estator absorve uma corrente elevada que pode alcançar magnitudes de até cinco vezes a sua corrente nominal. Essa corrente tem uma forte componente reativa que causa 0 sobreaquecimento do estator e rotor devido ao desequilíbrio magnético, nessas condições o gerador deve ser desligado da rede para evitar sérios danos [8].

O esquema de proteção mais popular e confiável para detecção de perda de excitação utiliza o relé tipo mho com deslocamento (offset). A característica de operação de um relé mho com deslocamento de uma única zona é mostrada na figura 3.16. Essa função mede a impedância vista desde os terminais da máquina e opera quando a impedância da falha cai dentro da característica circular.

Figura 3.16 - Característica do relé Mho - offset de uma zona.

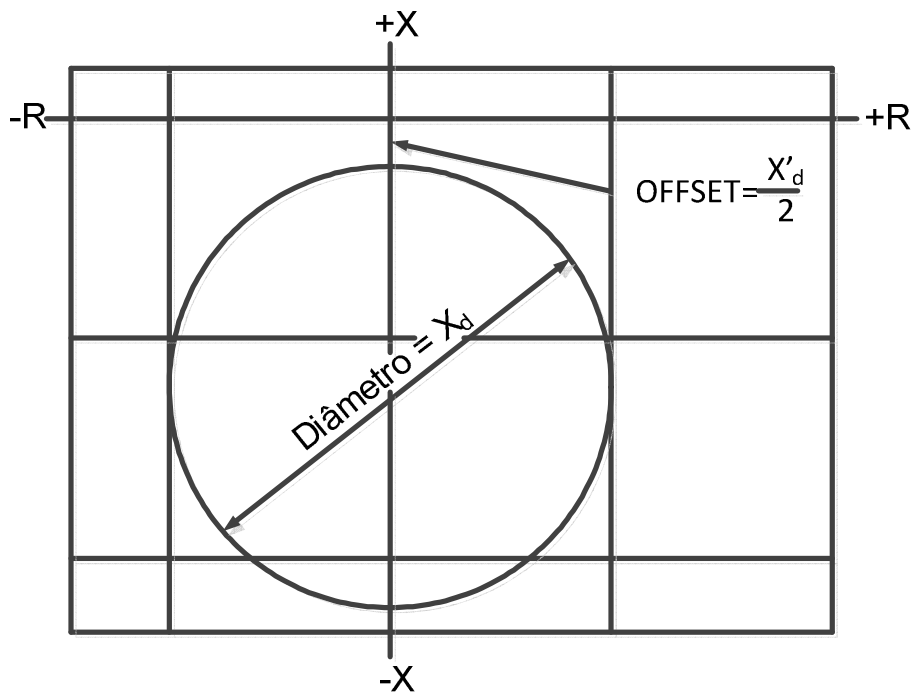

Fonte -Tutorial IEEE Proteção de geradores sínconos.

Para evitar a operação incorreta durante distúrbios no sistema e outras condições de falha, esse deslocamento é igual à metade da reatância transitória do eixo direto $X_{d}^{\prime} / 2$. O diâmetro do circulo é ajustado para ser igual a $X_{d}$. Pode-se usar um retardo de tempo de 0,5 a 0,6 segundos para ter a segurança contra oscilações estáveis de potência. Estes ajustes podem 
fornecer proteção contra perda de excitação do gerador desde carga zero até plena carga, sempre que a reatância síncrona de eixo direto $X_{d}$ do gerador encontre-se no intervalo de 1,0-1,2 p.u.

As máquinas modernas são projetadas com valores maiores de reatância síncrona de eixo direto $X_{d}$, no intervalo de $1,5-2.0$ p.u. Com estas reatâncias síncronas altas, o ajuste do diâmetro do relê mho igual a $X_{d}$ abriria a possibilidade de operação incorreta do relê durante a operação subexcitado. Para evitar estas operações incorretas, o diâmetro do círculo é limitado a 1,0 p.u. (na base do gerador), no lugar de $X_{d}$.

\subsection{PROTEÇÃO CONTRA SOBREEXCITAÇÃO}

A relação entre tensão (Volts) e frequência (Hertz) no gerador é proporcional ao valor de densidade de fluxo B no seu entreferro. Qualquer variação de tensão ou frequência envolve uma rápida saturação do núcleo magnético, provocando perdas por correntes parasitas. Produzindo-se uma sobretensão e sobrefrequência em simultâneo, não há aumento do fluxo magnético e seus efeitos térmicos são minimizados.

Dessa forma, Incrementos na tensão, quedas na frequência ou ambos os eventos produzem a sobrexcitação de geradores síncronos. A sobrexcitação provoca uma saturação do núcleo magnético do gerador, nessas condições as correntes induzidas causam o sobreaquecimento do núcleo.

Na figura 3.17 mostra-se a configuração para um esquema de proteção contra sobreexcitação. 
Figura 3.17 - Proteção contra sobrexcitação.

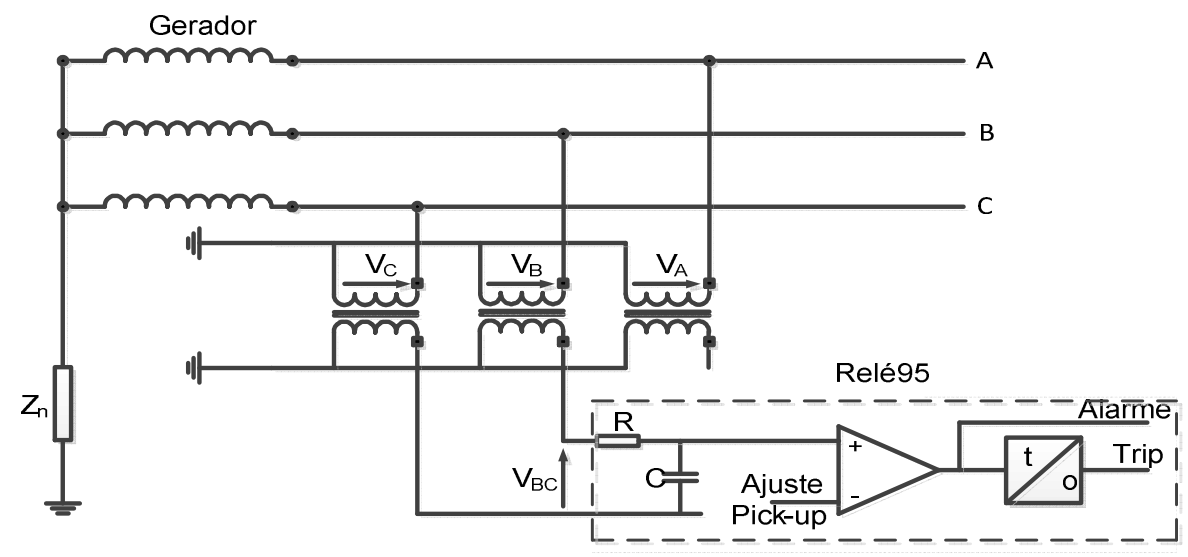

Fonte - IJB Proteção de geradores síncronos - 2012.

A excitação é supervisada através da monitoração da relação tensão/frequência, no divisor de tensão formado pelo resistor $\mathrm{R}$ e o capacitor $\mathrm{C}$, na entrada do relé 95. A tensão $V_{B C}$ é aplicada ao circuito $R-C$. A queda de tensão sobre o capacitor é comparada com o ajuste de "pick up" do relé. Quando esta tensão desenvolvida sobre o capacitor ultrapassa o ajuste de "pick up", o comparador gera um sinal de saída que produz um alarme de sobreexcitação e inicia um temporizador.

Se a sobreexcitação perdurar por um tempo superior o ajuste do temporizador, o relé gera um comando de desligamento da unidade. A tensão desenvolvida sobre o capacitor é diretamente proporcional à tensão do gerador, aplicada à entrada do relé $V_{B C} e$ inversamente proporcional à frequência. Quando a frequência aumenta, a reatância do capacitor diminui e, portanto diminui a tensão sobre ele. Desse modo a queda de tensão sobre o capacitor é proporcional à relação tensão/frequência (Volts/Hertz). Consequentemente o relé mede o nível de excitação da unidade.

De acordo com [45], o limite tensão/frequência em geradores na condição de operação contínua é igual a 1,05 p.u. na base do gerador. Os fabricantes de geradores síncronos fornecem as curvas limites de sobreexcitação. 


\subsection{PROTEÇÃO CONTRA CORRENTES DE DESEQUILÍBRIO NO ESTATOR}

Correntes desequilibradas no estator são prejudiciais para o gerador. Entre as causas de desequilíbrio de correntes, podemos citar as seguintes:

- Abertura de uma fase de uma linha de transmissão ou falha em um polo de um disjuntor.

- Falta desequilibrada próxima à usina geradora, não removida prontamente pela proteção.

- Falta no enrolamento do estator.

Correntes desbalanceadas, resultantes de cargas assimétricas provocam o aparecimento de componentes de sequência negativa nos enrolamentos do estator.

A circulação destas correntes de sequência negativa no estator induz uma corrente de $120 \mathrm{~Hz}$ no rotor, em relação à frequência nominal da máquina, que tende a circular na superfície do rotor, causando sobreaquecimento. Se o rotor permanecer por muito tempo submetido à condição de corrente desbalanceada, pode ser afetado termicamente [2],[3],[38].

Em função da dificuldade de supervisar e de localizar os pontos de aquecimento mais prejudiciais, são estabelecidos limites, dentro dos quais é possível operar os geradores com cargas desbalanceadas, sem risco de danificá-los.

Este limite de tempo pode ser expresso na seguinte forma:

$$
K=\int_{0}^{t} i_{2}^{2} d t
$$

Nessa Expressão, $i_{2}$ é a componente de sequência negativa da corrente do estator em função do tempo, expressa em p.u na base da máquina, e $\mathrm{K}$ uma constante que assume os valores de 30 para turbogeradores e de 40 a 60 para hidrogeradores. Em outras palavras, essa equação mostra que o tempo que o rotor é capaz de suportar esta condição é inversamente proporcional ao 
quadrado da corrente de sequência negativa:

$$
t=\frac{K}{i_{2}^{2}}
$$

Desta forma, é necessário monitorar constantemente o nível das correntes de sequência negativa, função exercida pela proteção contra desbalanço de carga (relé 46) que normalmente inclui um filtro de corrente de sequência negativa, temporizadores e, em alguns casos, um módulo de imagem térmica. Um esquema básico da proteção é mostrado na figura 3.18.

Figura. 3.18 - Proteção contra correntes desbalanceadas.

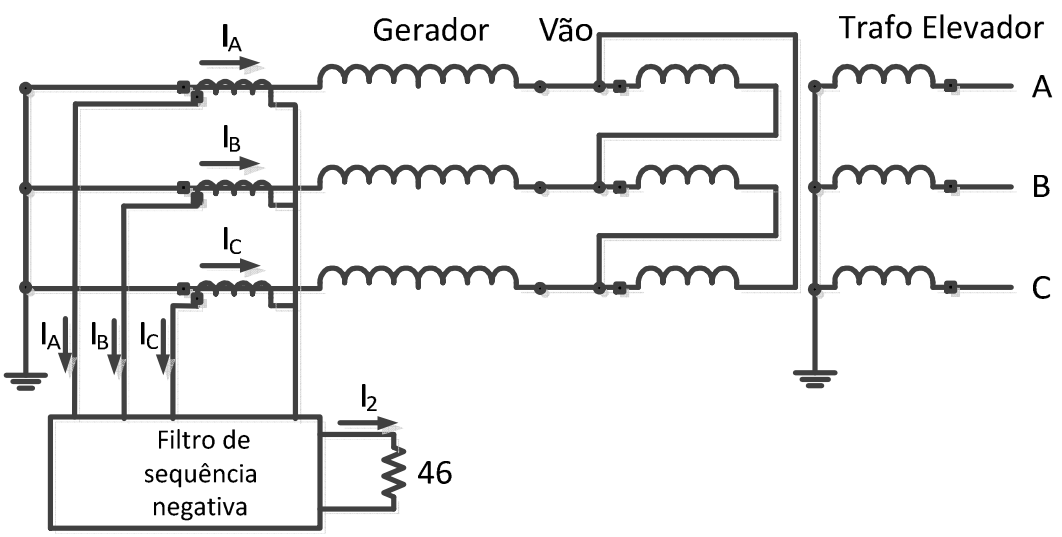

Fonte - IJB Proteção de geradores síncronos - 2012.

O relé de corrente de sequência negativa tem a seguinte característica:

$$
\begin{gathered}
\int \mathrm{i}_{2}{ }^{2} \geq \mathrm{K} \text { Alarme ou disparo } \\
\int{i_{2}}^{2}<K \text { Nenhuma operação }
\end{gathered}
$$

A constante $\mathrm{K}$ é normalmente fornecida pelo fabricante do gerador. Em geral, o relé 46 possui dois níveis de ajuste: um mais baixo, para alarme, e outro elevado, para desligamento.

As informações de corrente em cada fase, necessária para o relé, são obtidas através de um conjunto de TCs instalados junto ao neutro do gerador, e 
aplicadas ao filtro de sequência negativa. $O$ relé mede a magnitude da componente de sequência negativa presente no estator. Quando o valor de $I_{2}$ atinge o nível mínimo, através de um temporizador integrador, o relé gera um alarme, indicando a presença de correntes de sequência negativa acima de um determinado nível. Caso $I_{2}$ alcance um nível não permitido para a operação do gerador, após um retardo de tempo, atua o segundo estágio da proteção, desligando o gerador do sistema, porém mantendo-a girando com velocidade e tensão nominais, em vazio.

Os temporizadores são ajustados criteriosamente de modo a evitar alarmes ou desligamento que poderiam ser causados por oscilações ou perturbações rápidas que geram correntes de sequência negativa momentânea através do gerador. A corrente de sequência negativa num gerador também é útil para implementar uma função de proteção contra aquecimento excessivo do rotor, durante desbalanços no sistema.

A causa dos desbalanços normalmente esta fora do gerador: na maioria das vezes é um problema no sistema. Quando a proteção incorpora um modelo térmico do rotor, o que é muito simples para relés microprocessados, o sinal de saída do filtro de sequência negativa é aplicado ao modelo térmico, que simula a temperatura do gerador em função da corrente de sequência negativa, de forma a detectar um aquecimento excessivo pela circulação prolongada, mesmo em baixos níveis da corrente de sequência negativa.

\subsection{PROTEÇÃO CONTRA MOTORIZAÇÃO}

A monitoração do gerador ocorre quando a entrada de potência mecânica da turbina é interrompida, estando esta unidade conectada ao sistema. Quando isso acontece, o gerador passa atuar como um motor síncrono, acionando o eixo da turbina. No caso de unidades a vapor, a motorização do gerador pode danificar rapidamente a turbina, devido a sobreaquecimento. Em unidades com turbinas hidráulicas ou a gás a monitoração pode causar danos mecânicos (cavitação em turbinas hidráulicas) ou condições operativas inseguras. Assim, a proteção contra motorização existe em função da turbina e não do gerador. 
A proteção antimotorização é feita por elementos de potência reversa ou de mínima potência direta. Estes elementos medem o fluxo de potência ativa que sai do gerador. Se a saída de potência ativa cair abaixo de um valor mínimo ajustado, o elemento inicia um temporizador de tempo definido.

As proteções digitais, em geral, disponibilizam dois níveis de potência. Estes níveis são ajustados em p.u. da potência nominal da máquina.

A tensão e a corrente nominais determinam 1 p.u. de potência. Não havendo interesse em dois níveis de potência reversa para desligamento, um deles pode ser usado como proteção de sobrecarga. A faixa de ajuste é suficientemente larga para permitir esta aplicação.

Dentre as causas que provocam a motorização e modificam o regime de operação de um gerador síncrono, fazendo com que o mesmo opere como um motor, passando a consumir potência ativa da rede, são:

- Defeito interno no gerador.

- Defeito na turbina.

- Defeito no circuito de excitação.

- Defeito nos mancais.

- Perda de fluxo de água injetada na turbina.

- Qualquer perda de força motriz. 


\section{CAPÍTULO 4}

\section{PLATAFORMA PARA ENSAIOS E VALIDAÇÃO DE SISTEMAS DE PROTEÇÃO}

\subsection{ENSAIOS DE SISTEMAS DE PROTEÇÃO DE GERADORES EM SIMULADOR DE TEMPO REAL}

Diversos equipamentos como geradores, transformadores, linhas de transmissão e cargas compõem os sistemas elétricos de potência e as simulações têm sido reconhecidas como ferramentas importantes e necessárias para o projeto, teste e desenvolvimento desses equipamentos. Os avanços no hardware dos sistemas computacionais e nas técnicas para modelagem de sistemas de energia elétrica tem aumentado significativamente a aplicação da simulação digital [34].

A proteção das redes elétricas é uma área da engenharia elétrica que exige do projetista, além de sólidos conhecimentos em sistemas elétricos de potência, uma vasta experiência prática na aplicação e ajuste das funções de proteção. Quando realizando essa atividade, o projetista deve considerar as inúmeras possibilidades de condições operativas e de falta que podem ocorrer no sistema. A ocorrência de uma situação não prevista ou não considerada durante a etapa de projeto do sistema de proteção pode levar à sua atuação incorreta e, eventualmente, a um evento sistêmico de grandes proporções (blecaute). Dessa forma, a disponibilidade de facilidades ou recursos laboratoriais que, ao final da etapa de projeto do sistema de proteção e antes de sua implantação em campo, permita simular e testar o desempenho, frente a centenas de situações possíveis de falta, dos ajustes definidos para as funções utilizadas no sistema de proteção de um dado componente da rede seria de grande valia. Isso permite que eventuais erros de ajuste (ou mesmo erros na implementação das funções de proteção pelos fabricantes do IED) possam ser prontamente identificados e corrigidos antes da instalação e comissionamento do sistema de proteção em campo. 
Neste capítulo é apresentado e discutido a utilização de um sistema, baseado em simulador de tempo real (RTDS), para ensaios de sistemas de proteção de geradores síncronos.

O simulador de tempo real utilizado neste trabalho encontra-se instalado no LProt - Laboratório de Proteção e Automação de Sistemas Elétricos, foi fornecido pelo fabricante RTDS e é constituído por 4 racks, abrigados em 2 cubículos, com um total de 12 cartões de processamento GPC, como pode ser visto na Figura 4.1. Em termos de entradas e saídas, o simulador possui a seguinte configuração:

- Três cartões de saídas analógicas (GTAO), com um total de 36 canais para saída de sinais analógicos.

- Cartões de entradas analógicas (GTAl) - total de 24 canais para entrada de sinais analógicos.

- Dois cartões de entradas digitais (GTDI) - total de 128 entradas digitais.

- Dois cartões de saídas digitais (GTDO) - total de 128 saídas digitais.

- Dois cartões (GTNET-GSE) para envio/recebimento de mensagens GSE (IEC 61850) - cada cartão permite até 32 entradas digitais + 32 saídas digitais a ser trocada entre o RTDS e até 5 IEDS utilizando mensagens GOOSE.

- Cartões para envio de valores amostrados (IEC 61850-9-2) - total de 24 sinais analógicos enviados para os IEDs a uma taxa de 80 amostras/ciclo.

Além do simulador, o Laboratório dispõe de 04 amplificadores de sinais analógicos, marca Omicron, cada um com três canais de tensão e três canais de corrente, permitindo o ensaio de até quatro IEDs simultaneamente. 
Figura 4.1 Simulador de Tempo Real utilizado nos ensaios.

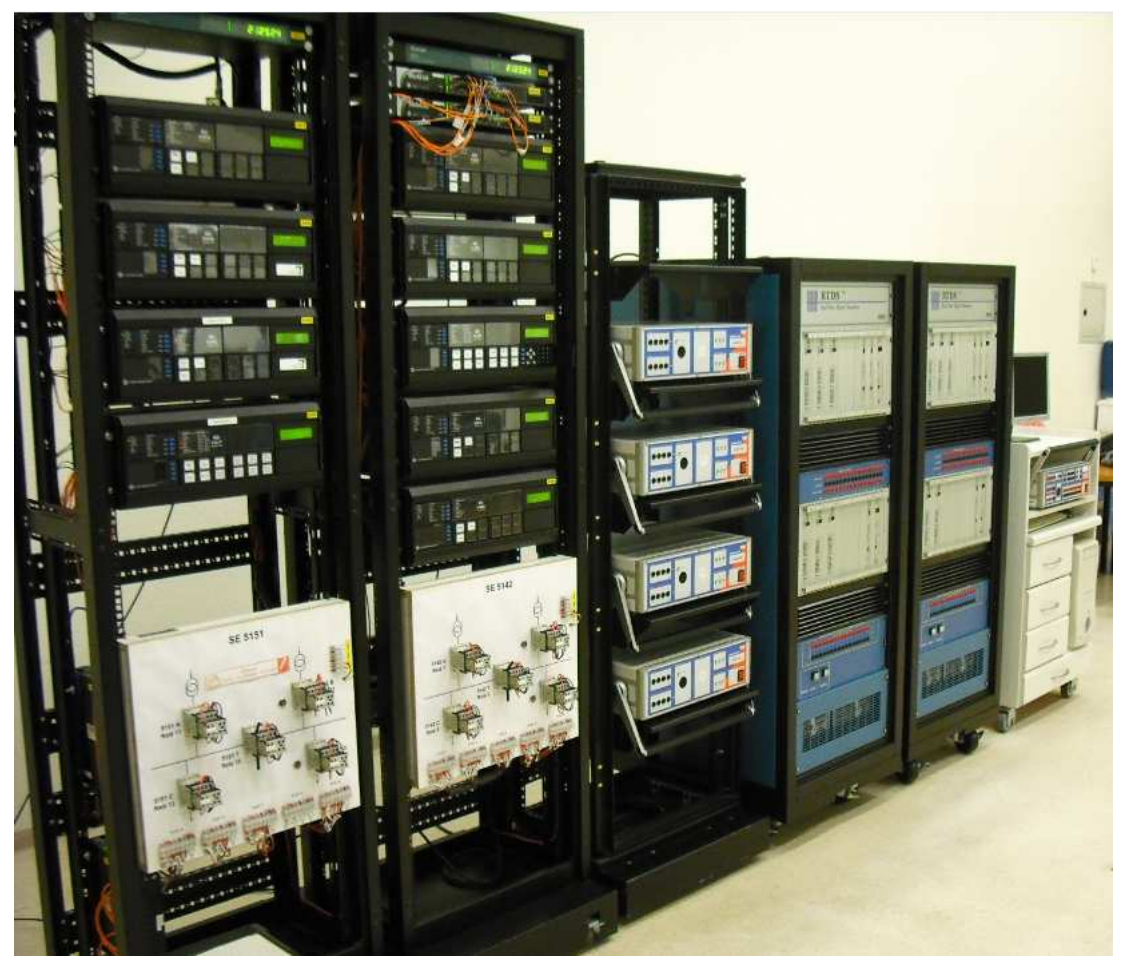

Fonte - Própio autor.

O Simulador, mostrado na Figura 4.1, foi utilizado para realizar a simulação dos geradores síncronos de uma usina hidrelétrica hipotética submetidos a vários tipos de faltas, em diferentes pontos dos enrolamentos do estator, para diversas condições de carregamento. Neste capítulo serão mostradas, a título de ilustração, todas as etapas das simulações realizadas. Particular atenção foi dada à solução desenvolvida para realizar o ensaio da função de subtensão de terceira harmônica no neutro (27TH).

Os sinais digitais das tensões e correntes no gerador, obtidos através de simulação no RTDS, foram sintetizados nos cartões de saída analógica (tensões de saída de $\pm 10 \mathrm{~V}$ ) e em seguida convertidos, pelos amplificadores Omicron, em tensões ou correntes com amplitudes iguais às que seriam obtidas nos secundários dos TCs e TPs da instalação real. Os canais de entradas analógicas do IED de proteção do gerador recebem essas tensões e correntes e, dessa forma, é possível avaliar a resposta das funções de proteção ajustadas frente a cada um dos inúmeros eventos de falta simulados. O IED envia sinais de abertura dos disjuntores de volta para o simulador que 
realiza as mudanças na topologia da rede sendo simulada.

Como ilustrado na figura 4.2, com esse procedimento de ensaios realizase simulações em laço fechado conhecidas como hardware-in-the-loop (HIL).

Figura 4.2 - Simulação em tempo real em laço fechado com RTDS.

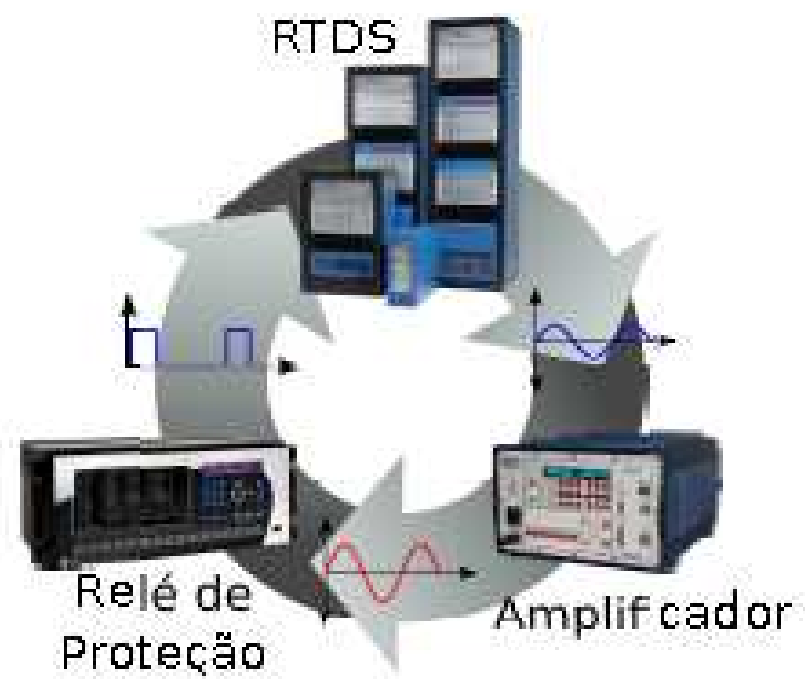

Fonte - Monaro M. R. - 2013.

\subsection{DESCRIÇÃO DO SISTEMA SIMULADO}

O sistema elétrico a ser utilizado como exemplo neste trabalho é composto por uma geração hidrelétrica de $960 \mathrm{MVA}$, conectada a uma barra de $345 \mathrm{kV}$ através de 2 linhas de transmissão de $250 \mathrm{~km}$, sendo uma em circuito duplo (total de 3 circuitos). Admite-se que a usina é constituída por 6 geradores síncronos de 160 MVA cada, com tensão nominal de $15 \mathrm{kV}$. A cada gerador é associado um transformador elevador, de $160 \mathrm{MVA}$, enrolamentos conectado na ligação $\Delta / Y$, como mostrado na figura 4.3.

De forma a reduzir a carga computacional das simulações de tempo real realizadas, utilizou-se o sistema equivalente simplificado, mostrado na figura 4.3, constituído por duas máquinas.

O primeiro gerador representa a máquina individualizada cujo sistema de proteção pretende-se estudar e, dessa forma, possui os mesmos parâmetros de cada um dos 6 geradores da usina. Já o segundo gerador representa 0 
equivalente para as outras 5 máquinas da usina que foram agrupadas em uma única. Para tanto, considerou-se sua potência nominal igual a 800 MVA (os parâmetros em pu permanecem os mesmos).

O sistema equivalente a ser simulado, como mostrado na figura 4.4, possui onze barras e duas máquinas síncronas com potências nominais de 160 MVA e 800 MVA, que estão conectadas através de transformadores elevadores a três circuitos de linhas de transmissão de 345 kV, 250 km.

Figura 4.3 - Rede exemplo utilizada neste trabalho.

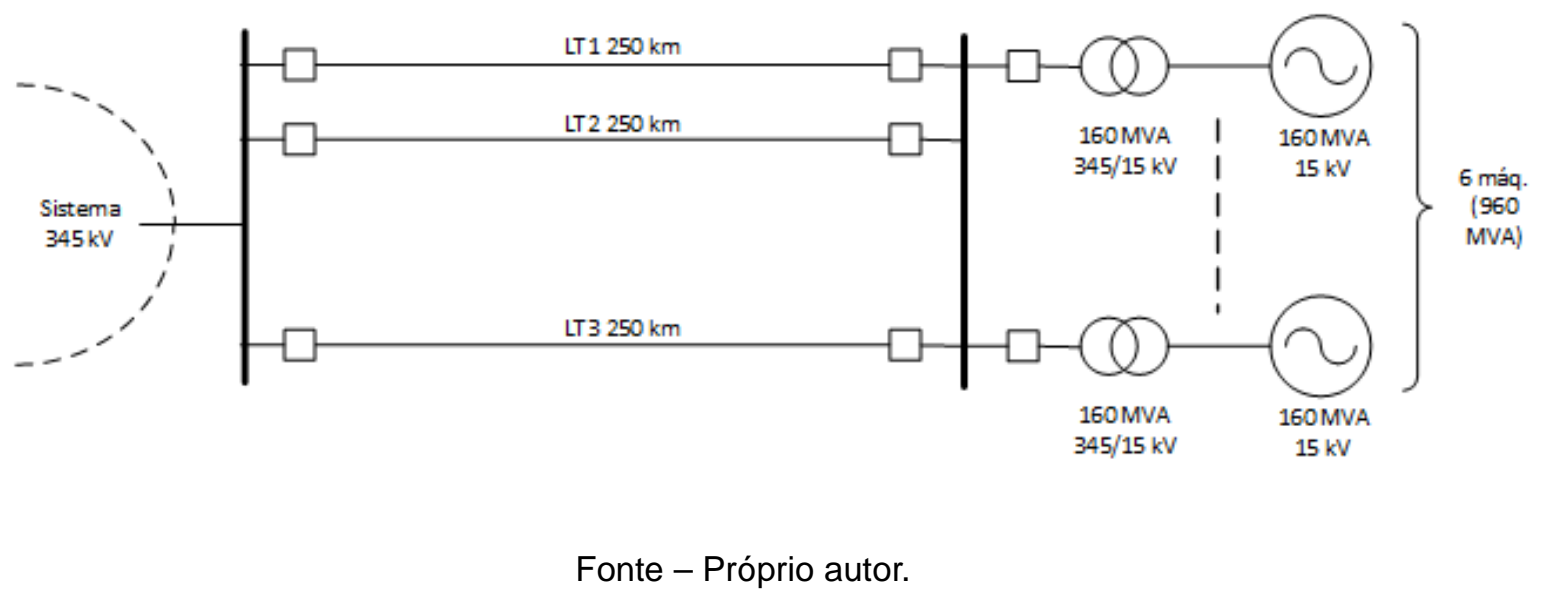

Para a tarefa de ensaio de sistemas de proteção de geradores, a solução ideal seria utilizar, no simulador de tempo real, um modelo de máquina síncrona baseado na abordagem da função de enrolamento modificado (Modified Winding Function Approach) (MWFA) [12].

Essa abordagem calcula as indutâncias considerando a distribuição real dos enrolamentos da máquina e, dessa forma, as componentes harmônicas presentes nas tensões induzidas são determinadas com precisão.

Esse modelo, além de incluir a distribuição real dos enrolamentos do estator no cálculo de suas indutâncias, também considera a forma real do rotor, do arco polar, das ranhuras e dos efeitos do ponto de operação no cálculo da variação real da permeância como uma função da posição angular do rotor.

Estas características são incluídas no modelo através de alguns dados e características, como o número de polos, número de ranhuras do estator, a 
distribuição dos enrolamentos e geometria dos polos do rotor [55].

As principais vantagens dessa teoria é que consegue simular corretamente as componentes harmônicas presente nas tensões de fase e representar exatamente a indutância de pequenas porções do enrolamento.

Isso é importante, dado que, para verificar experimentalmente 0 desempenho da proteção $100 \%$ do estator para faltas à terra, é necessária a utilização de um modelo de máquina síncrona capaz de representar, com boa precisão, a magnitude das componentes de terceira harmônica [12].

O modelo MWFA mostra-se bastante adequado para representação de alguns fenômenos de forma mais completa e detalhada a respeito da distribuição não senoidal da força magneto motriz FMM e saturação, [56].

Atualmente o modelo MWFA ainda não está disponível na biblioteca do software RSCAD em virtude da elevada carga computacional que ele impõe ao hardware do RDTS, inviabilizando a simulação em tempo real.

Neste trabalho, para contornar essa limitação e viabilizar os ensaios da função de proteção de faltas à terra para $100 \%$ do estator usando o modelo de máquina síncrona em tempo real disponível no RSCAD, baseado na teoria dq0, emprega-se uma abordagem alternativa adicional, conforme sugerido na referência [58].

Para gerar as componentes harmônicas de terceira ordem das tensões, não fornecidas por esse modelo, será utilizado um circuito auxiliar descrito mais à frente neste texto.

As tensões fornecidas aos relés serão obtidas somando-se as tensões puramente senoidais produzidas pelo modelo de gerador do RSCAD com as componentes de $180 \mathrm{~Hz}$ fornecidas por esse circuito auxiliar.

A figura 4.4 mostra a rede exemplo representada no RSCAD utilizando o modelo de gerador síncrono disponível nesse software. 


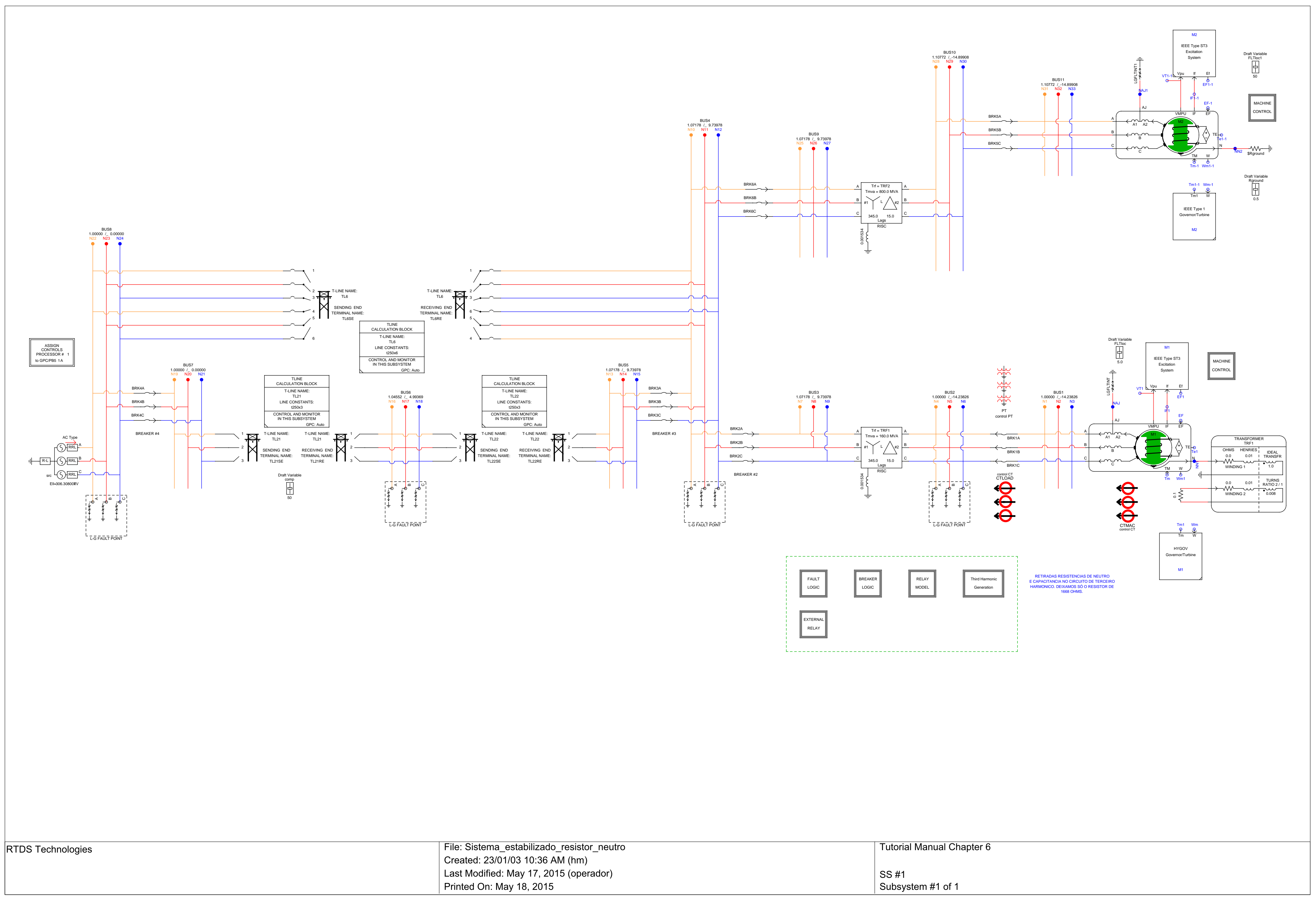


A figura 4.5 mostra a representação adotada pelo modelo disponível no RSCAD para simular os geradores síncronos. Essa representação é utilizada para a máquina 1, na qual será realizado os ensaios para análise do sistema de proteção. A fase $A$ da indutância de enrolamento do estator está dividida em dois subenrolamentos $A 1$ e $A 2$, os enrolamentos de eixo direto e eixo de quadratura são representados por $D$ e $Q$, também o enrolamento de campo é representado por F. NA1, NB1 e NC1 são os nós de tensões nos terminais do estator, NAJ representa um nó de tensão de enrolamento de fase $\mathrm{A}$, dividido em dois subenrolamentos, NN1 é um nó de tensão no neutro, EF1 e IF1 são os nós do enrolamento de campo e podem ser conectados de forma manual e automática, Te é o torque elétrico.

Figura 4.5 - Configuração do modelo de máquina síncrona incorporado no RTDS.

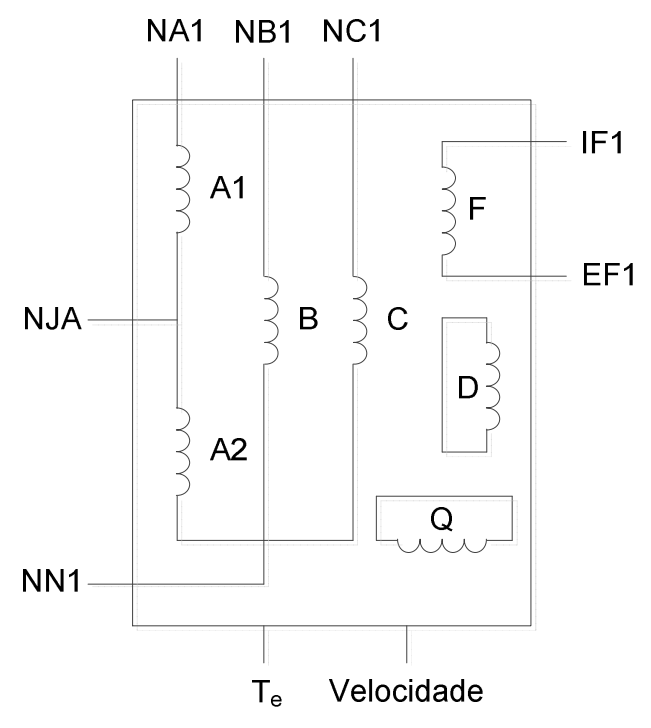

Fone - Dehkordi A. B.- 2010

A figura 4.6 apresenta o circuito auxiliar, conforme sugerido na referência [58], utilizado neste trabalho, para produzir a componente de terceira harmônica presente nas tensões de fase. Sabe-se que essa percentagem dessa componente varia com o carregamento da máquina. Normalmente, quando a máquina opera a plena carga essa percentagem é máxima e é mínima na situação de carga leve. $\mathrm{Na}$ abordagem simplifica utilizada, considera-se que a percentagem de $180 \mathrm{~Hz}$ varia linearmente entre $3 \%$ e $5 \%$ à medida que potência ativa fornecida pelo gerador varia entre 0 e $160 \mathrm{MW}$. 
Normalmente, esses valores são obtidos através de ensaios de campo realizados na máquina a ser protegida.

Figura 4.6 - Circuito para geração da componente de terceira harmônica das tensões.
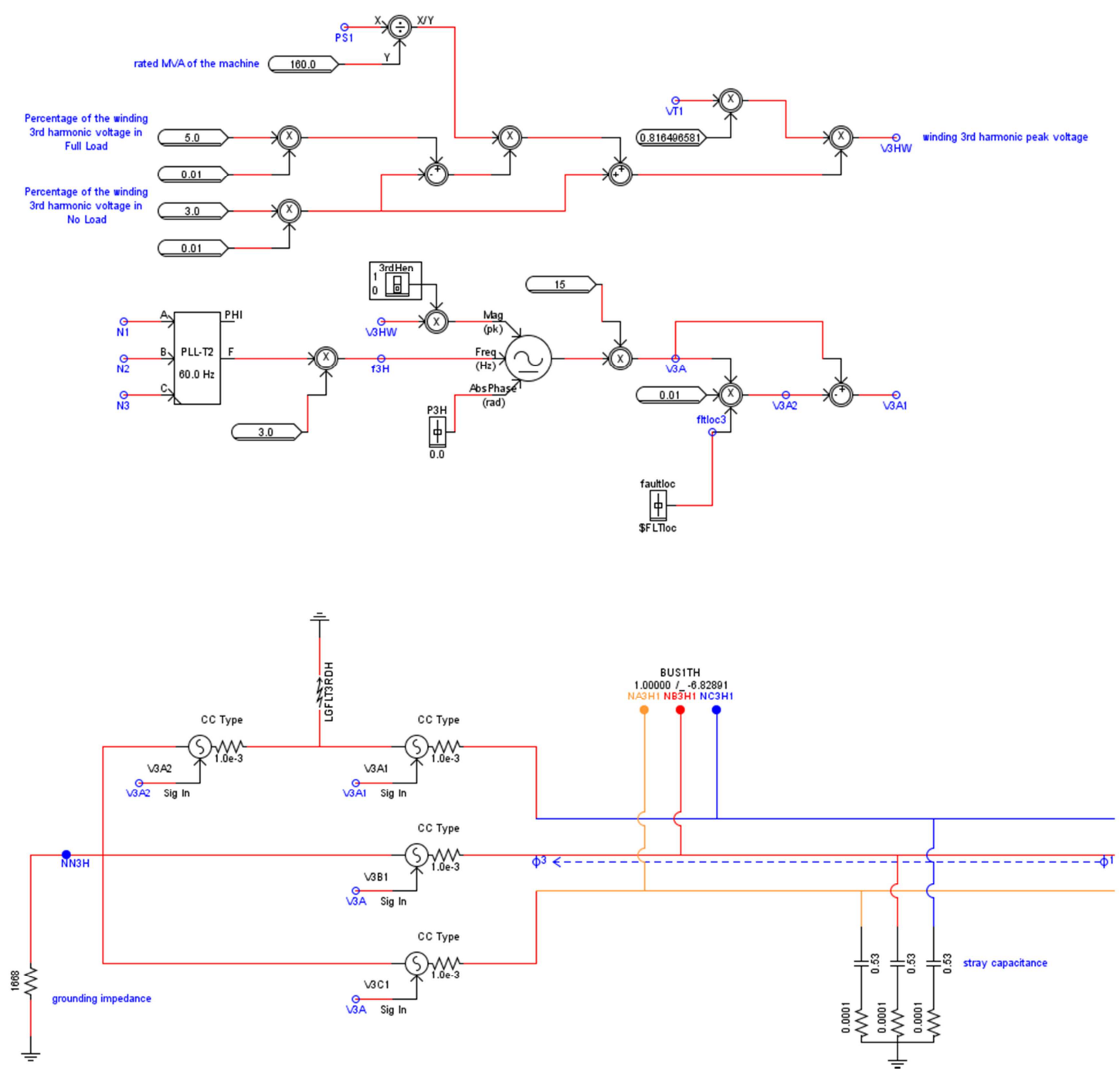

Fonte - Próprio autor.

O circuito mostrado na parte superior da figura 4.6 tem como variáveis de entrada a potência ativa fornecida (PS1) e o valor eficaz da tensão de linha nos terminais do gerador (VT1) e como parâmetros as percentagens mínimas (3\%) e máximas (5\%) de $180 \mathrm{~Hz}$. A saída desse circuito é a amplitude da componente de terceira harmônica que será inserida em cada fase do gerador (V3HW), obtida através de uma interpolação linear entre esses dois valores. $\mathrm{O}$ segundo circuito dessa figura gera os sinais senoidais de $180 \mathrm{~Hz}$ que serão utilizados nas fontes de tensão do circuito inferior (V3A1, V3A2, V3A3) da 
figura 4.6. A partir dessas tensões, este último circuito fornece as tensões de terceira harmônica no resistor de aterramento e nos terminais do gerador, isto é, sobre as capacitâncias parasitas.

As tensões de $60 \mathrm{~Hz}$, no secundário dos TPs, fornecidas pelo circuito da figura 4.4 são somadas com as correspondentes tensões de $180 \mathrm{~Hz}$ geradas no circuito da figura 4.6, como mostrado na figura 4.7. Essas tensões, representando as três tensões de fase e a do neutro, são sintetizadas pelos cartões D/A do RTDS, amplificadas e injetadas nos canais analógicos de tensão do IED.

Figura. 4.7. Soma das tensões de $60 \mathrm{~Hz}$ e $180 \mathrm{~Hz}$ para as tensões de fase e de neutro.

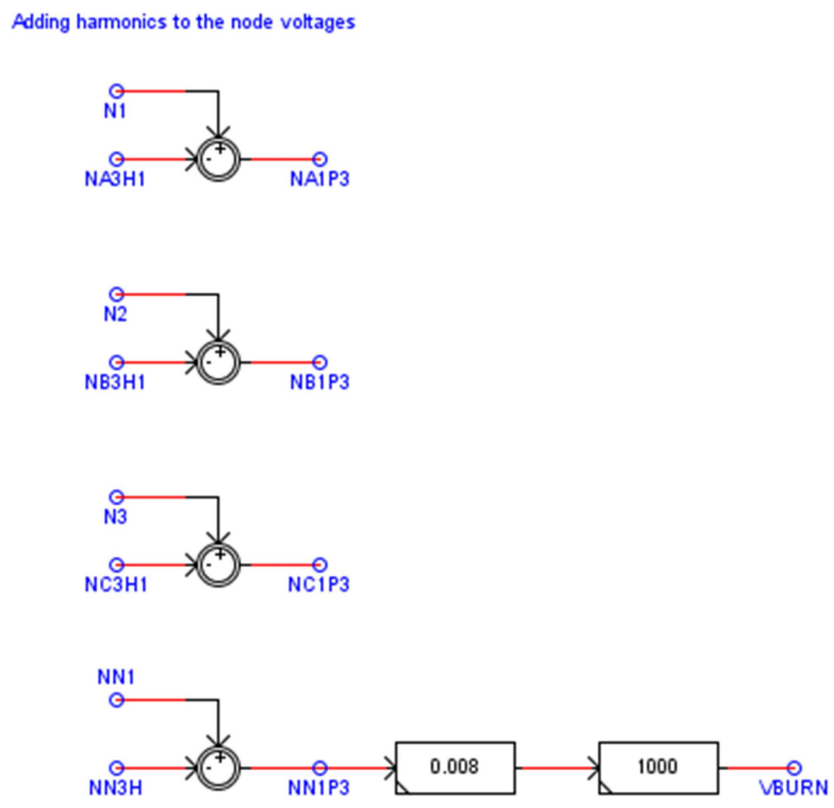

Fonte - Própio autor.

As figuras 4.8 e 4.9 mostram as tensões de fase (VAN, VBN, VCN) e de neutro, obtidas com essa metodologia, para o gerador operando em condições normais, em carga pesada (150 MW) e leve (48 MW), respectivamente. No primeiro caso o valor RMS da tensão de $180 \mathrm{~Hz}$ presente sobre o resistor de neutro vale $360 \mathrm{~V}$. Já em carga leve essa tensão se reduz para $311 \mathrm{~V}$, devido à redução observada na percentagem de terceita harmônico presente nas tensões de fase produzidas pelo gerador. 
Além dos circuitos mostrados nas figuras 4.4, 4.6 e 4.7, existem outras diversas lógicas implementadas no RSCAD para implementar a plataforma de simulação e ensaio do sistema de proteção do gerador. Essas lógicas são apresentadas nas figuras 4.10 até 4.14 e brevemente comentadas a seguir.

Figura 4.8. Tensões de fase e neutro para gerador operando em carga pesada.

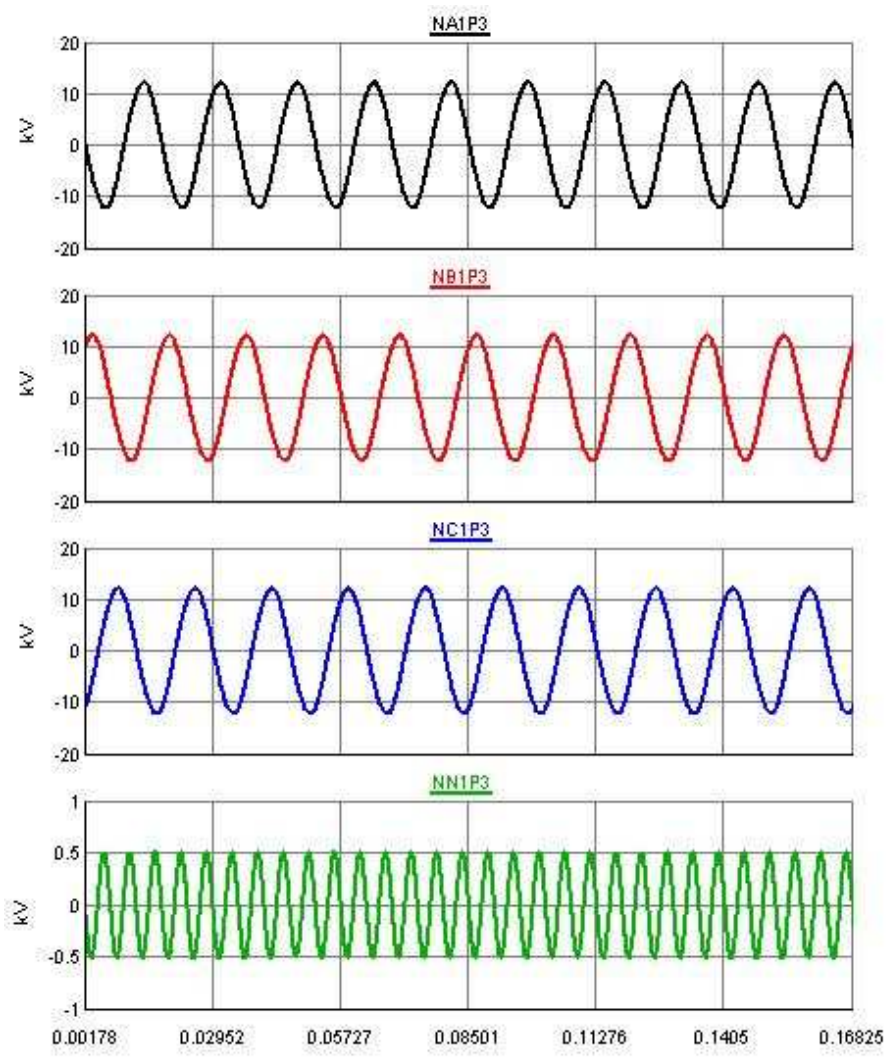

Fonte - Própio autor.

- Lógica de falta: Esta lógica foi implementada para aplicar faltas internas na máquina e faltas externas na barra ou linhas.

- Lógica do disjuntor: Esta lógica é implementada para controle da abertura e fechamento de cada um dos disjuntores.

- Lógica do relé: Esta lógica está implementada para uma comunicação com um rele externo, onde o RTDS envia sinais de tensões e correntes para um relé externo que depois são amplificados pelo OMICROM antes de chegar ao IED G60. O RTDS envia o estado dos disjuntores para IED G60 e estes recebem informações para abrir e fechar os disjuntores.

- Lógica da máquina: Esta lógica está implementada para representar os 
controles exercidos pelos reguladores de tensão e velocidade existentes na turbina e no gerador síncrono.

Figura 4.9 - Tensões de fase e neutro para gerador operando em carga leve.

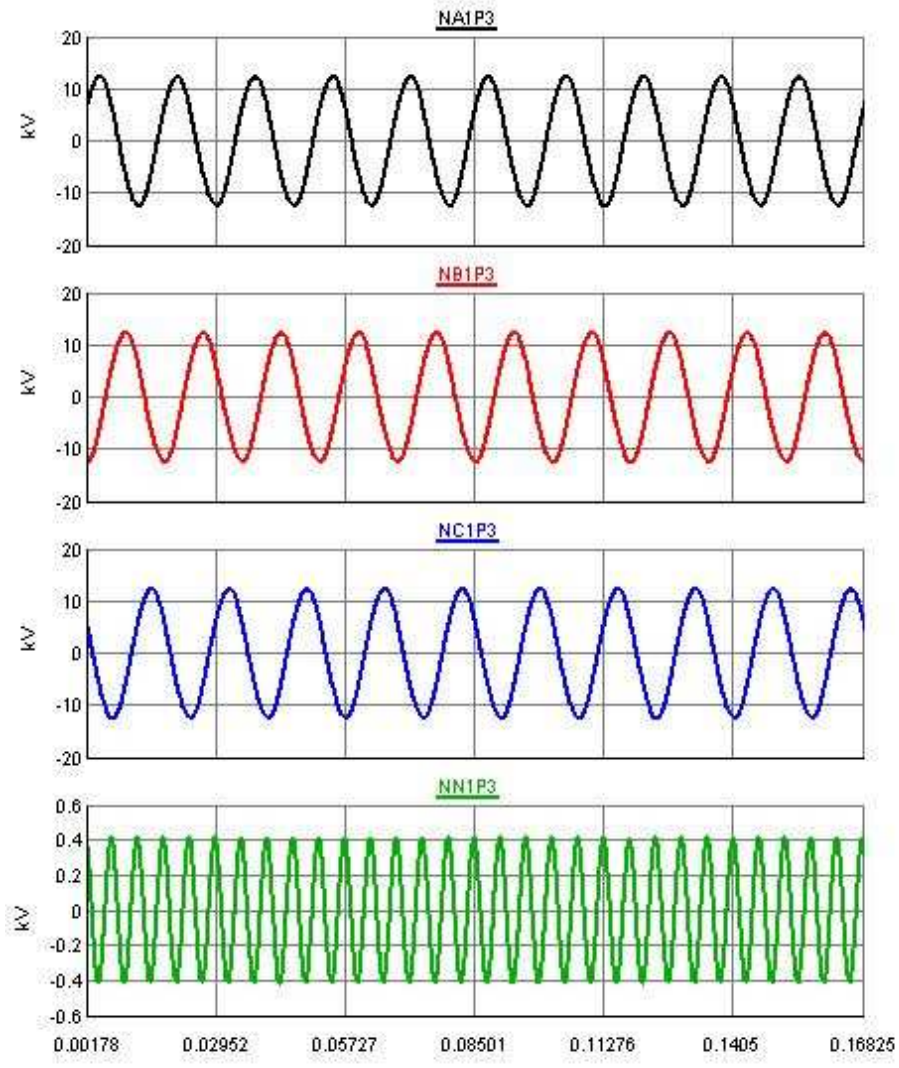

Fonte - Própio autor.

Figura 4.10 - Lógica de controle de máquina RTDS.

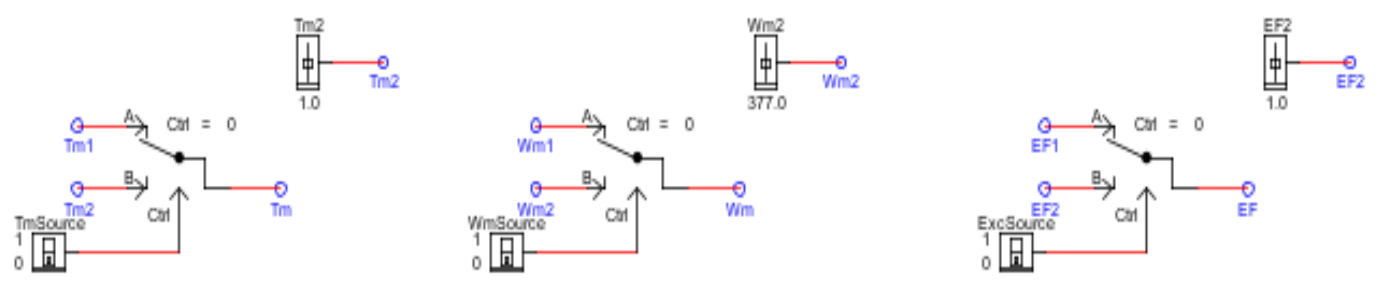

Fonte - Dehkordi A. B, Testing SEL-300 - 2010. 
Figura 4.11 - Lógica de faltas no RTDS.

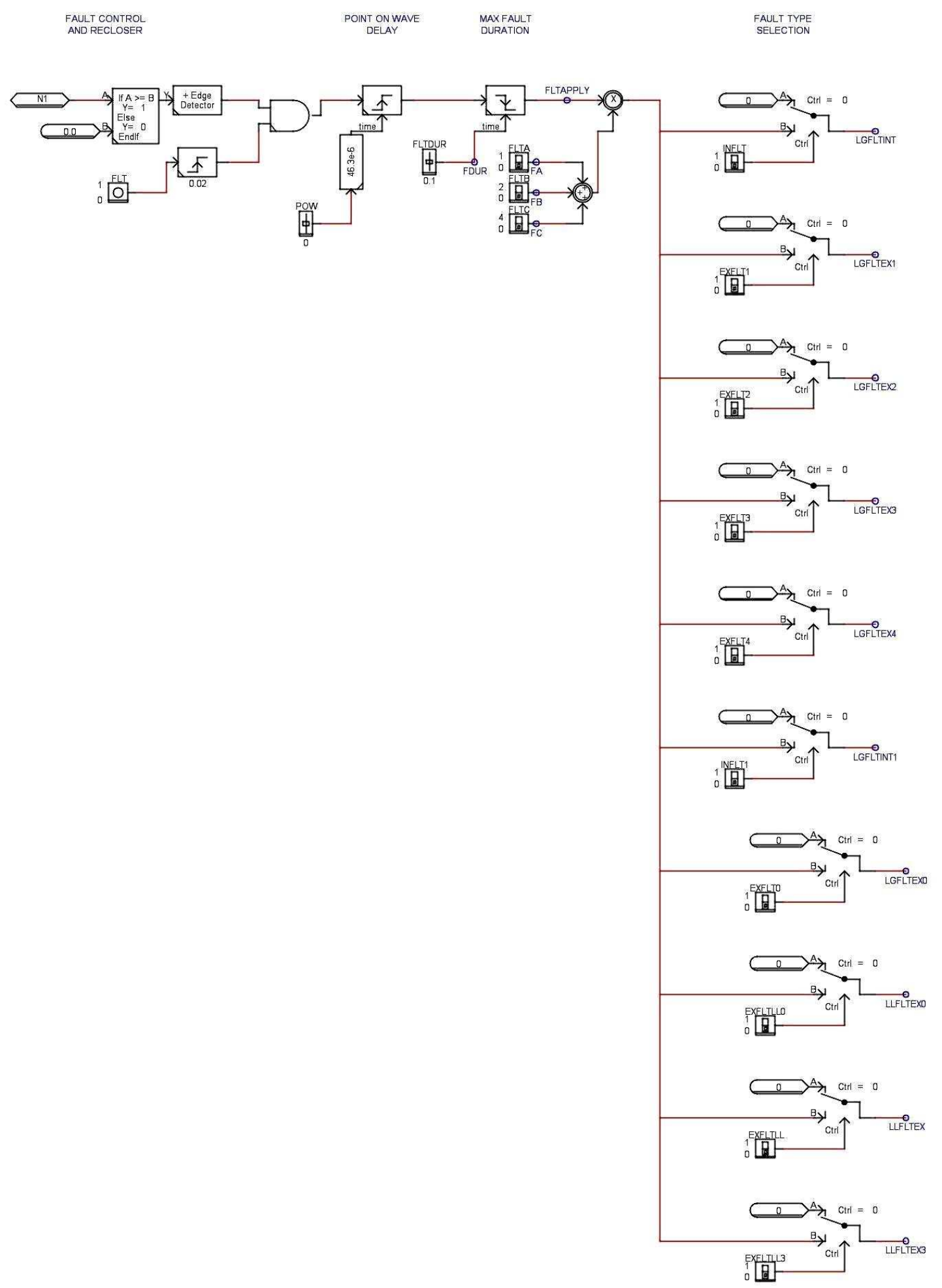

Fonte - Própio autor. 
Figura 4.12 - Lógica de falta externa no RTDS.
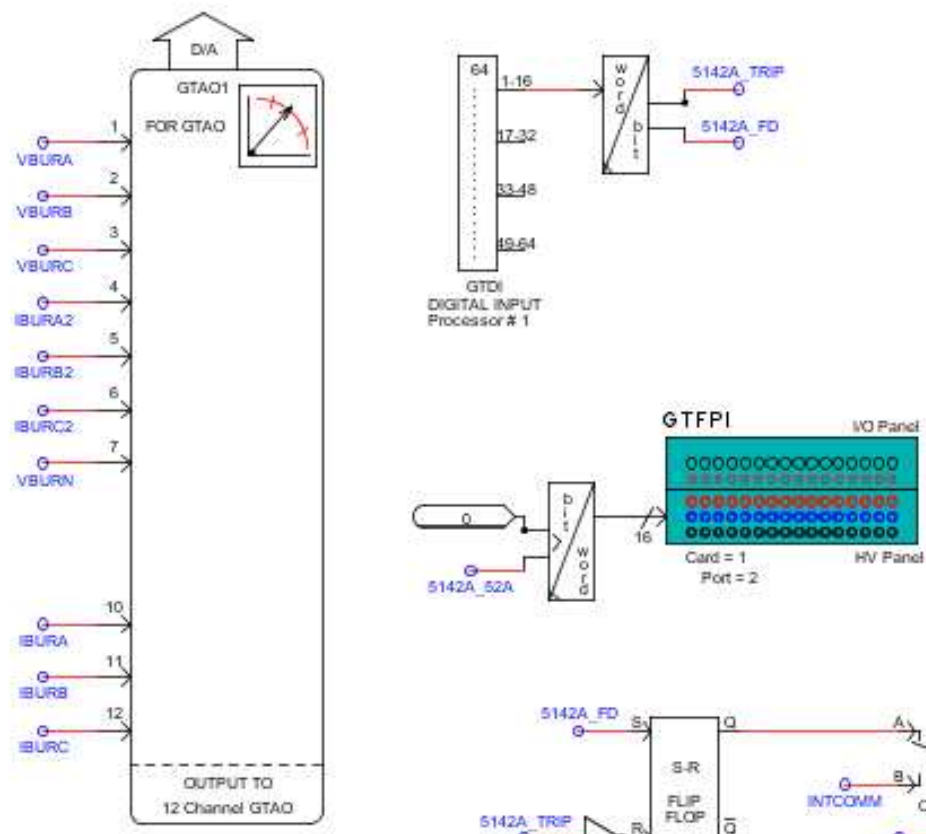

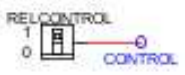

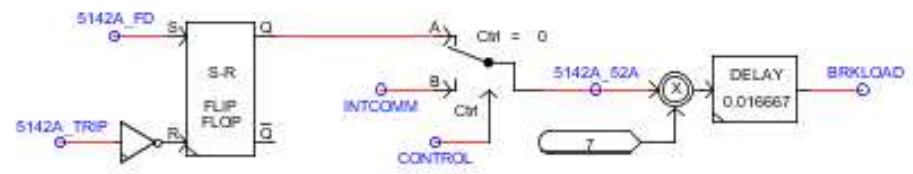

Fonte - Dehkordi A. B, Testing SEL-300 - 2010.

Figura 4.13 - Lógica do relé no RTDS.
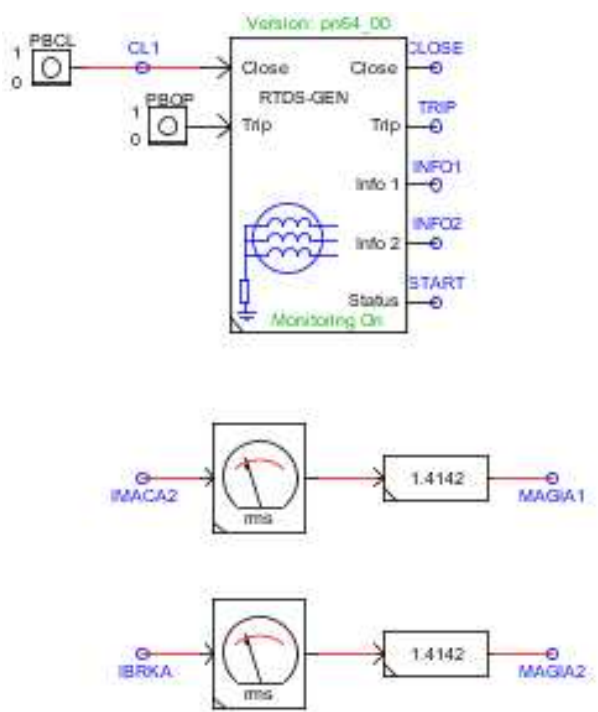

Fonte - Dehkordi A. B, Testing SEL-300 - 2010. 
Figura 4.14 - Lógica do disjuntor.

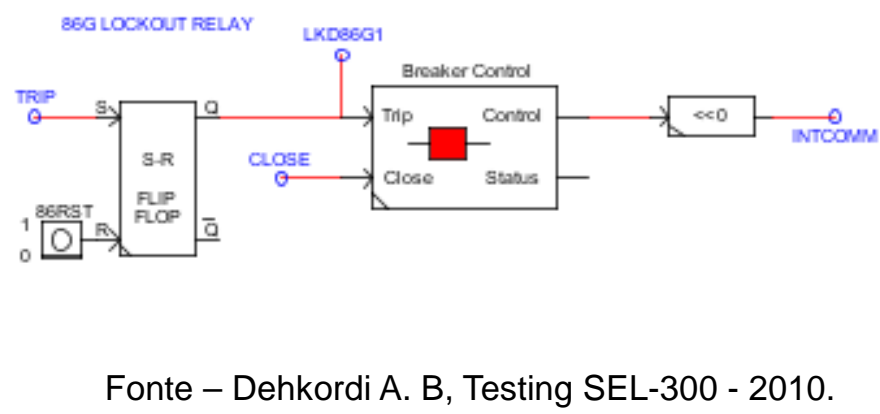

Os dados para os diversos componentes da rede mostrada na figura 4.3, que será utilizada no estudo de caso apresentados nos capítulos 5 e 6 deste trabalho, são detalhados nos itens a seguir.

\subsection{GERADOR SÍNCRONO}

A maior parte dos modelos de máquinas síncronas utiliza a transformada dq0 para simulação de transitórios eletromagnéticos, [49]. Essa transformada faz uso da natureza simétrica dos enrolamentos do estator. Entretanto, uma falta interna divide o enrolamento em duas seções e a simetria deixa de existir entre a fase em falta e os outros enrolamentos. Logo, a simplificação matemática obtida pela transformada dq0 deixa de existir. Então, para a simulação de faltas internas é conveniente lançar mão do modelo equivalente por fase que comporta as assimetrias entre os enrolamentos do gerador inseridas pelas faltas [50], [51], [52].

Para representar o gerador síncrono durante a simulação de faltas internas, usou-se o modelo de máquina síncrona disponível no RSCAD que possibilita simular faltas fase-terra, em uma das fases do gerador síncrono. Este modelo foi desenvolvido por [53] e as faltas podem ser aplicadas entre 5\% e $95 \%$ da fase A. Esse modelo não contempla outros tipos de falta. Os parâmetros elétricos do gerador síncrono utilizado no exemplo são mostrados na tabela 4.1 . 
Tabela 4.1 - Características elétricas do gerador síncrono.

\begin{tabular}{|c|c|c|c|c|c|}
\hline PARÂMETRO & VALOR & PARÂMETRO & VALOR & PARÂMETRO & VALOR \\
\hline $\mathrm{X}_{\mathrm{d}}$ & 1,86 p.u. & $\mathrm{X}_{\mathrm{q}}$ & 0,233 p.u. & $\mathrm{R}_{\mathrm{a}}$ & $0,002 \Omega$ \\
\hline $\mathrm{X}_{\mathrm{d}}$ & 0,282 p.u. & $\mathrm{T}_{\text {do }}$ & $5,8 \mathrm{~s}$ & $\mathrm{X}_{\mathrm{l}}$ & 0,206 p.u. \\
\hline $\mathrm{X}_{\mathrm{d}}$ & 0,233 p.u. & $\mathrm{T}_{\mathrm{d}}$ & $0,035 \mathrm{~s}$ & $\mathrm{H}$ & $3.6 \mathrm{MWs} / \mathrm{MVA}$ \\
\hline $\mathrm{X}_{\mathrm{q}}$ & 0,81 p.u. & $\mathrm{T}_{\mathrm{q}}$ & $0,054 \mathrm{~s}$ & & \\
\hline
\end{tabular}

\subsection{SISTEMA DE EXCITAÇÃO DO GERADOR SÍNCRONO}

A função básica do sistema de excitação é fornecer corrente direta para o enrolamento de campo da máquina síncrona. Além disso, este sistema faz funções de proteção e controle para o correto funcionamento do sistema potência.

Funções de controle incluem controle de tensão e de potência reativa e funções de proteção visando garantir que os limites de capacidade da máquina e outros equipamentos não sejam ultrapassados.

O sistema de excitação teve muitas formas ao longo dos anos. Nos modernos geradores são utilizados somente sistemas de excitação estática.

Para o sistema elétrico exemplo utilizado neste trabalho foi adotado o sistema de excitação estática. $O$ modelo de excitação e controle de tensão utilizado no gerador é o Type ST3A excitation system, [54]. A figura 4.15, o diagrama de blocos e tabela 4.2, mostram as constantes do modelo utilizado para o sistema.

Tabela 4.2 - Constantes do sistema de excitação e controle do gerador síncrono.

\begin{tabular}{|c|c|c|c|c|c|c|c|c|c|c|}
\hline$T_{R}$ & \multicolumn{2}{|c|}{$V_{\text {LMAX }}$} & \multicolumn{2}{|c|}{$V_{\text {LMN }}$} & $\mathrm{KJ}_{\mathrm{J}}$ & $T_{c}$ & $T_{B}$ & $\mathrm{~K}_{\mathrm{A}}$ & $\mathrm{T}_{\mathrm{A}}$ & $\mathrm{K}_{\mathrm{I}}$ \\
\hline $0,0 \mathrm{~s}$ & \multicolumn{2}{|c|}{0,1 p.u } & \multicolumn{2}{|c|}{$-0,1 \mathrm{p} . \mathrm{u}$} & 200 & $1,0 \mathrm{~s}$ & $6,493 \mathrm{~s}$ & 8.5 & $0,4 \mathrm{~s}$ & 0,0 \\
\hline$V_{\text {RMax }}$ & \multicolumn{2}{|c|}{$V_{\text {RMin }}$} & \multicolumn{2}{|c|}{$K_{P}$} & $K_{G}$ & EFDMax & $\mathrm{K}_{\mathrm{c}}$ & $X_{L}$ & $\mathrm{~V}_{\mathrm{G} \text { Max }}$ & $\Theta$ \\
\hline 2,50 p.u & 0,03 p.u & 1,00 & 4,80 & 6,9 p.u & 0,20 & 0,081 & 5,00 & & $0^{\circ}$ & \\
\hline
\end{tabular}


No diagrama da figura 4.15. $V_{c}$ é a tensão no terminal do gerador síncrono, $V_{s}$ é a entrada da ação do estabilizador do sistema de potência ou Power System Stabilizer (PSS), $V_{\text {ref }}$ é a tensão de referência que pode ser utilizada para controlar a potência reativa fornecida/consumida pelo gerador síncrono, $\mathrm{E}_{\mathrm{FD}}$ tensão campo e $\mathrm{I}_{\mathrm{FD}}$ é a corrente de campo do gerador síncrono.

Figura 4.15- Diagrama de blocos do sistema de excitação e controle de tensão.

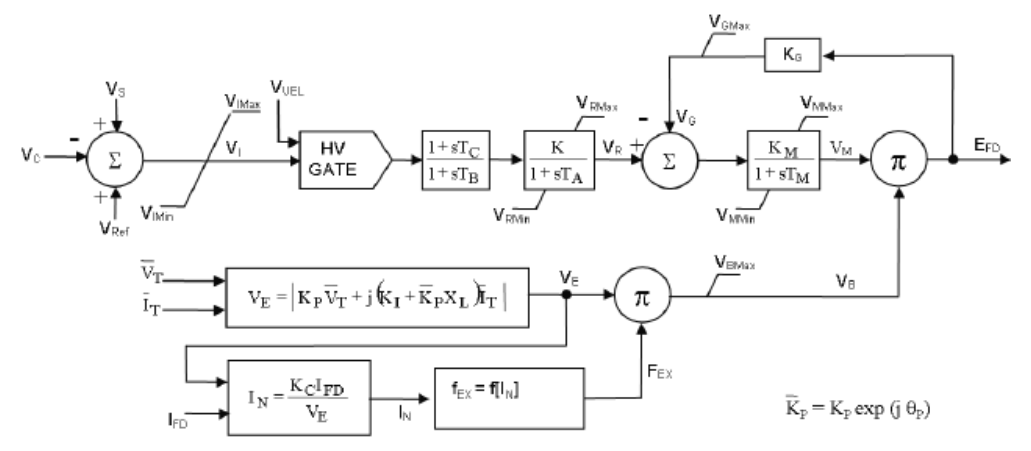

Fonte - IEEE STD 421.5 Recommended Practice for Excitatiion System Models for Power System Stability - 2005.

\subsection{TURBINA E REGULADOR DE VELOCIDADE}

Os geradores síncronos deste sistema são de dois polos, optou-se por fontes motrizes que tenha um regulador de velocidade PI para controlar a velocidade. Um laço permanente de inclinação é incluído como parte do regular de velocidade, de modo que a carga do sistema será compartilhada através de vários geradores. O modelo da turbina hidráulica é mostrado na Figura 4.16, [44]. A Tabela 4.3 mostra as constantes utilizadas.

Tabela 4.3 - Constantes dos reguladores e turbina a vapor do sistema RTDS.

\begin{tabular}{|c|c|c|c|c|c|}
\hline PD & TD & Tr & Tf & Tg & VELM \\
\hline 0,05 p.u & 0,5 p.u & $6,0 \mathrm{~s}$ & $0,05 \mathrm{~s}$ & $0,5 \mathrm{~s}$ & $0,167 \mathrm{~s}$ \\
\hline Gmax & Gmin & Tw & At & Dt & Qnl \\
\hline 1 & 0,08 & $2,0 \mathrm{~s}$ & 1,2 & 0,2 & 0,08 \\
\hline
\end{tabular}


Figura 4.16 - Diagrama de blocos para turbina e regulador de velocidade.
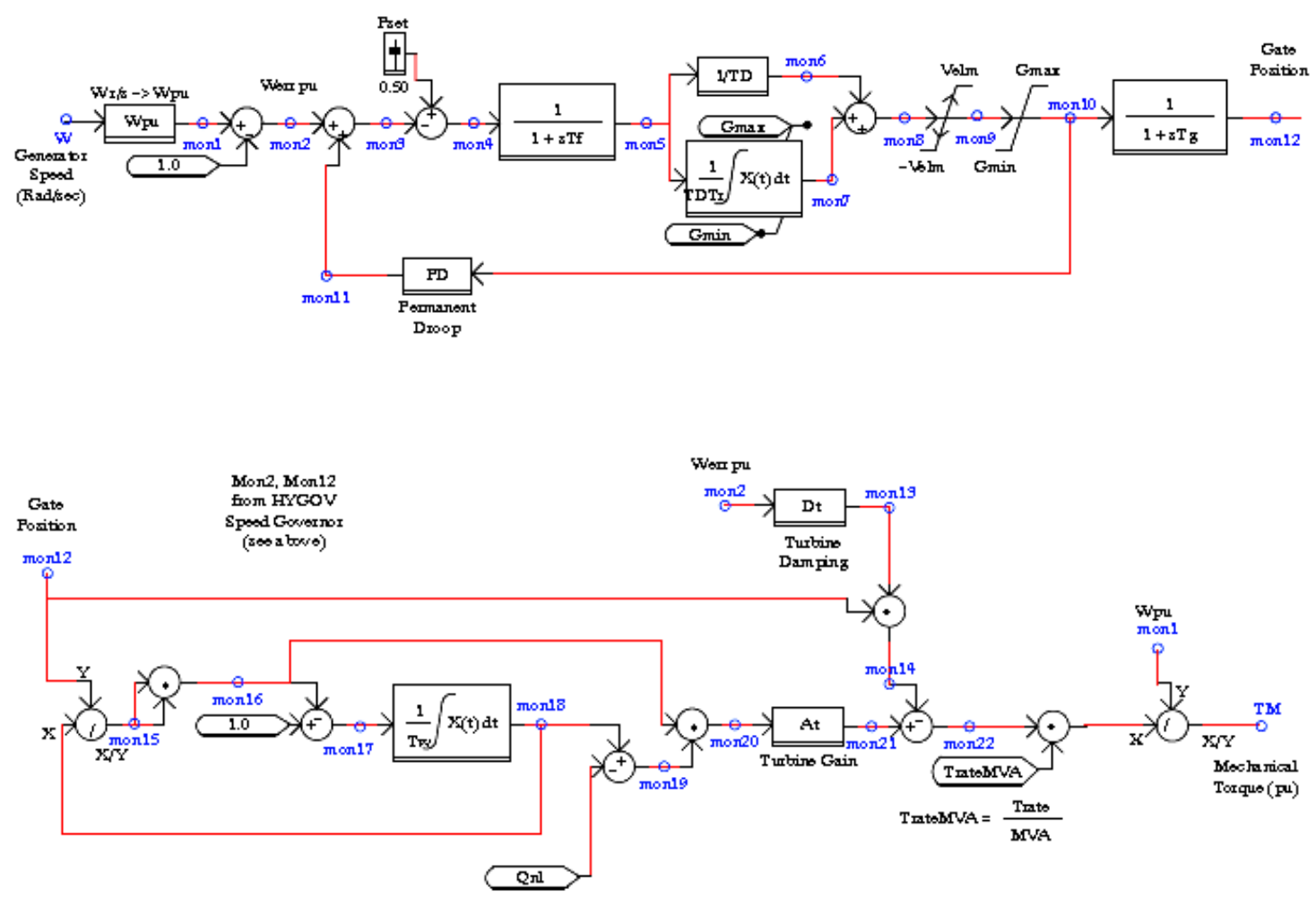

Fonte - RTDS Tecnologies - 2006.

\subsection{LINHAS DE TRANSMISSÃO}

O sistema de transmissão é composto por duas linhas de transmissão em paralelo, sendo a primeira uma linha de circuito simples subdividida em dois trechos TL21 e TL22. A segunda linha foi considerada como sendo de circuito duplo (TL6). Essas linhas estão interconectadas na mesma barra. Como pode ser observado na figura 4.3, as duas linhas trabalham com tensão de $345 \mathrm{kV}$ e possuem comprimento de $250 \mathrm{Km} \mathrm{A}$ tabela 4.4 ilustra as características das linhas. 
Tabela 4.4 - Dados construtivos das linhas de transmissão no RTDS.

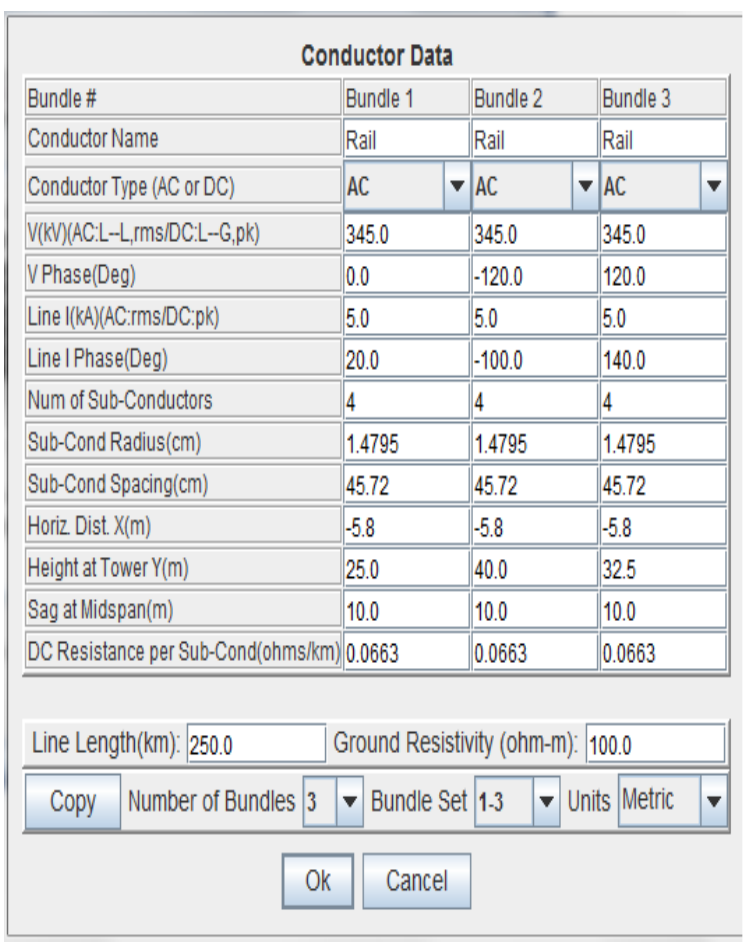

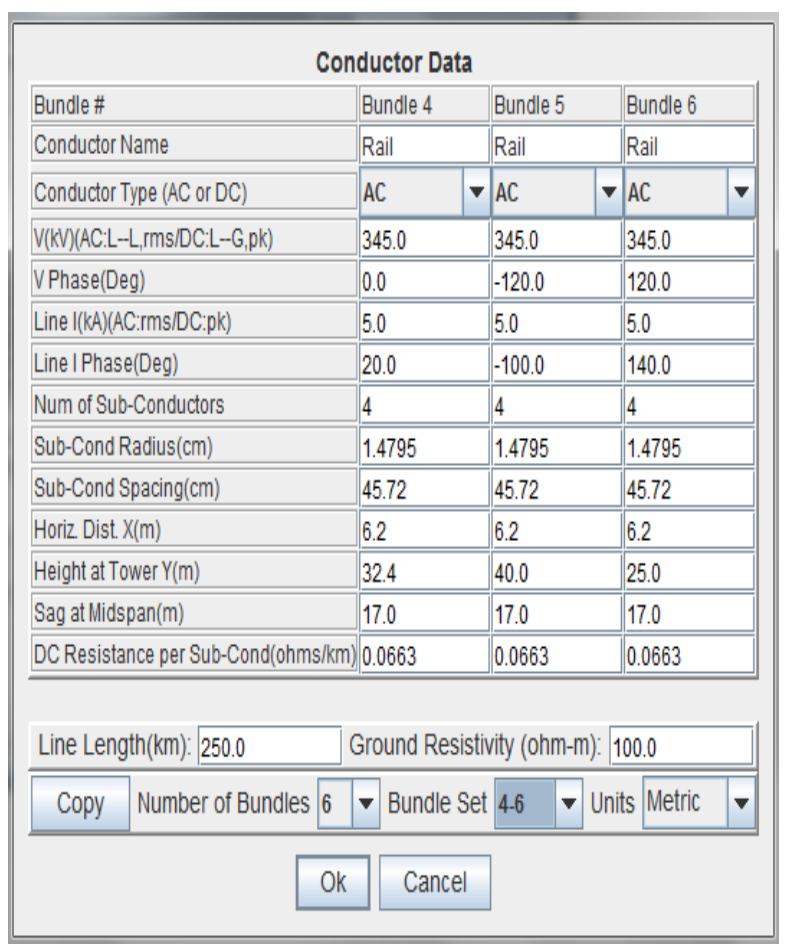

\begin{tabular}{|c|c|c|c|c|c|c|c|c|c|}
\hline \multicolumn{10}{|c|}{ Ground Wire Data } \\
\hline \multicolumn{2}{|c|}{ Ground Wire\# } & Conductor 1 & \multicolumn{2}{|c|}{ Conductor 2} & Conductor 3 & \multicolumn{2}{|c|}{ Conductor 4} & \multicolumn{2}{|c|}{ Conductor 5} \\
\hline \multicolumn{2}{|c|}{ Conductor Name } & EHS $3 / 80$ & \multicolumn{2}{|c|}{ PGW AFL } & 7/16 Steel & \multicolumn{2}{|c|}{ 7/16 Steel } & \multicolumn{2}{|l|}{$7 / 116$ Steel } \\
\hline \multicolumn{2}{|c|}{ Conductor Radius(cm) } & 0.47625 & \multicolumn{2}{|l|}{0.561} & 0.55245 & \multicolumn{2}{|c|}{0.55245} & \multicolumn{2}{|l|}{0.55245} \\
\hline \multicolumn{2}{|c|}{ Horiz Dist. X(m) } & -5.8 & \multicolumn{2}{|l|}{5.8} & -5.0 & \multicolumn{2}{|c|}{-5.0} & \multicolumn{2}{|l|}{-5.0} \\
\hline \multicolumn{2}{|c|}{ Height at Tower Y(m) } & 47.5 & \multicolumn{2}{|l|}{47.5} & 35.0 & \multicolumn{2}{|c|}{35.0} & \multicolumn{2}{|l|}{35.0} \\
\hline \multicolumn{2}{|c|}{ Sag at Midspan(m) } & 11.49 & 11.49 & & 10.0 & \multicolumn{2}{|c|}{10.0} & \multicolumn{2}{|l|}{10.0} \\
\hline \multicolumn{3}{|c|}{ DC Resistance(ohms/km) 2.175} & \multicolumn{2}{|l|}{0.4818} & 2.8645 & \multicolumn{2}{|c|}{2.8645} & \multicolumn{2}{|l|}{2.8645} \\
\hline \multirow[t]{2}{*}{ Copy } & \multicolumn{2}{|c|}{ Number of Ground Wires: } & 4 & \multicolumn{3}{|c|}{ Conductor Set: 1.5} & $\nabla$ Units: & Metric & $\nabla$ \\
\hline & & & OK & & ancel & & & & \\
\hline
\end{tabular}

O sistema simulado está implementado para simular faltas internas fase terra, sendo que as faltas externas podem ser do tipo fase-terra, dupla fase, dupla fase-terra e trifásicas. As faltas internas fase-terra podem ser simuladas entre $5 \%$ e $95 \%$ do enrolamento da fase $A$ do gerador. As faltas externas podem ser aplicadas em qualquer ponto da linha ou nas barras conectadas ao gerador, como mostrado na figura 4.17. Os ajustes dos inúmeros parâmetros da simulação podem ser realizados através das chaves e sliders existentes na interface de controle mostrada na figura 4.18. 
Figura 4.17 - Rede simulada no RTDS.

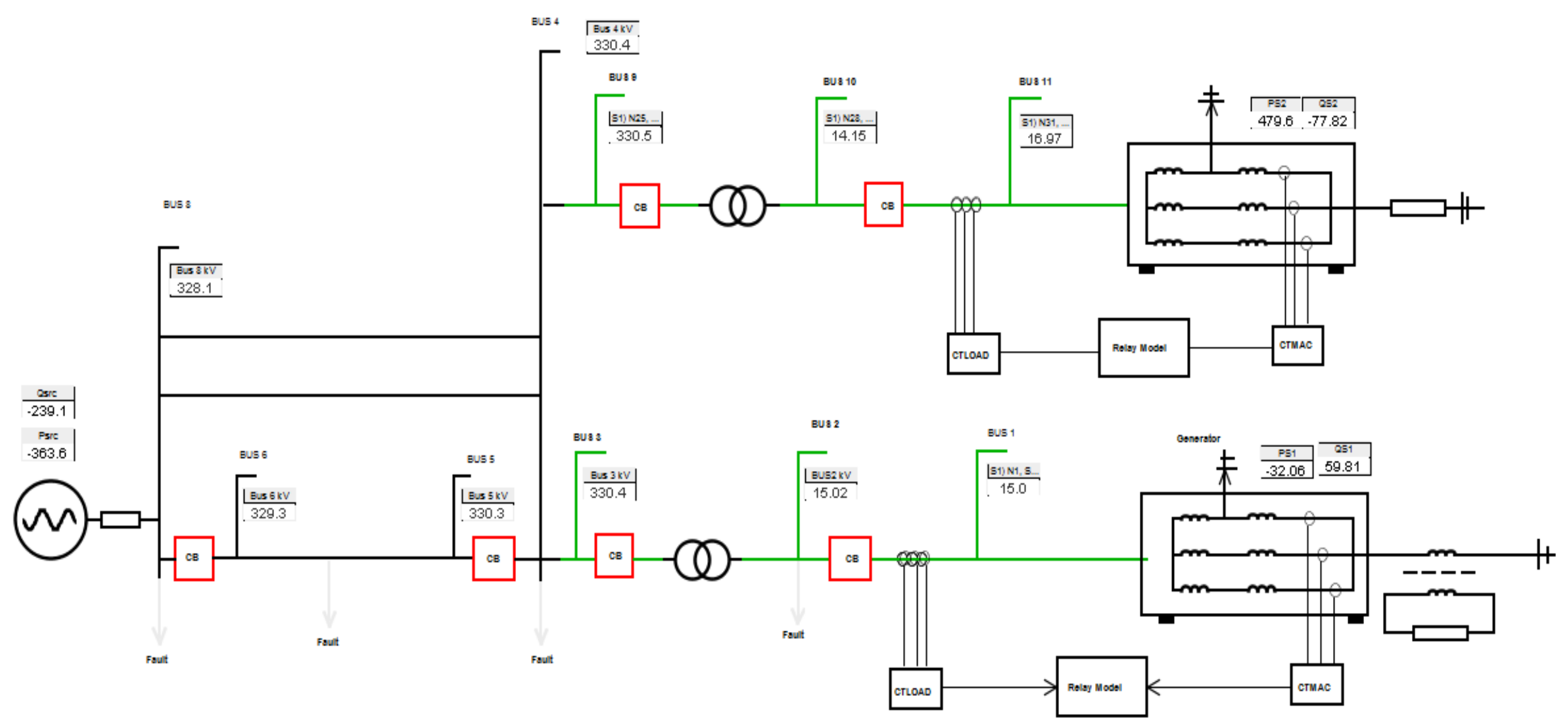

Fonte - Próprio autor. 
Figura 4.18 - Controle do sistema simulado.
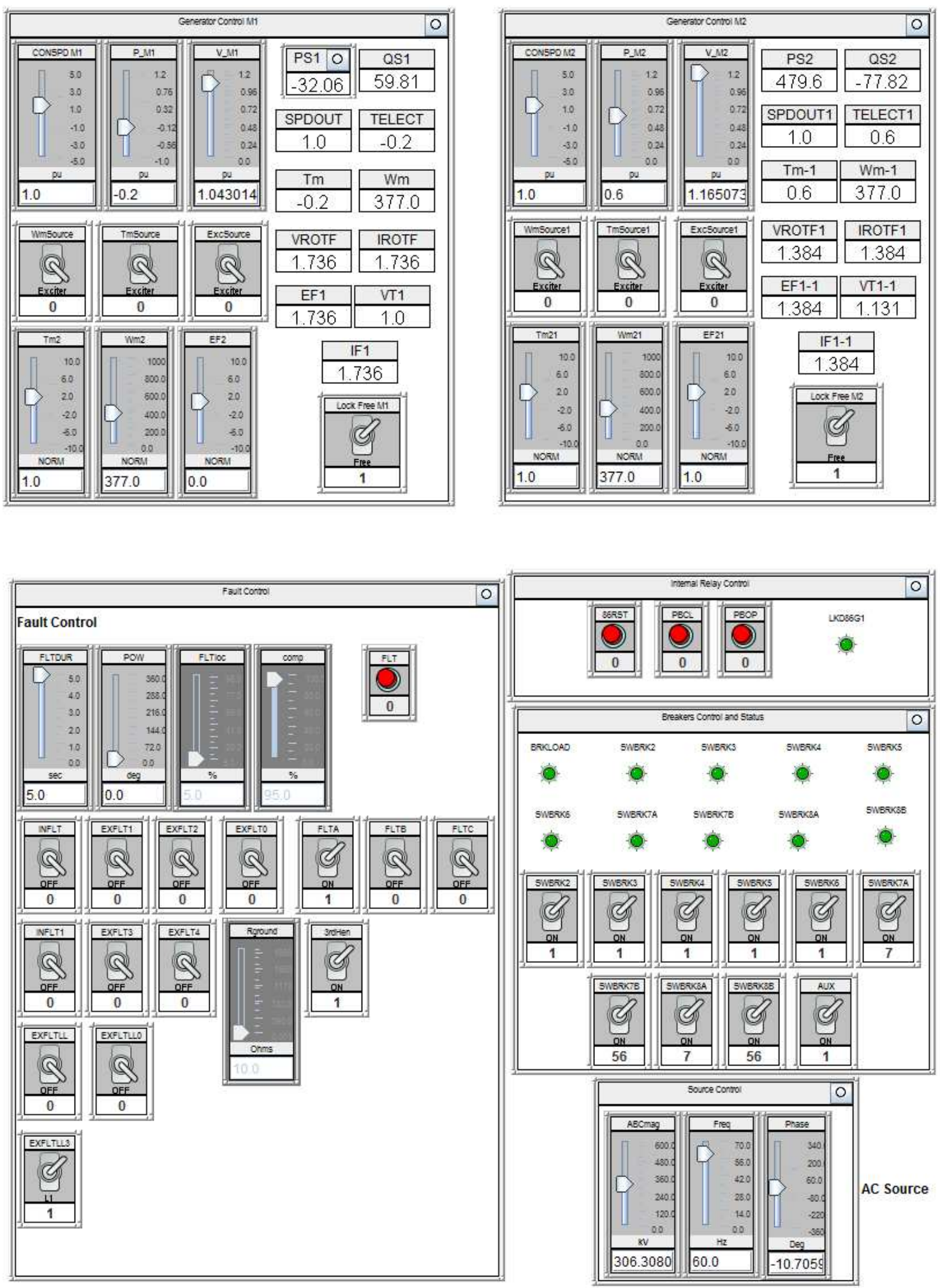

Fonte - Próprio autor. 


\section{CAPÍTULO 5}

\section{ESTUDO DE CASO: AJUSTE E ENSAIO DE SISTEMA DE PROTEÇÃO DE GERADORES}

Como já comentado, em um sistema elétrico de potência é de fundamental importância a rápida e precisa detecção de anomalias em componentes primários da rede, para que estes possam ser rapidamente isolados do sistema elétrico.

Um sistema de proteção mal ajustado pode não atuar em situações de defeito dentro de sua zona de proteção ou atuar indevidamente para faltas externas à sua zona de proteção.

Isso leva ao comprometimento da segurança e da estabilidade do sistema elétrico de potência.

Sabe-se que situações faltosas prolongadas podem danificar os componentes do sistema elétrico de potência o que acarreta em custos de manutenção e acréscimo do tempo de restabelecimento.

Portanto, quanto maior a eficiência na detecção e isolamento das situações anormais, maior confiabilidade, segurança e rentabilidade terá a operação do sistema elétrico de potência.

Neste capítulo, para ilustrar a metodogia discutida ao longo deste trabalho, é feito um estudo de caso utilizando uma rede exemplo. Para tanto, é feito o projeto do ajuste das principais funções de proteção do gerador e, em seguida, realizado os ensaios com a utilização da plataforma de simulação em tempo real (simulador RTDS) visando verificar a validade desses ajustes para diversas situações de faltas internas e externas ao gerador.

\subsection{AJUSTE DAS PRINCIPAIS FUNÇÕES DE PROTEÇÃO DO GERADOR}

Para ajuste da função de proteção do enrolamento do estator foram considerados os seguintes parâmetros para o sistema mostrado na figura 5.1. 
Dados dos geradores.

\begin{tabular}{|c|c|c|c|c|c|c|c|}
\hline & SN (MVA) & VN (kV) & Xd (p.u) & X'd (p.u) & X"d (p.u) & X2 & X0 \\
\hline G1 & 160 & 15 & 1,86 & 0,282 & 0,233 & 0,233 & 0,146 \\
\hline G2 & 800 & 15 & 1,86 & 0,282 & 0,233 & 0,233 & 0,146 \\
\hline
\end{tabular}

I2T capabilidade $=10$

$I_{2} T$ capabilidade $=10$

$I_{2}$ capabilidade $=8 \%$

Potência de motorização = 16MW (10\%)

Dados do transformador elevador.

\begin{tabular}{|c|c|c|c|}
\hline & SN (MVA) & V1/V2 (kV) & Xcc (p.u) \\
\hline T1 & 160 & $15 / 345$ & 0,12 \\
\hline T2 & 800 & $15 / 345$ & 0,12 \\
\hline
\end{tabular}

Linhas de transmissão.

\begin{tabular}{|l|c|c|c|c|c|}
\hline & $\mathrm{VN}(\mathrm{kV})$ & $\mathrm{L}(\mathrm{Km})$ & $\mathrm{Z}_{1}(\Omega / \mathrm{km})$ & $\mathrm{Z} 0(\Omega / \mathrm{Km})$ & $\mathrm{ZOM}(\Omega / \mathrm{Km})$ \\
\hline L1 (circuito simples) & 345 & 250 & $0,02+\mathrm{j} 0,26$ & $0,26+\mathrm{j} 1,13$ & \\
\hline L2 (circuito duplo) & 345 & 250 & $0,017+\mathrm{j} 0,031$ & $0,25+\mathrm{j} 1,02$ & $0,24+\mathrm{j} 0,70$ \\
\hline
\end{tabular}

Equivalente thevenin da barra de $345 \mathrm{Kv}$.

$$
\begin{aligned}
& Z_{1}=4,34+24,62 \Omega \\
& Z_{0}=3,34+24,62 \Omega
\end{aligned}
$$

Capacitâncias parasitas nos terminais do gerador.

\begin{tabular}{|l|c|}
\hline \multicolumn{1}{|c|}{ Componente } & $\mathrm{C}(\mu \mathrm{F})$ \\
\hline Estator gerador & 0,24 \\
\hline Para-raios & 0,25 \\
\hline Barramento 15Kv & 0,005 \\
\hline Enrolamento de 15kV trafo & 0,03 \\
\hline TP & 0,005 \\
\hline Total & 0,53 \\
\hline
\end{tabular}

Apartir desses dados podemos construir os diagramas sequenciais em p.u como mostrado na figura 5.1 . 
Figura 5.1 - Diagramas sequênciais para a rede exemplo.

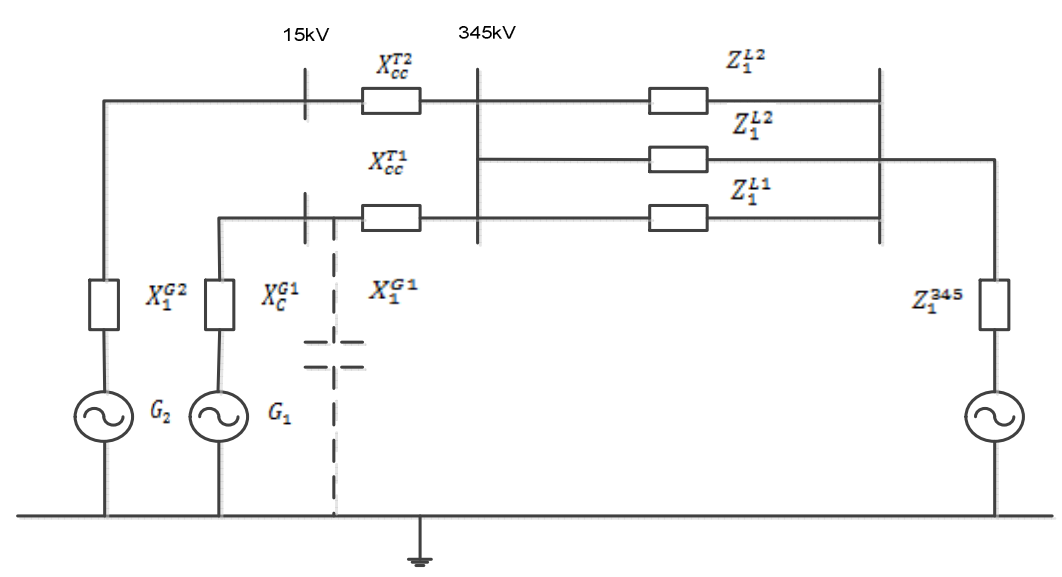

a) Diagrama de sequência positiva

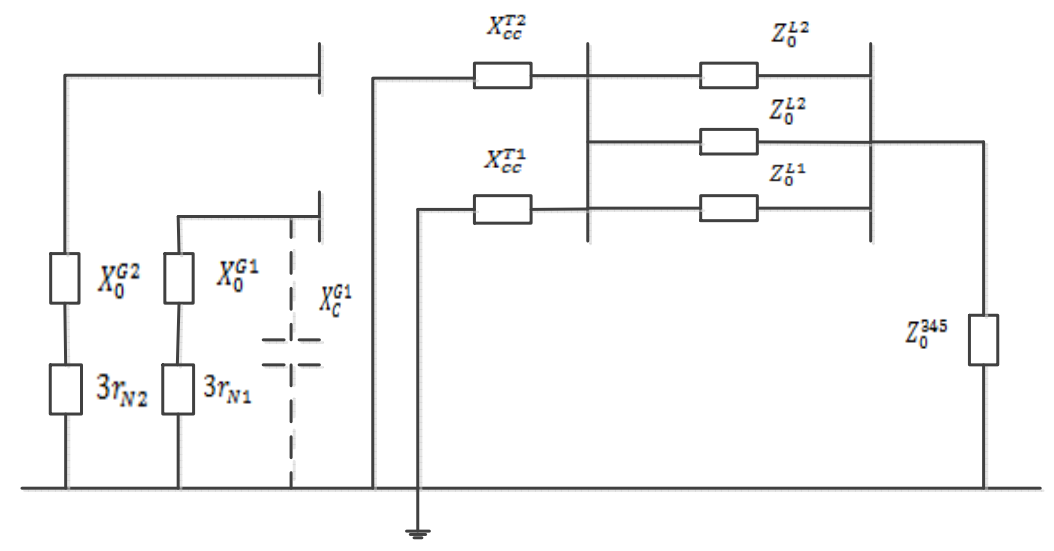

b) Diagrama de sequência zero

Fonte - Própio autor.

Na base 160 MVA, as impedâncias mostradas na figura 5.1, assumem os seguintes valores:

\section{GERADOR}

$X_{1}^{G 1}=X^{\prime \prime}{ }_{d}=\mathrm{j} 0,233$ p.u.

$X_{1}^{G 2}=X^{\prime \prime}{ }_{d} * \frac{160}{800}=\mathrm{j} 0,0466$ p.u.

$X_{0}^{G 1}=j X_{0}=j 0,164$ p.u.

$X_{0}^{G 2}=0,164 * \frac{160}{800}=\mathrm{j} 0,0328$ p.u.

$X_{C}^{G 1}=-J \frac{1}{2 * \pi * 60 * 0.53 * 10^{-6}} * \frac{160}{15^{2}}=-j 3559 p . u$ 


\section{TRANSFORMADOR}

$X_{C C}^{T 1}=J 0,12 p \cdot u$

$X_{C C}^{T 2}=J 0,12 * \frac{160}{800}=j 0.024 p \cdot u$

LINHAS DE TRANSMISSÃO (TL12=TL22=L1), (TL6=L2)

$Z_{1}^{L 1}=(0,02+j 0,26) * 250 * \frac{160}{345^{2}} \cong j 0,087 p . u$

$Z_{1}^{L 2}=(0,017+j 0,31) * 250 * \frac{160}{345^{2}} \cong j 0,104 p \cdot u$

$Z_{0}^{L 1}=(0,26+j 1.13) * 250 * \frac{160}{345^{2}} \cong j 0,379 p \cdot u$

$Z_{0}^{L 2}=(0,25+j 1,02) * 250 * \frac{160}{345^{2}} \cong j 0,342 p \cdot u$

$Z_{0}^{M}=(0,24+j 0,7) * 250 * \frac{160}{345^{2}} \cong j 0,235 p \cdot u$

\section{EQUIVALENTE DE $345 \mathrm{KV}$}

$Z_{1}^{345}=Z_{0}^{345}=(4,34+j 24,62) * 250 * \frac{160}{345^{2}} \cong j 0,033 p \cdot u$

Para dimensionamento do resistor de aterramento será adotado o critério discutido no capítulo 2 para aterramento de geradores através de alta impedância. Para tanto, pode-se impor.

$3 r_{N 1}=\left|X_{0}^{G 1}\right|=3559 p \cdot u$

O valor do resistor no gerador G1, em Ohms, será

$R_{N}^{G 1}=r_{N 1} \frac{15^{2}}{160}=\frac{3559}{3} * \frac{15^{2}}{160}=1668 \Omega$

Como discutido no capitulo 2, por razoes práticas é mais conveniente instalar esse resistor no secundário de um transformador de distribuição, como mostrado na figura 5.2. 
Figura 5.2 - Forma de aterramento do gerador G1.

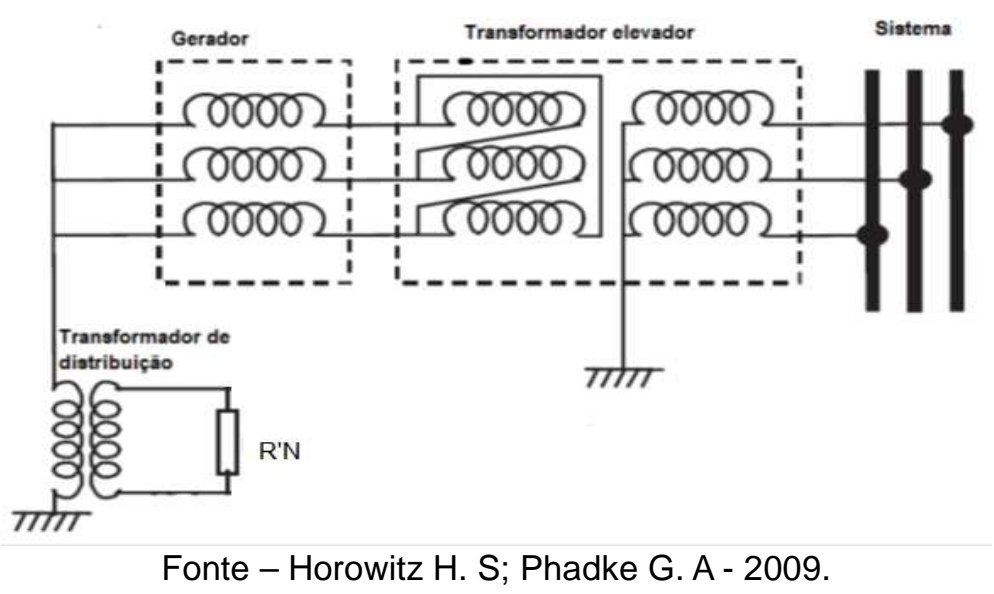

Utilizando-se um frafo de relação $15 \mathrm{kV} / 120 \mathrm{~V}$, o valor da resistência de aterramento $R_{N}^{\prime}$, a ser instalado no enrolamento de baixa tensão desse transformador, é dado por:

$R_{N}^{\prime}=1665 *\left(\frac{120}{1500}\right)^{2}=0,1 \Omega$

Considerando o sistema exemplo em vazio e com tensão em todas as barras igual a $1.0 \angle 0$ p.u, os diagramas da figura 5.1 podem ser reduzidos, mantendo-se o gerador G1 em evidência, como mostrado na figura 5.3.

Figura 5.3 - Diagramas sequênciais reduzidos.

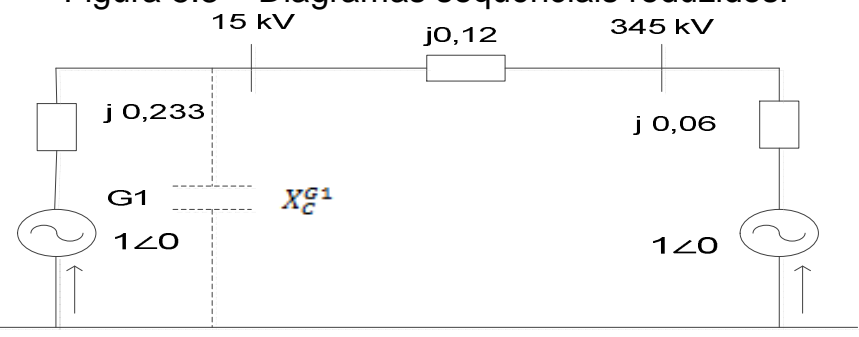

a) Diagrama de sequência positiva reduzido.

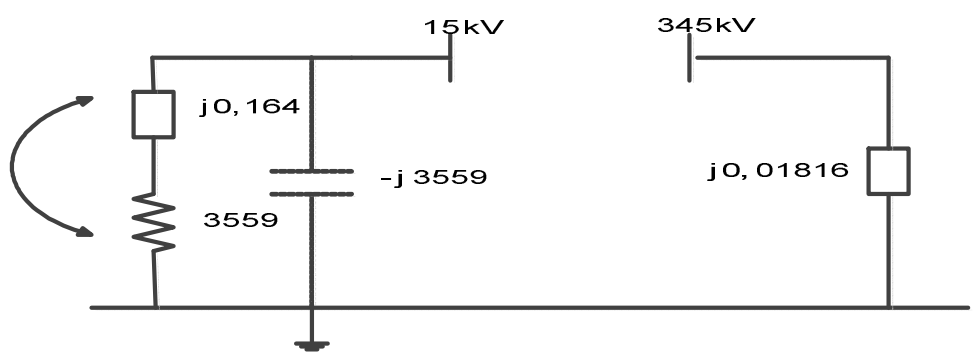

b) Diagrama de sequência zero reduzido.

Fonte - Própio autor. 


\subsubsection{DEFINIÇÃO DO TRANSFORMADOR DE CORRENTE (TC)}

A corrente de carga máxima no gerador é:

$$
I_{L}=\frac{160000}{\sqrt{3} 15}=6155 \mathrm{~A}
$$

Com o uso dos diagramas sequênciais determina-se a distribuição da corrente máxima para curto trifásico nos terminais do gerador, dentro da zona de proteção primária da função $87 \mathrm{G}$, como mostrado na figura 5.4.

Figura 5.4 - Correntes para curto circuito trifásico interno.

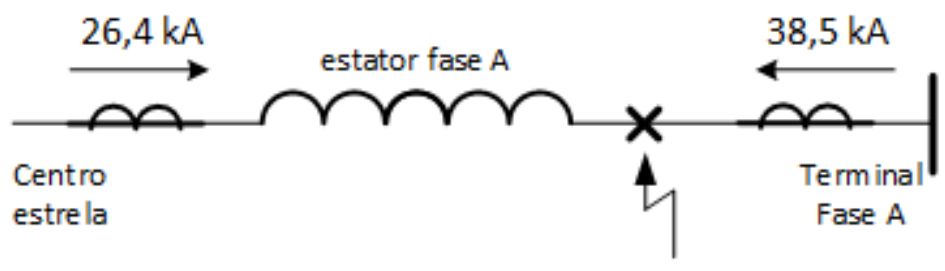

$$
\text { Fonte - Própio autor }
$$

Obviamente, devido à alta impedância de aterramento do gerador, uma falta fase-terra, também nos terminais do gerador, não terá nenhuma influência no dimensionamento dos TCs. A titulo de ilustração, a figura 5.5 mostra a pequena magnitude das correntes para esse tipo de falta: 3,28 A no lado do neutro; $1,94 \mathrm{~A}$ no lado terminal e uma corrente de falta fase-terra total de 5,22 $A$, a qual retorna pelo neutro do gerador. Vale observar que essa será a máxima corrente de falta fase-terra, à medida que o ponto de falta se deslocar em direção ao centro estrela a magnitude das correntes apresentadas serão ainda menores.

Figura 5.5 - Correntes para falta fase-terra interna nos terminais do gerador.

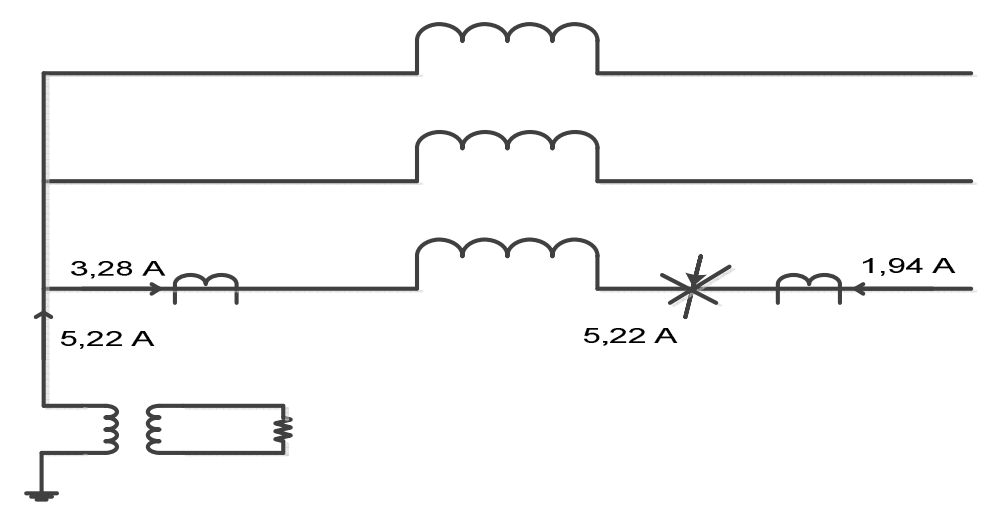

Fonte - Própio autor. 
Considerando-se um burden no secundário do TC de $0,2 \Omega$ e as correntes máximas de carga (6158 A) e curto trifásico máximo (38,5 kA), verifica-se que um TC com relação de 8000/1, classe 10B400, pode ser utilizado com segurança. Nessas condições, não haverá risco de saturação do TC nem em situações de máximo off-set das correntes de curto.

\subsubsection{DEFINIÇÃO DO TRANSFORMADOR DE POTENCIAL (TP)}

Para o TP instalado nos terminais do gerador será utilizado um TP de 15000/120 V, isto é, com relação de transformação 125:1. Já as tensões do neutro serão medidas no secundário do transformador de aterramento, o qual também possui relação de 125:1 (15000/120 V).

\subsubsection{AJUSTE DAS FUnÇÕES DE PROTEÇÃo PARA FALTAS ENTRE FASE NO ESTATOR}

Como discutido no capítulo, a função de proteção principal para detecção de faltas no estator é a função $87 G$. No IED G60, utilizado nos ensaios realizados em laboratório, essa função possui a característica diferencial percentual constituída por dois trechos com inclinações distintas, como mostrado na figura 5.6.

Figura 5.6 - Característica diferencial percentual ajustada para a função 87G.

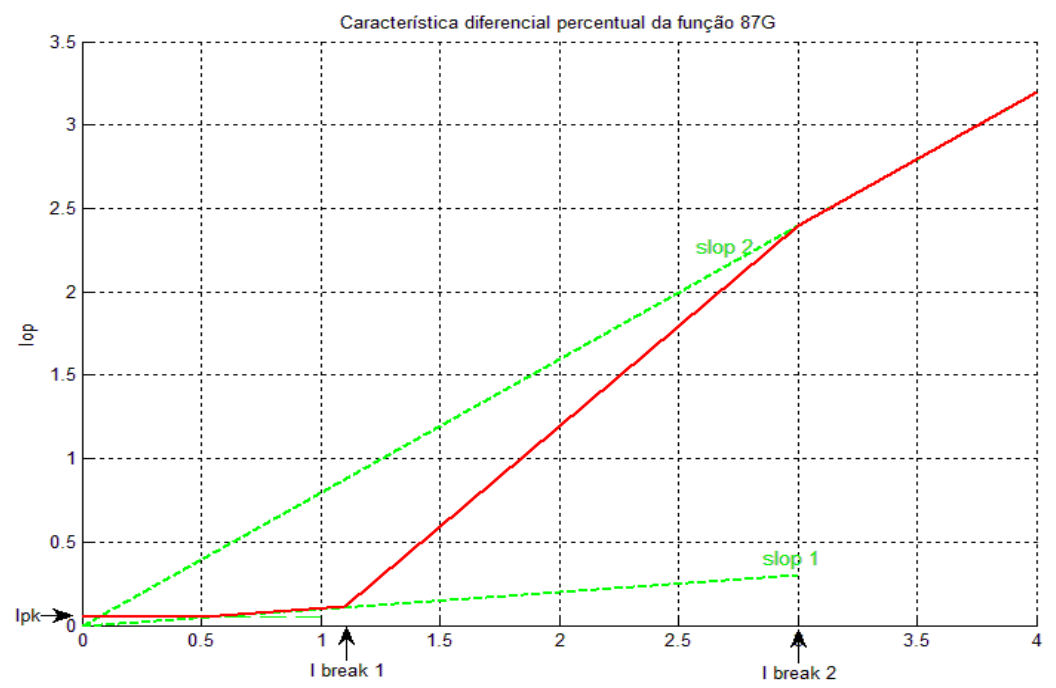

Fonte - Própio autor. 
Para correntes de restrição na faixa $0<\operatorname{Irest}<\mathrm{Ibr} 1$, para que ocorra atuação da função $87 \mathrm{G}$, as duas condições a seguir devem ser satisfeitas:

$$
\begin{aligned}
& \text { llop } \mid>\text { lpk } \\
& \text { |lop| > slop1*||rest| }
\end{aligned}
$$

Já para correntes de restrição acima de IBr2, a função irá ativar se |lop|>slop2*||rest|. Entre IBr1 e IBr2 existe uma faixa de transição.

Considerando que a corrente nominal do gerador, no secundário do TC adotado, é de $0,77 \mathrm{~A}$, adotou-se os seguintes valores para os parâmetros ajustados da função $87 \mathrm{G}$ :

$$
\begin{aligned}
& \mathrm{I}_{\mathrm{pk}}=0,05 \mathrm{~A} \\
& \mathrm{I}_{\mathrm{Br} 1}=I_{\text {rest } 1}=1,1 \mathrm{~A} \\
& \mathrm{I}_{\mathrm{Br} 2}=I_{\text {rest } 2}=3,0 \mathrm{~A} \\
& \text { Slop1 }=0,1 \\
& \text { Slop2 }=0,8
\end{aligned}
$$

Com isso garante-se uma sensibilidade elevada para correntes nominais de operação, situação em que os erros dos TCs são baixos, e uma menor sensibilidade durante elevadas correntes de falta, quando podem ocorrer erros de transformação significativos nos TCs.

A partir desses ajustes, é interessante analisar a resposta da função $87 \mathrm{G}$ para as duas faltas calculadas no item anterior. Para a falta trifásica nos terminais do gerador, tem-se os seguintes parâmetros:

$$
\begin{aligned}
& I_{\text {op }}=(26400+38500) / 8000=8,11 A_{\text {sec }} \\
& I_{\text {rest }}=(26400+38500) / 16000=4,05 A_{\text {sec }}
\end{aligned}
$$

A localização desse ponto na característica diferencial percentual é mostrada na figura 5.7. Pode-se observar que a falta é detectada com total segurança. 
Figura 5.7 - Resposta da função $87 G$ para curto-circuito trifásico e fase-terra nos terminais do gerador.

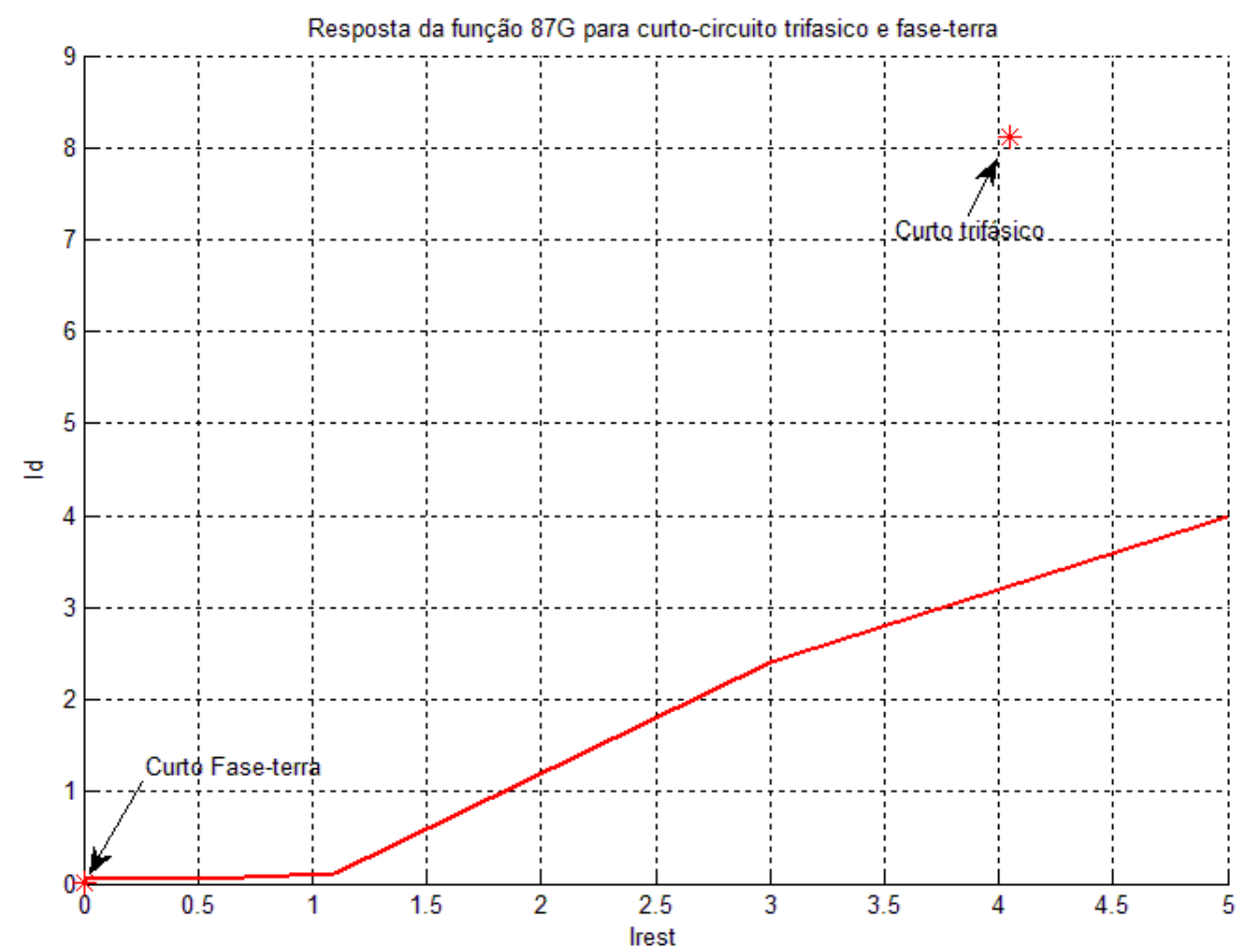

Fonte - Própio autor.

Já para a falta fase-terra nos terminais do gerador, devido à elevada resistência de aterramento utilizada, o ponto de medição cai praticamente na origem da característica da função $87 G$ e não se pode garantir sua atuação com segurança. A corrente de operação e restrição, neste caso, são dadas por:

$$
\begin{aligned}
& I_{\text {op }}=(3,28+1,94) / 8000=6,52^{*} 10^{-4} \mathrm{~A} \\
& \mathrm{I}_{\text {rest }}=(3,28+1,94) / 16000=3,26^{*} 10^{-4} \mathrm{~A}
\end{aligned}
$$

Isso mostra que a função $87 \mathrm{G}$ é ineficaz para detectar faltas fase-terra em geradores aterrados através de alta impedância. Esse tipo de falta será detectada pelas funções $59 \mathrm{~N}$ e $100 \%$ de proteção para faltas fase-terra no estator.

$$
I_{\text {nom }}=\frac{S_{\text {nom }}}{\sqrt{3} V_{\text {nom }}}=\frac{160 \mathrm{MVA}}{\sqrt{3} 15 \mathrm{KV}}=6158 \mathrm{~A}
$$




\subsubsection{AJUSTE DA FUNÇÃO DE DISTÂNCIA (21)}

A função 21 é utilizada para fornecer proteção de retaguarda tanto para o gerador quanto para as linhas de transmissão. Neste trabalho será considerado que a função utiliza os sinais de tensão e corrente fornecidos pelos TP e TC instalados nos terminais do gerador. Dessa forma, são habilitadas duas zonas da função 21. A zona 1 será ajustada para fornecer retaguarda para os sistemas de proteção das linhas de $345 \mathrm{KV}$, enquanto que a zona 3 será ajustada na direção reversa, fornecendo retaguarda para 0 gerador.

\section{Ajuste da zona 1 (retaguarda para as linhas)}

Essa zona deverá ser ajustada de forma que uma falta, envolvendo duas ou mais fases, ocorrendo em qualquer ponto das linhas de transmissão, seja detectada com segurança. Este critério é atendido impondo-se que a zona seja ajustada com alcance suficiente para dectetar um curto trifásico no final do LT (a $250 \mathrm{~km}$ do gerador). A definição desse alcance, para a rede exemplo utilizada, é dificultada pelo efeito de in-feed produzido pelos outros cinco geradores que se encontram em paralelo. Para superar essa dificuldade, a rede foi simulada com uso do toolbox SimPowerSystems do Matlab, como mostrado na figura 5.8 .

Com o uso desta ferramenta, calculou-se os fasores das tensões e correntes em todos os elementos da rede e em seguida a impedância medida pela função 21, nos terminais do gerador, durante em curto trifásico no final da linha de circuito simples. Essa impedância foi calculada para duas condições operativas:

a) Todos os circuitos de linha operando.

b) Um dos circuitos da linha de circuito duplo desligado. 
Figura 5.8 - Rede simulada no Matlab.

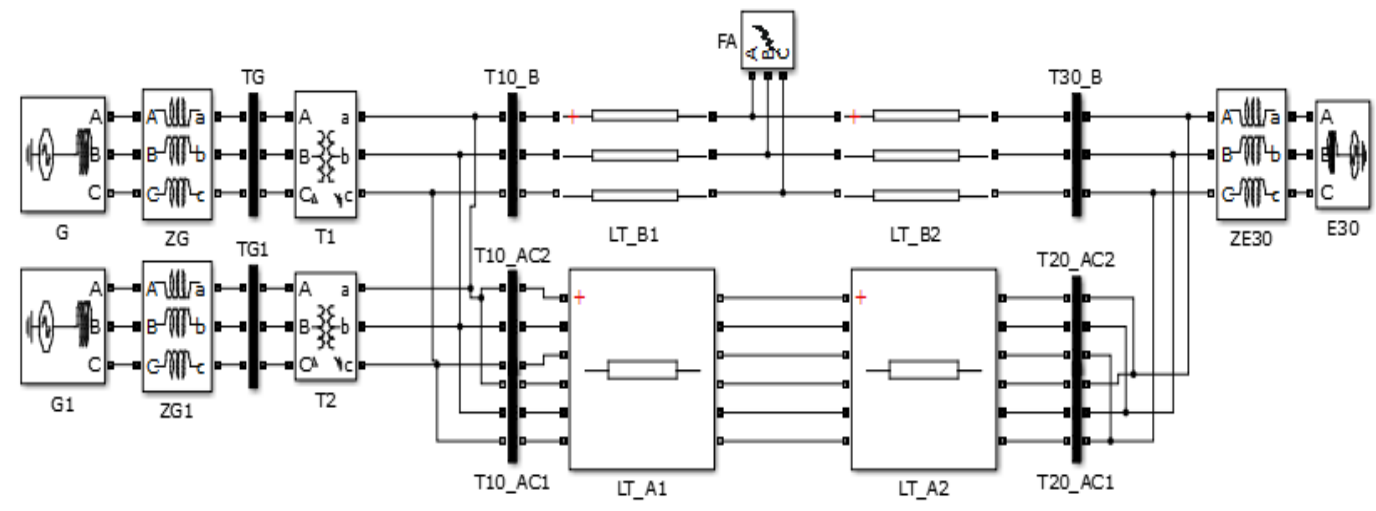

Fonte - Próprio autor.

As correntes medidas nos principais componentes da rede, durante essa falta, para as duas condições operativas são mostradas na figura 5.9. Nessa figura também é mostrada a impedância medida nos terminais do gerador.

Figura 5.9 - Corrente e Impedância medida durante curto trifásico no final da linha.

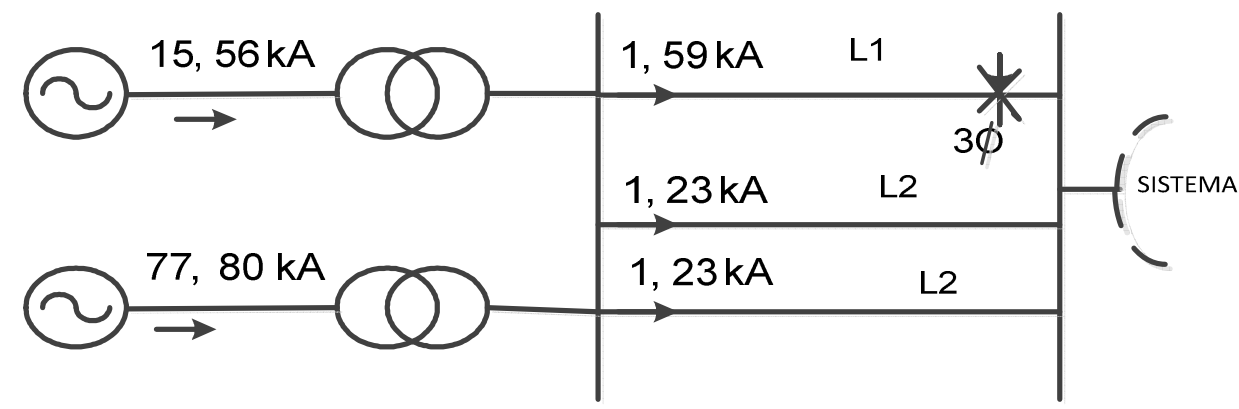

$Z_{\text {medido }}^{21}=0,4556 \angle 87.8^{\circ}$

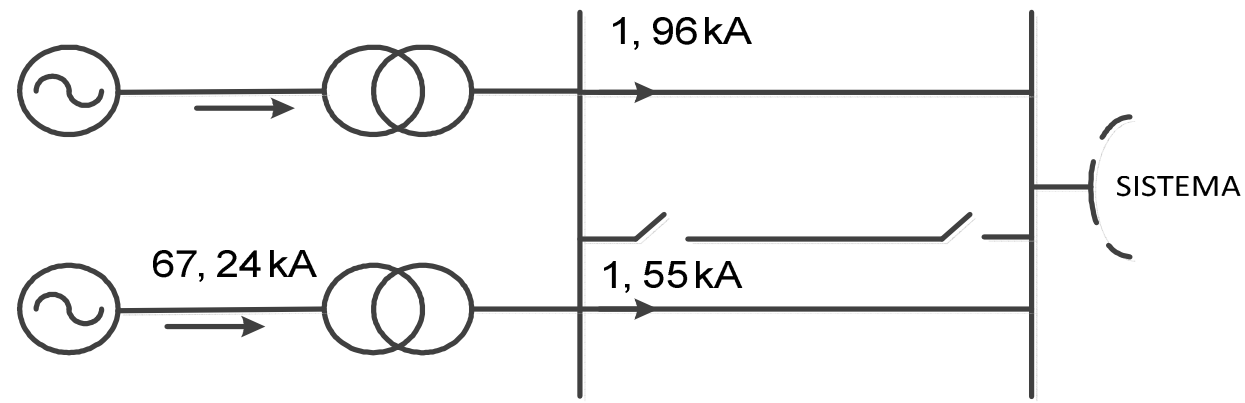

$$
Z_{\text {medido }}^{21}=0,5883 \angle 87,3^{\circ}
$$

Fonte - Própio autor. 
Como pode ser observado da figura 5.9, a situação mais crítica ocorre com o sistema operando com um dos circuitos da linha desligado.

Dessa forma, o ajuste adotado será fixado $20 \%$ acima do valor medido para essa condição, visando garantir que a função irá atuar com segurança. Para a fase do alcance será adotado o valor de $80^{\circ}$, ao invés dos $87,3^{\circ}$ indicado, com o objetivo de garantir cobertura para uma eventual resistência de arco. Com base nessas considerações, para essa zona será adotado característica Mho, com o alcance indicado a seguir.

$$
Z_{1}^{21}=0,7 \angle 80^{\circ} \Omega_{\text {prim }}
$$

Referindo-se esse valor para grandeza do secundário dos transformadores de instrumentação, resulta.

$$
\begin{aligned}
& Z_{1}^{21}=0,7 \frac{n T C}{n T P} \angle 80=0,7 * \frac{8000}{125} \angle 80^{\circ} \\
& Z_{1}^{21}=44,8 \angle 80^{\circ} \Omega_{\mathrm{sec}}
\end{aligned}
$$

A temporização dessa zona depende da informação sobre os ajustes das proteções de distância das linhas de transmissão, dado que ela deverá coordenar com a segunda zona dessas proteções. Normalmente, um atraso de 1 a 15 seg é suficiente para garantir coordenação. Assim, será adotado um atraso de $1 \mathrm{seg}$ para a zona 1. A título de ilustração, a figura 5.10 mostra a localização da impedância medida (valores primários) para o curto no final da linha (2 circuitos em operação), mostrando que o ajuste adotado é adequado. 
Figura 5.10 - Localização da impedância medida durante curto trifásico no final da linha.

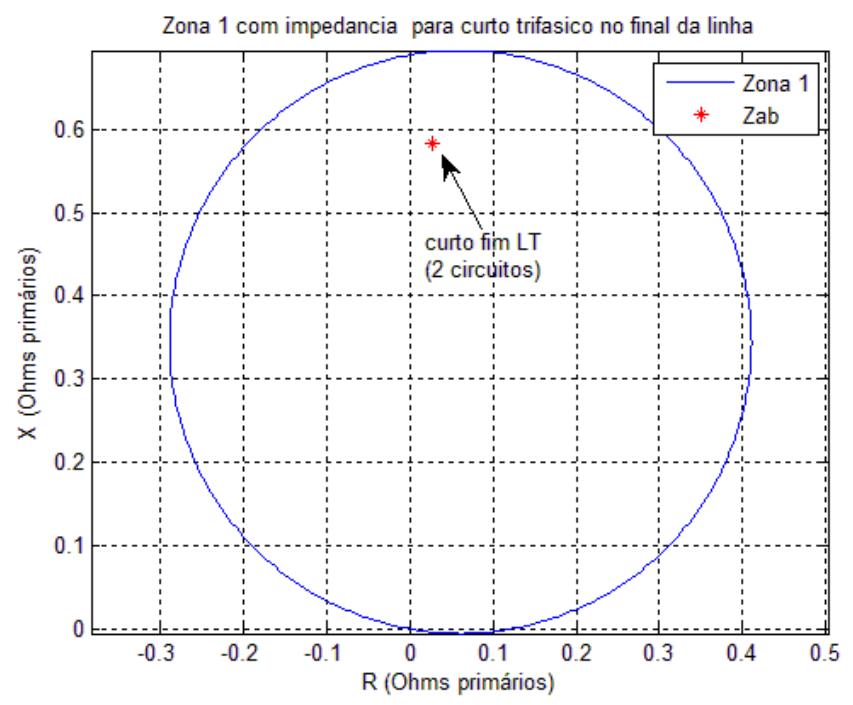

Fonte - Própio autor.

\section{Ajuste da zona 3 (retaguarda para o gerador)}

Esta zona é ajustada para alcançar $120 \%$ da resistência de eixo direto do gerador.

$$
\begin{aligned}
& Z_{\text {GERADOR }}=X_{d} \frac{V_{N}{ }^{2}}{S_{N}}=\frac{15^{2}}{160}=2,615 \Omega \text { prim } \\
& Z_{3}^{21}=1,2 Z_{\text {GERADOR }}=1,2^{\star} 2,615 \\
& Z_{3}^{21}=3,14 \angle-90^{\circ} \Omega \text { prim }
\end{aligned}
$$

Referindo essa impedância para o secundário dos transformadores de instrumentação, resulta:

$$
\begin{aligned}
& Z_{3}^{21}=3,14 * \frac{8000}{125} \angle-90^{\circ} \\
& Z_{3}^{21}=200 \angle-90^{\circ} \Omega \mathrm{sec}
\end{aligned}
$$

\subsubsection{AJUSTE DA FUNÇÃO PARA FALTAS À TERRA NO ESTATOR}

\section{- Função 59G}

Para equacionamento de curto circuto fase-terra nos terminais do 
gerador, os diagramas sequênciais da figura 5.3 deveriam ser associados como mostrado na figura 5.11 .

Figura 5.11 - Associação dos diagramas sequênciais para falta fase-terra dos terminais do gerador.

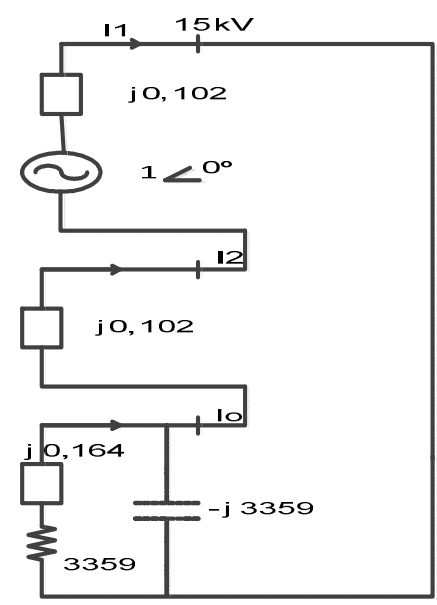

Fonte - Própio autor.

A corrente de sequência zero fornecida para o ponto de falta pode ser calculada por:

$$
I_{0}=\frac{1 \angle 0}{2 * j 0,102+\frac{3359}{\sqrt{2}} \angle-45^{\circ}}=0,421 * 10^{-3} \angle 45 p . u
$$

Corrente retornando pelo resistor de aterramento vale.

$$
I_{N}=3 I_{0}^{N}=3 * \frac{0,421 * 10^{-3}}{\sqrt{2}} * \frac{160 * 10^{3}}{\sqrt{3} 15}=5,5 \mathrm{~A}
$$

A circulação desta corrente irá produzir uma tensão no resistor de aterramento, instalado no secundário do transformador, dada por:

$$
\begin{aligned}
& V_{N}=R_{N} * I_{N} * \frac{15000}{120}=0,1 * 5,5 * 125 \\
& V_{R}=68,75 \mathrm{~V}
\end{aligned}
$$

Essa tensão poderá ser detectada pela função 59G desde que o pick-up 
dessa função seja fixado abaixo desse valor, isto é:

$$
V_{P K}^{59 G}<68,75 \mathrm{~V}
$$

Vale observar que é interessante que esse pick-up seja o mais baixo possível, pois, à medida que o ponto de falta for deslocado ao longo do enrolamento, em direção ao centro estrela, a corrente de falta fase-terra irá diminuir, diminuindo também a tensão produzida sobre o resistor.

O limiar interior do pick-up da função 59G é imposto pela pequena corrente de $60 \mathrm{~Hz}$ que circula pelo neutro durante a operação normal do gerador. Devido às pequenas diferenças nas magnitudes das tensões de fase, as correntes nas capacitâncias parasitas das três fases não somam zero e produzem essa pequena corrente que retorna pelo neutro. Neste trabalho será adotado que o máximo valor para essa corrente é 0,3 A. Desta forma, o limiar inferior para pick-up é dado por:

$$
V_{P K}^{59 G}>0,3 * \frac{1500}{120} * 0,1=3,75 \mathrm{~V}
$$

Com base neste resultado será fixado o ajuste abaixo.

$$
V_{P K}^{59 G}=5,0 \mathrm{~V}
$$

Com este ajuste, a percentagem de enrolamento, próximo ao centro estrela, que estará fora da proteção da função $59 \mathrm{~N}$, pode ser estimada por:

$$
\% \text { sem proteção }=\frac{5}{68,75} * 100=7,3 \%
$$

Como essa falta, devido às baixas correntes produzidas, não gera danos imediatos ao gerador, o tempo de atuação da função 59 G será fixado em 0,5 segundo.

\section{- FUNÇÃO 100\% DE PROTEÇÃO NO ESTATOR}

Para fornecer proteção para os cerca de $7 \%$ do enrolamento do estator 
que não se encontram protegidos pela função $59 \mathrm{G}$, neste trabalho serão utilizadas as funções baseadas no monitoramento da tensão de terceira harmônica do gerador. Para aplicação dessas funções é conveniente realizar medições de campo com o objetivo de avaliar a percentagem de terceira harmônica presente nas tensões de fase para as várias condições de carregamento do gerador. Neste trabalho será considerado que a percentagem de terceira harmônica nas tensões de fase do gerador varia entre um mínimo de $3 \%$, quando o gerador opera em carga leve, até um máximo de $5 \%$, quando operando a plena carga. Seja $E_{3 H}$ essa tensão de $180 \mathrm{~Hz}$, expressa em p.u.

$$
0,03 \leq E_{3 H} \leq 0,05
$$

Sabe-se que a terceira harmônica se comporta como uma componente de sequência zero. Dessa forma, quando se considera sua presença nas tensões de fase, ela deve ser indicada no diagrama de sequência zero, como mostrado na figura 5.12. O valor das reatâncias indutivas e capacitivas foram alteradas por um fator de 3 , em relação ao apresentado originalmente na figura 5.3 , devido a se considerar, neste caso, a frequência igual a $180 \mathrm{~Hz}$.

Figura 5.12 - Diagrama de sequência zero considerando-se a componente de $180 \mathrm{~Hz}$ nas tensões de fase.

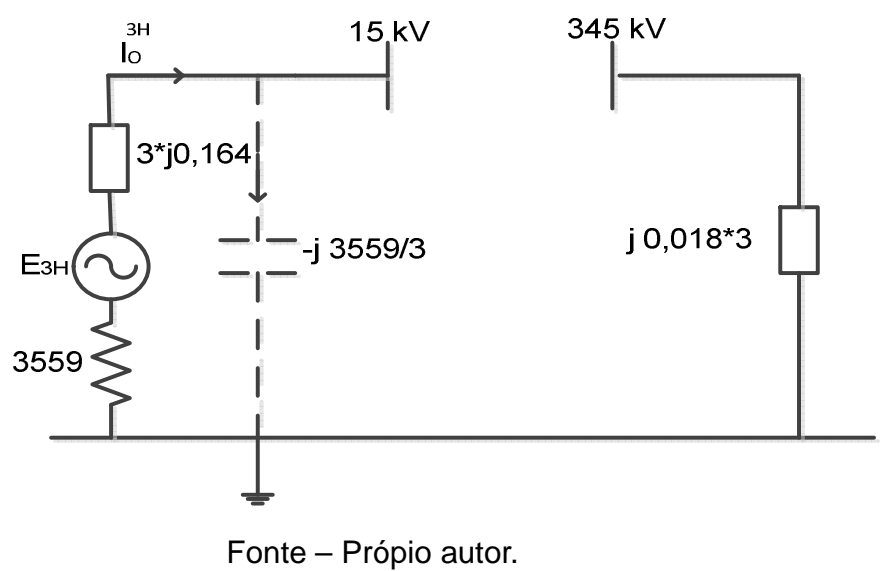

Com o gerador operando em condições normais, a corrente de sequência zero $(180 \mathrm{~Hz})$ que irá circular pelas capacitâncias parasitas é dada por: 


$$
I_{0}^{3 H} \cong \frac{E_{3 H}}{3559-j \cdot \frac{3559}{3}} \quad \text { p.u }
$$

A corrente retornando pelo resistor de aterramento vale:

$$
I_{N}^{3 H}=3 I_{0}^{3 H}=\frac{3}{3711 \angle 71,6} \cdot E_{3 H} \cdot \frac{160 * 10^{3}}{\sqrt{3} 15}=4,921 \angle 71,6 E_{3 H} \quad A
$$

A correspondente tensão sobre esse resistor é dada por:

$$
V_{N}^{3 H}=R_{N}\left|I_{N}^{3 H}\right|=1668 * 4,925 * E_{3 H}=8,215 E_{3 H} \mathrm{~V}
$$

Obs: $E_{3 H}$ na expressão acima representa a tensão em p.u, isto é, a percentagem de terceira harmônica presente na tensão de fase.

Refletindo a tensão de neutro para o secundário do trato de aterramento, resulta:

$$
\begin{aligned}
& V_{N_{s e c}}^{3 H}=8215 \cdot E_{3 H} \cdot \frac{120}{1500} \\
& V_{N_{s e c}}^{3 H}=65,72 * E_{3 H} \mathrm{~V}
\end{aligned}
$$

Para a variação considerada de $E_{3 H}$ entre 3\% e 5\%, a tensão de $180 \mathrm{~Hz}$ no secundário do trato de aterramento, para o gerador operando em condições normais, irá variar entre 1,97 e 3,29 Volts.

Quando ocorrer uma falta fase-terra no enrolamento do estator, próximo do centro estrela, grande parte dessa corrente de $180 \mathrm{~Hz}$ que se encontra retornando pelo resistor de aterramento irá retornar pelo ponto de falta. Com isso, a tensão de $180 \mathrm{~Hz}$ no secundário do trafo irá sofrer uma redução significativa.

Utilizando uma função de subtensão, sensível à terceira harmônica (função 27TH), com pick-up ajustado abaixo de 1,97 Volts, é possível detectar faltas fase-terra no trecho do enrolamento não protegido pela função 59G. Com base nos resultados apresentados, será adotado o seguinte ajuste para função 
$27 \mathrm{TH}$.

$V_{P K}^{27 T H}=1,7 \mathrm{~V}$

Delay $=1,0 \mathrm{seg}$ (tempo definido)

Vale observar que, caso a variação da percentagem de terceira hormônica nas situações de plena carga e vazio seja muito ampla, pode existir dificuldades para a aplicação segura da função 27TH. Para esse caso, os fabricantes disponibilizam uma função alternativa (denominada 100\%stator ground no manual do G60). Essa função não monitora a grandeza $V_{N}^{3 H}$ diretamente (a qual varia muito), mas sim a relação $V_{N}^{3 H} / E_{3 h}$ onde $E_{3 h}$ é calculada por:

$$
E_{3 h=} V_{N}^{3 H}+V_{T}^{3 H}
$$

$V_{T}^{3 H}=$ Componente da terceira hormônica presente nas tensões de fase nos terminais do gerador.

A figura 5.13, mostra detalhes da função na forma implementada no IED G60 e GE.

Figura 5.13 - Detalhes da função implementada no IED G60 da GE.

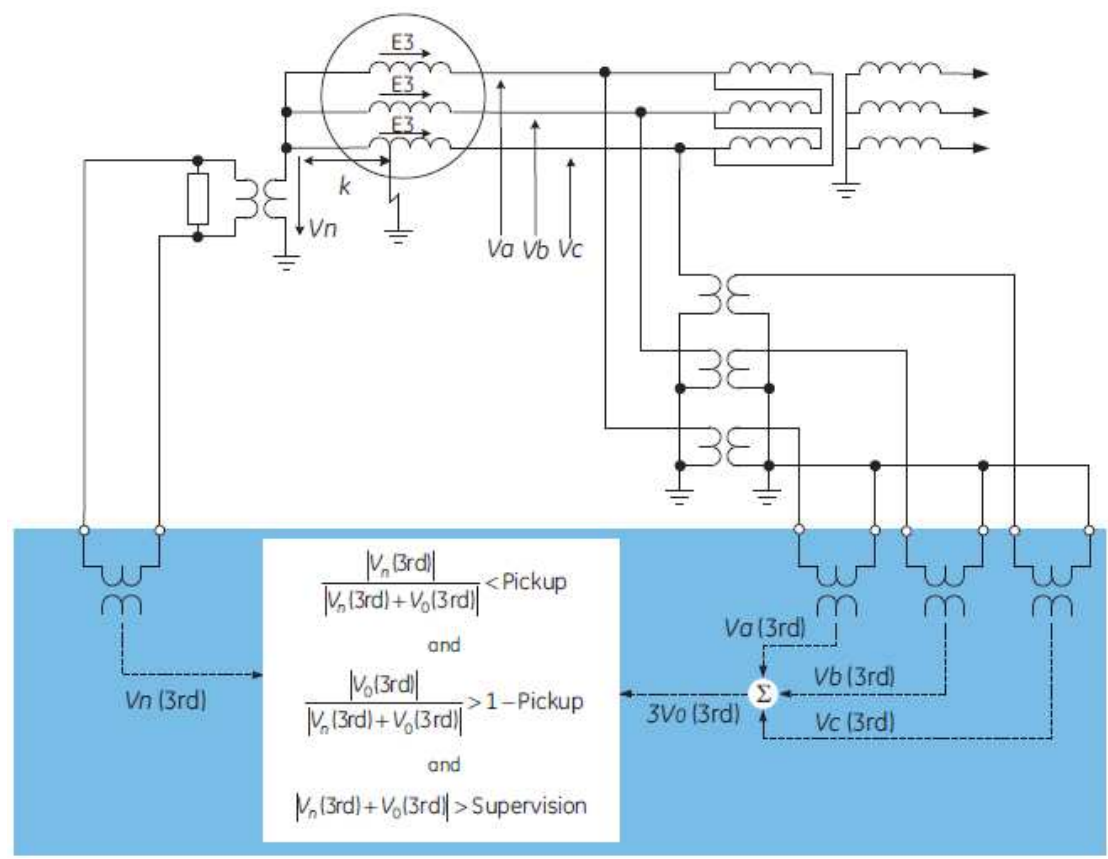

Fonte - Próprio autor. 
Os seguintes ajustes foram adotados para essa função:

Pick Up $=0,5$

Supervision $=0,01$

Delay $=1,0$ seg.

Neste trabalho, as duas funções foram habilitadas, simultaneamente visando avaliar o desempenho de cada uma delas.

\subsubsection{FUNÇÃO DESBALANÇO DE CORRENTE}

$$
\begin{aligned}
& I_{\text {nom }(p u)}=\frac{I_{\text {nom }} \text { rim }}{C T_{\text {prim }}}=\frac{6158}{8000}=0,770 \mathrm{pu} . \\
& \text { Pick up }=0,7^{\star} I_{2} \\
& \text { Capabilidade }=0,7^{\star} 8 \%=5,6 \%
\end{aligned}
$$

\subsubsection{FUNÇÃO PERDA DE EXCITAÇÃO}

$$
\begin{aligned}
& Z_{b(s e c)}=\frac{\text { base } K V^{2} \text { Relação } C T}{\text { base MVA Relação } V T}=\frac{(15 \mathrm{KV})^{2} 8000}{160 \mathrm{MVA} 125}=90 \Omega \\
& X_{d}^{\prime}(\mathrm{sec})=X^{\prime}{ }_{d} Z_{b(\mathrm{sec})}=0,82 * 90=25,38 \Omega \\
& X_{d}^{\prime}(\mathrm{sec})=X_{d}{ }_{d} Z_{b(s e c)}=1,86 * 90=167,4 \Omega \\
& \text { Centro } 1=\frac{Z_{b(s e c)}+X_{d(s e c)}}{2}=\frac{90+23,265}{2}=57,69 \Omega \\
& \text { Radio } 1=\frac{Z_{b(s e c)}}{2}=\frac{90}{2}=45 \Omega
\end{aligned}
$$

Pickup delay $1=0,06 \mathrm{seg}$

Centro $2=\frac{X_{d(s e c)}+X^{\prime} d(s e c)}{2}=\frac{167,4+25,38}{2}=96,39 \Omega$

Radio $2=\frac{X_{d(s e c)}}{2}=\frac{167,4}{2}=83,7 \Omega$ 


\subsubsection{FUNÇÃO ANTI-MOTORIZAÇÃO}

$$
\begin{aligned}
S_{\min } & =\frac{1}{2} * \frac{\text { relação de potência de Motorização ( Primário Watts) }}{3 * \text { CT Fase Primario } * \text { Relação VT Fase } * \text { Secondário Fase VT }} \\
S_{\min } & =\frac{1}{2} * \frac{16 * 10^{6} \mathrm{~W}}{3 * 8000 * 125 * 69,3}=0,038 \mathrm{pu} .
\end{aligned}
$$

\subsection{ENSAIOS DO SISTEMA DE PROTEÇÃO DO GERADOR NA PLATAFORMA DE SIMULAÇÃO EM TEMPO REAL.}

Para avaliar o desempenho do sistema de proteção dos geradores da rede exemplo, projetado conforme descrito no item anterior, realizou-se uma série de simulações de faltas utilizando a plataforma de ensaios descrita no capítulo 4.

A seguir é apresentado uma breve discussão dos eventos de falta simulados e do desempenho esperado para cada uma funções de proteção habilitadas e parametrizadas no relé $\mathrm{G} 60$, utilizado nesse sistema de proteção.

\section{a)- Faltas nos terminais do gerador}

A maioria das faltas no enrolamento do estator ocorrem em regiões próximas dos terminais.

A maioria dessas faltas são do tipo fase-terra produzidas a partir de uma falha no isolante do condutor. Um flashover, que causa danos ao isolante, tem maior probabilidade de ocorrer próximo dos terminais, devido ao maior stress elétrico nessa região. Faltas entre espiras próximas, não são detectadas pela função diferencial, e também evoluem para uma falta fase-terra. As faltas entre fases são mais raras e, normalmente ocorrem nos terminais dos enrolamentos, onde há maior aproximação entre duas fases.

Como mostrado no item anterior, faltas entre fases, no interior da zona de proteção da função $87 \mathrm{G}$ são detectadas com segurança por essa função. $A$ zona 3 da função 21 também irá ser sensibilizada por esse tipo de falta e fornecerá retaguarda para a função $87 \mathrm{G}$. Para faltas fase-terra, no entanto, mesmo aquelas ocorrendo nos terminais do gerador, não há uma garantia 
segura de autação da função $87 \mathrm{G}$, devido às baixas correntes que circulam nessa situação. Essas faltas são detectadas pela função 59G.

No item 5.2.1 a seguir são apresentados a resposta do sistema de proteção para faltas nos terminais do gerador. Foram simulados duas faltas (dupla-fase e fase-terra) dentro da zona de proteção da função 87G, e uma falta fase-terra, também no $15 \mathrm{kV}$, porem fora dessa zona.

\section{b)- Faltas internas ao enrolamento do estator}

Faltas internas ao enrolamento do estator são mais raras e quando ocorrem, normalmente, são do tipo fase-terra. Na maior parte do enrolamento elas serão detectadas pela função 59G. Apenas em um pequeno trecho, próximo ao centro estrela, a função 59G não terá sensibilidade suficiente, devido à pequena magnitude da corrente de falta. No item 5.1 estimou-se que esse trecho sem proteção corresponde a 7,3\% do enrolamento. A cobertura nessa região será feita pelas funções baseadas no monitoramento da tensão de $180 \mathrm{~Hz}$ no neutro (funções $27 \mathrm{TH}$ e $100 \%$ do estator).

No item 5.2.2 são mostradas a resposta da proteção para faltas faseterra ocorrendo a $15 \%$ e a $5 \%$, neste último caso considerando operação em carga pesada e leve.

\section{c)- Faltas no $345 \mathrm{kV}$}

Faltas nas linhas de 345 kV deverão ser detectadas pela função 21 (zona 1) ajustada para fornecer retaguarda para as proteções primárias das LT. Faltas dupla-fase tambem pode provocar a partida da função de sequência negativa (desbalanço de corrente). Para avaliar o desempenho dessas funções, no item 5.2.3 é apresentado os resultados para uma falta dupla-fase, com resistência de 0,5 Ohms, ocorrendo no final de um dos circuitos das LT.

\section{d)- Perda de Excitação}

Para este evento simulou-se a abertura do disjuntor de campo do gerador síncrono. Os resultados do ensaio são apresentados no item 5.2.4. 


\section{e)- Motorização do Gerador}

A simulação desse evento consistiu em subitamente aplicar um torque negativo igual a $10 \%$ o torque nominal da turbina. O responsta da função 32 é mostrada no item 5.2.5.

\subsubsection{SIMULAÇÃO DE FALTAS NOS TERMINAIS DO GERADOR}

\section{a)- Faltas internas à zona de proteção da função $87 \mathrm{G}$}

Com o gerador operando a plena carga (150 MW), foram ensaiadas duas faltas nos terminais do gerador, no interior da zona de proteção do $87 \mathrm{G}$. A primeira falta foi do tipo dupla-fase (AB), sendo que a figura 5.14 apresenta a oscilografia e o registro de eventos gerados durante esse evento. Os três primeiros sinais analógicos da oscilografia são as correntes registradas no relé e os três últimos são as tensões de fase. A partir da análise do registro de eventos e dos sinais digitais mostrados na oscilografia, verifica-se que a função 87G operou corretamente, detectando a falta e gerando o sinal de trip para os disjuntores. Observa-se também a partida da função 21, zona 3 (retaguarda para o gerador), conforme esperado. A segunda falta simulada, nesse mesmo ponto, foi do tipo fase-terra (AN). Os resultados registrados no IED são mostrados na figura 5.15. Verifica-se que mesmo com a pequena corrente de falta à terra, houve a atuação da função $87 \mathrm{G}$. Isso deve-se ao ajuste bastante sensível fixado para essa função. 
Figura 5.14 - Curto dupla-fase $(A B)$ nos terminais do gerador, interno à zona de proteção do 87G.
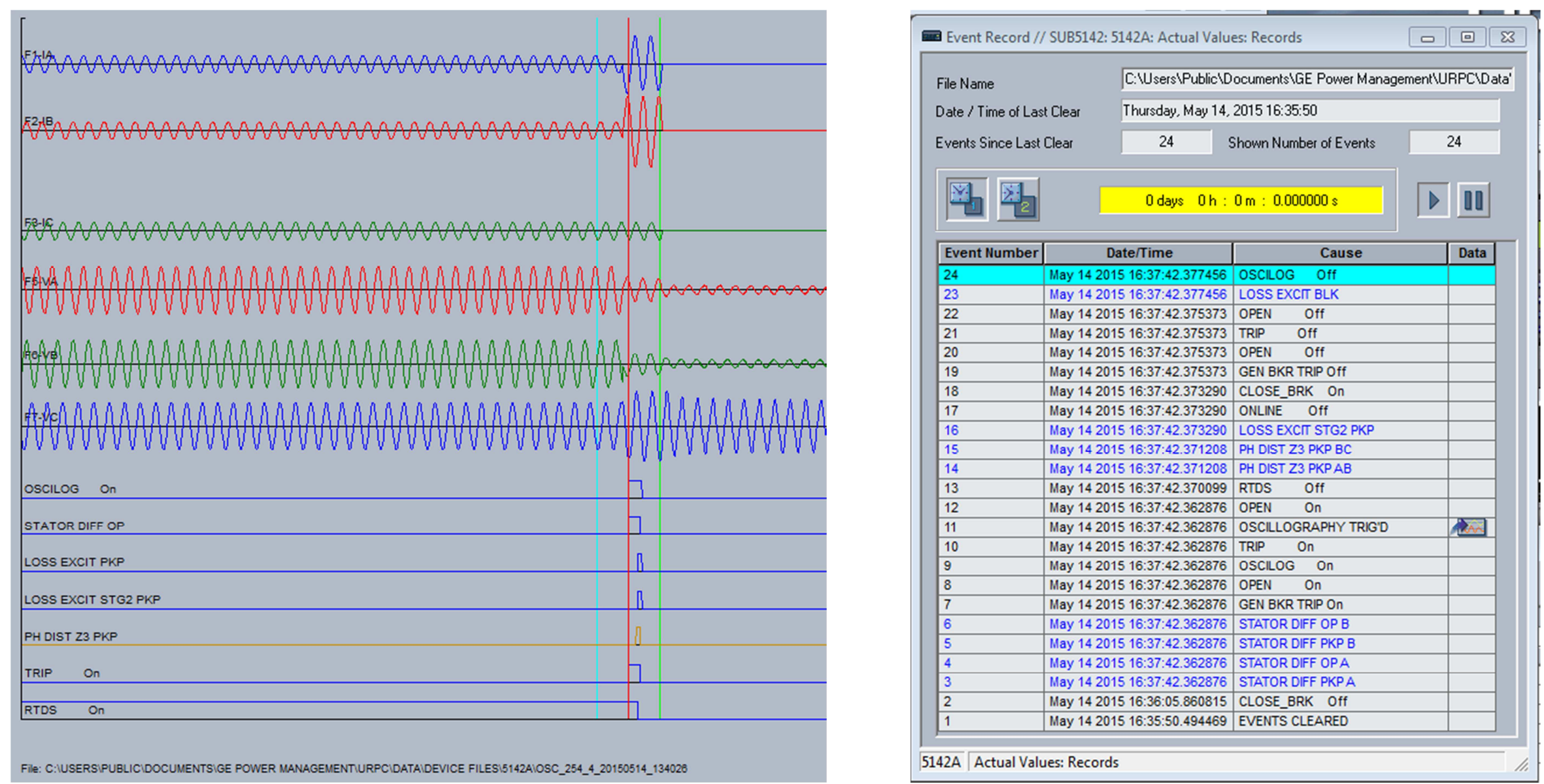

Fonte - Próprio autor. 
Figura 5.15 - Curto Fase-terra (AN) nos terminais do gerador, interno à zona de proteção do $87 \mathrm{G}$.

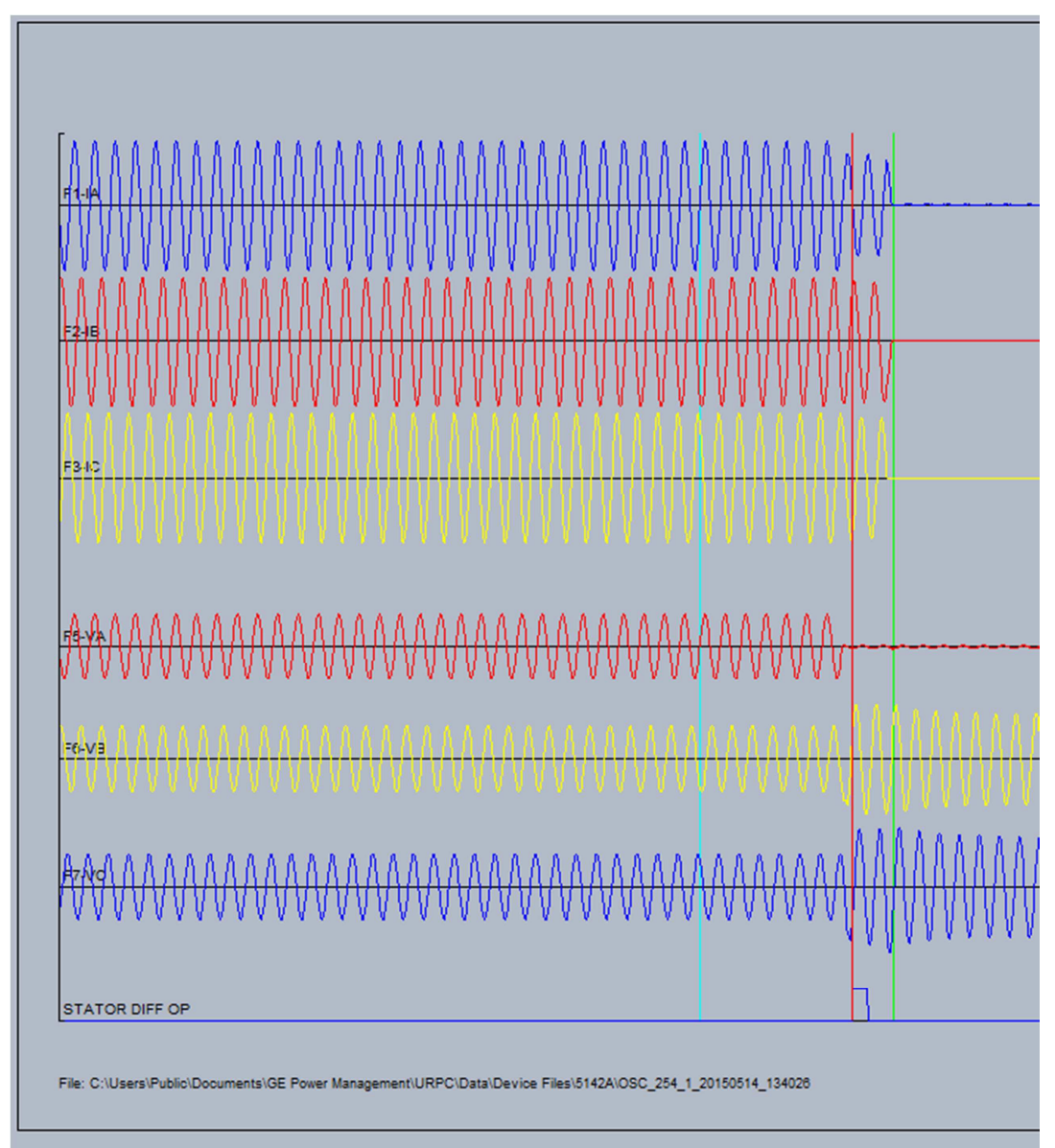

\begin{tabular}{|c|c|c|c|c|c|}
\hline \multicolumn{3}{|c|}{ Event Record // SUB5142: 5142A: Actual Values: Records } & 口 & 回 & $\mathfrak{E}$ \\
\hline \multirow{3}{*}{$\begin{array}{l}\text { File Name } \\
\text { Date / Time of Last Clear } \\
\text { Events Since Last Clear }\end{array}$} & \multicolumn{5}{|c|}{ 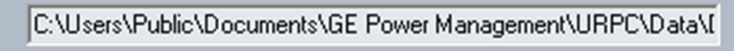 } \\
\hline & \multicolumn{4}{|c|}{ Thursday, May 14, 2015 14:38:06 } & \\
\hline & Clear & Shown Number of Events & \multicolumn{2}{|c|}{19} & \\
\hline 我 & \multicolumn{2}{|c|}{0 days $0 \mathrm{~h}: 0 \mathrm{~m}: 0.000000 \mathrm{~s}$} & \multirow[t]{2}{*}{$D$} & प & \\
\hline Event Number & Date/Time & Cause & & Data & \\
\hline 19 & \multirow{2}{*}{\begin{tabular}{|l|} 
May 142015 14:39:05.826161 \\
May 142015 14:39:05.826161 \\
\end{tabular}} & \multicolumn{2}{|l|}{ Off } & & \\
\hline 18 & & TRIP $\quad$ Off & & & \\
\hline 17 & May 142015 14:39:05.826161 & OSCILOG Off & & & \\
\hline 16 & May 142015 14:39:05.826161 & OPEN Off & Off & & \\
\hline 15 & May 142015 14:39:05.826161 & \multicolumn{2}{|l|}{ TRIP Off } & & \\
\hline 14 & May 142015 14:39:05.824080 & \multicolumn{2}{|l|}{ Off } & & \\
\hline 13 & May 142015 14:39:05.824080 & \multicolumn{2}{|l|}{ On } & & \\
\hline 12 & May 142015 14:39:05.824080 & & & \\
\hline 11 & May 142015 14:39:05.824080 & \multicolumn{2}{|l|}{ Off } & & \\
\hline 10 & May 142015 14:39:05.820448 & \multicolumn{2}{|l|}{ Off } & & \\
\hline 9 & \multirow{2}{*}{$\begin{array}{l}\text { May } 142015 \text { 14:39:05.813668 } \\
\text { May } 142015 \text { 14:39:05.813668 }\end{array}$} & \multicolumn{2}{|l|}{ On } & & \\
\hline 8 & & OSCILLOGRAPHY TRIG'D & & 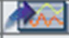 & \\
\hline 7 & May 142015 14:39:05.813668 & \multicolumn{2}{|l|}{ On } & & \\
\hline 6 & May 142015 14:39:05.813668 & OSCILOG On & & & \\
\hline 5 & May 142015 14:39:05.813668 & OPEN On & & & \\
\hline 4 & May 142015 14:39:05.813668 & GEN BKR TRIP On & & & \\
\hline 3 & May 142015 14:39:05.813668 & STATOR DIFF OPA & & & \\
\hline 2 & May 142015 14:39:05.813668 & STATOR DIFF PKPA & & & \\
\hline 1 & May 14 2015 14:38:06.262811 & EVENTS CLEARED & & & \\
\hline
\end{tabular}

Fonte - Próprio autor. 


\section{b)- Falta externa à zona de proteção da função $87 G$}

A figura 5.16 mostra a resposta do sistema de proteção para a mesma falta fase-terra do item anterior, somente deslocando-se o ponto de falta para após o TC dos terminais do gerador. Como essa falta encontra-se, agora, fora da zona de proteção do $87 \mathrm{G}$, não ocorre mais a atuação dessa função. A falta, neste caso, foi detectada e isolada pela função $59 \mathrm{G}$.

A oscilografia mostrada nessa figura é a fornecida pelo RTDS, onde são registradas as três tensões de fase e a tensão sobre o resistor de aterramento (tensão monitorada pela função 59G). Observa-se, durante a pré-falta, a existência de uma pequena tensão de $180 \mathrm{~Hz}$ sobre esse resistor. Após a ocorrência da falta (instante em que a tensão $V_{A N}$ é zerada), surge uma tensão elevada de $60 \mathrm{~Hz}$ que é detectada pela função 59G. Conforme mostrado no registro de eventos, o delay dessa função é de 5 segundos. Devido à sobretensão que as fases $B$ e $C$ ficam sujeitas, durante a falta, ocorre a partida da função Volts/Hertz. 
Figura 5.16 - Curto circuito fase-terra (NA) nos terminais do gerador, externo à zona de proteção do 87G

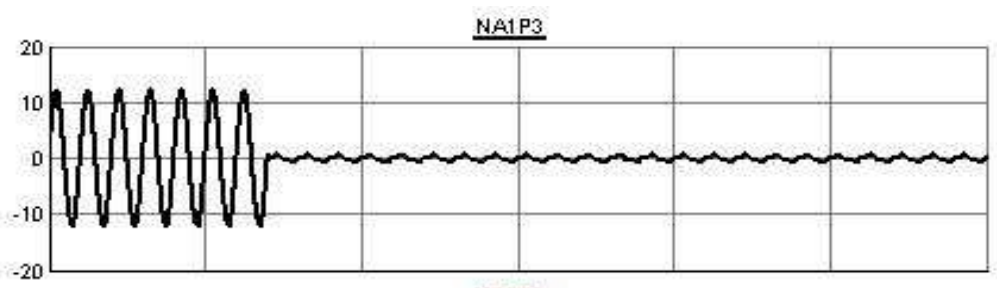

NE1P3

3
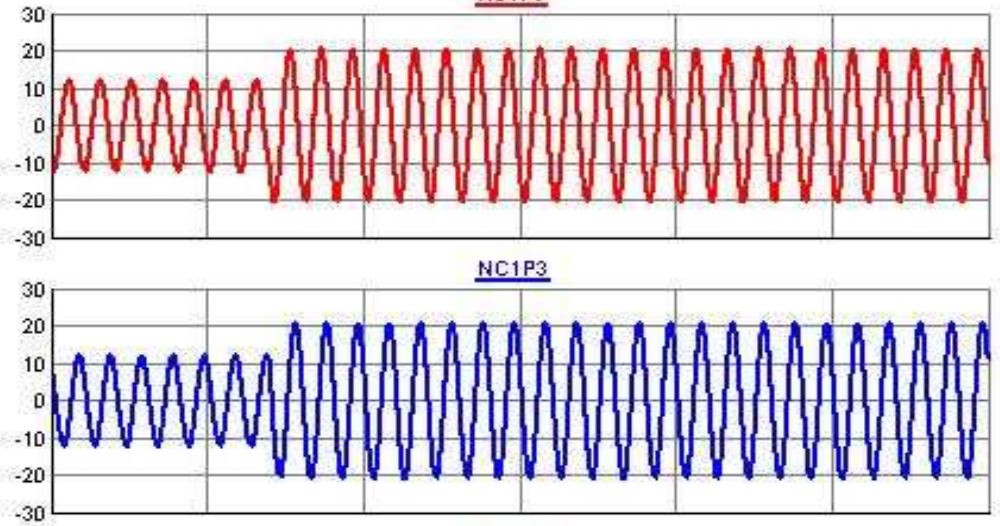

IN1P3

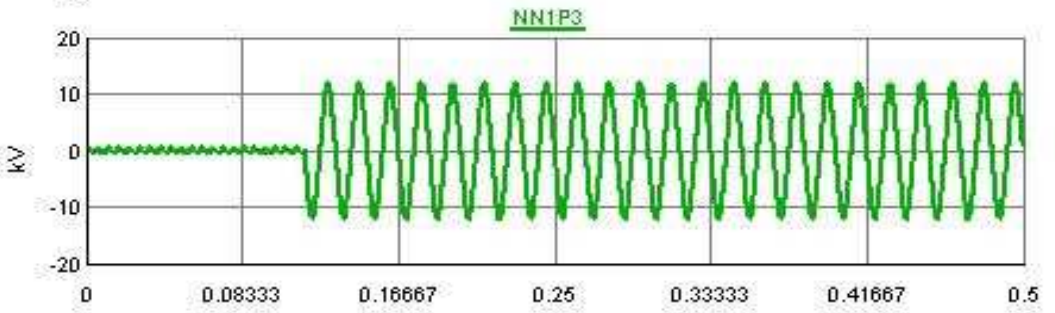

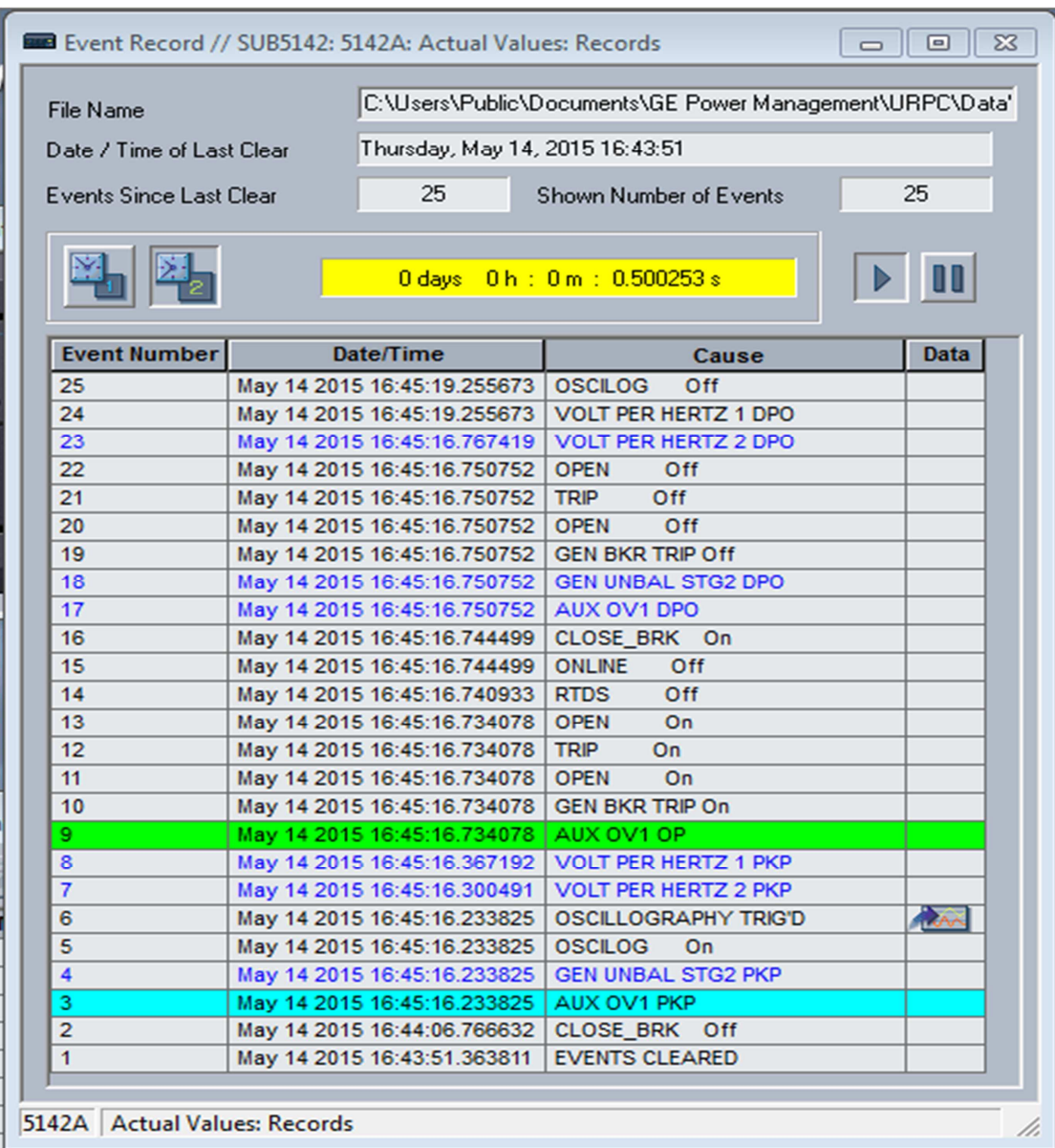

Fonte - Próprio autor. 


\subsubsection{SIMULAÇÃO DE FALTAS INTERNAS AO ESTATOR}

Neste item são analisadas três faltas fase-terra localizadas ao longo do enrolamento do estator. Vale observar que, com os ajustes definidos no item 5.1 , espera-se que a função $59 \mathrm{G}$ forneça proteção para até $7,3 \%$ do enrolamento, sendo o restante protegido pelas função $27 \mathrm{TH}$ e $100 \%$ do estator. A primeira falta simulada encontra-se a $15 \%$ do centro estrela (gerador a plena carga) e as outras duas a $5 \%$ (uma com a gerador a plena carga e a outra em carga leve). Os resultados obtidos são apresentados nos itens a seguir.

\section{a)- Falta fase-terra a $15 \%$ do enrolamento do estator (gerador a plena carga)}

As figuras 5.17 e 5.18 mostram os resultados obtidos para este ensaio. Analisando-se o registro de eventos observa-se que a falta foi detectada e isolada pela função 59G, conforme esperado, com delay de $500 \mathrm{mseg}$. Observa-se também a partida das funções $27 \mathrm{TH}$ e $100 \%$ do estator, as quais não atuam devido ao maior delay adotado para essas funções (1.0 seg).

\section{b)- Falta fase-terra a $5 \%$ do enrolamento do estator (gerador a plena carga)}

Os resultados para este caso são mostrados nas figuras 5.19 e 5.20. Esta falta encontra-se fora da zona de cobertura da função 59G, conforme previsto. Analisando-se a oscilografia da figura 5.19, observa-se que a tensão de $60 \mathrm{~Hz}$ sobre o resistor de aterramento, durante a falta, apresenta uma pequena magnitude, quase da mesma ordem que a tensão de $180 \mathrm{~Hz}$ existente na pré-falta. Como essa magnitude fica abaixo do valor de pick-up, a função $59 \mathrm{G}$ não atua. A falta foi detectada e isolada pelas funções $27 \mathrm{TH}$ e $100 \%$ do estator que operaram simultaneamente (as duas foram ajustadas com delay de $1.0 \mathrm{seg})$.

Como essas duas funções baseiam-se na componente de terceira harmônica presente nas tensões de fase e essa grandeza depende do ponto de operação da máquina, a falta foi simulada para duas situações de 
carregamento: plena carga e carga leve.

Para o caso discutido neste item considerou-se a máquina operando em plena carga, situação em as tensões de fase apresentam uma componente de terceira harmônica da ordem de $5 \%$. O caso de carga leve é apresentado no item a seguir

\section{c)- Falta fase-terra a $5 \%$ do enrolamento do estator (gerador em carga leve)}

Os resultados para esse caso, mostrados nas figuras 5.21 e 5.22, são semelhantes ao caso anterior. Como esperado, novamente ocorre a partida das funções $27 \mathrm{TH}$ e $100 \%$ do estator. Dado, no entanto, que esta última partiu com 12 ms de atraso, ela não chega a atuar, sendo a falta isolada pela atuação da função $27 \mathrm{TH}$.

Os resultados apresentados mostram que as funções de proteção de faltas à terra no estator (59G, $27 \mathrm{TH}$ e $100 \%$ do estator) encontram adequadamente ajustadas.

Figura 5.17 - Curto-circuito fase-terra no estator a $15 \%$ do centro estrela.

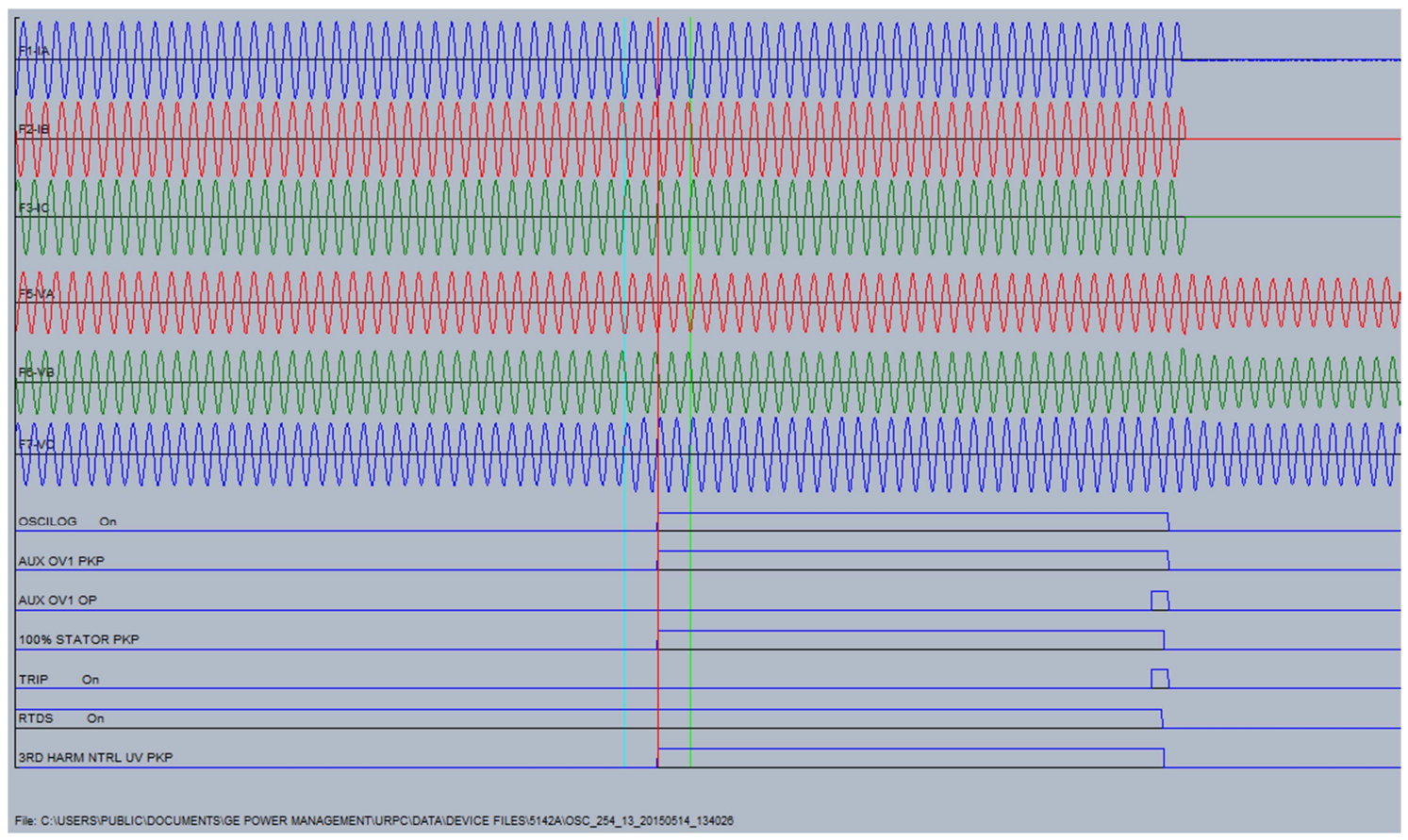

Fonte - Próprio autor. 
Figura 5.18 - Curto-circuito fase-terra no estator a $15 \%$ do centro estrela.

NA1P3

3

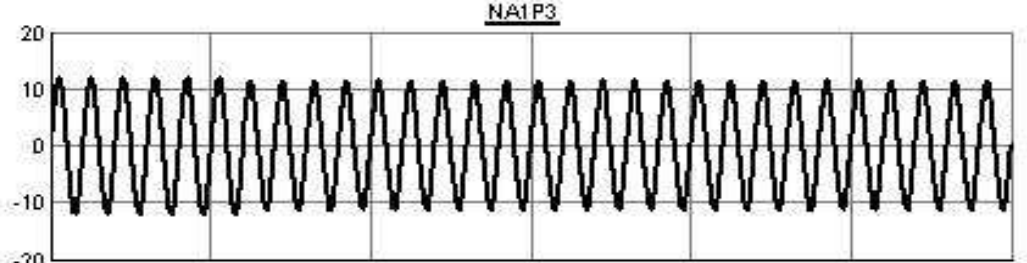

$\underline{\text { NE1P3 }}$

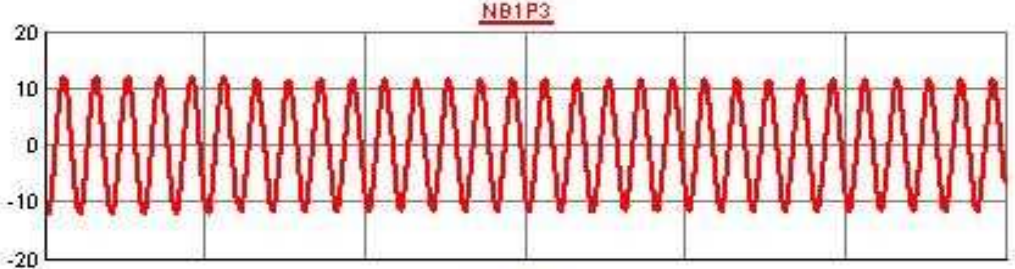

$\underline{\mathrm{NC1P3}}$

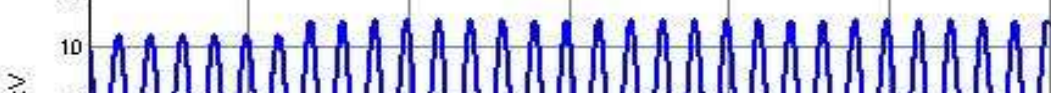

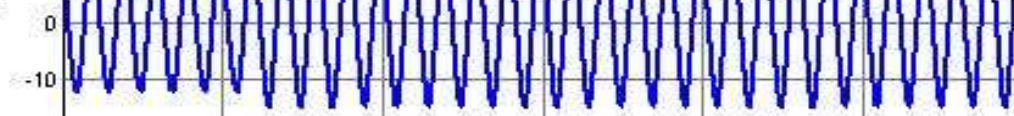
$-20$

AN1P3

Z

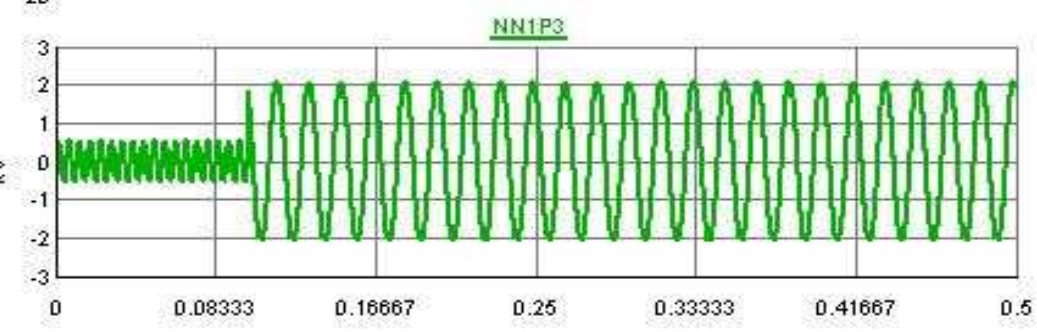

Event Record // SUB5142: 5142A: Actual Values: Records

0

File Name

Date / Time of Last Clear

Events Since Last Clear

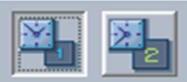

Event Number

\begin{tabular}{|l|l|l|r|} 
Daterime & \multicolumn{2}{c}{ Cause } \\
24 & May 14 2015 17:44:56.945916 & OPEN Off
\end{tabular}

\begin{tabular}{|l|l|l|l}
22 & May 14 2015 17:44:56.945916 & OSCILOG Off \\
\hline 21 & May $14201517: 445694516$ & OPEN Off
\end{tabular}

\begin{tabular}{|l|l|l|l}
21 & May 14 2015 17:44:56.945916 & OPEN Off \\
\hline 20 & May 14 2015 17:44:56945916 & GEN BKR TRIP Off
\end{tabular}

\begin{tabular}{l|lll}
\hline 19 & May 14 2015 17:44:56.945916 & GEN BKR TRIP Off \\
\hline 19 & May $14201517: 44: 56945916$ & AUXOV1DPO \\
\hline
\end{tabular}

\begin{tabular}{|l|l|l}
18 & May 14 2015 17:44:56.945916 & AUX OV1 DPO \\
\hline 18 & May 142015 17:44:56.941753 & $100 \%$ STATOR STG2 DPO
\end{tabular}

\begin{tabular}{|l|l|l|l|}
17 & May $14201517: 44: 56.941753$ & $100 \%$ STATOR STG1 DPO \\
\hline
\end{tabular}

\begin{tabular}{l|l|l|l}
116 & May 142015 17:44:56.939671 & CLOSE_BRK On \\
\hline 15 & CLE $14201517: 44: 56939671$ & ONE
\end{tabular}

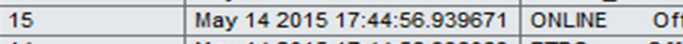

\begin{tabular}{|l|l|l|l}
\hline 14 & May 14 2015 17:44:56.936083 & RTDS Off \\
\hline 13
\end{tabular}

\begin{tabular}{l|lll}
13 & May 14 2015 17:44:56.929262 & OPEN & On \\
\hline 12 & OPy $14201517: 4456.92222$ & & \\
\hline 11 & OPEN & On
\end{tabular}

\begin{tabular}{|l|l|l|l}
12 & May 14 2015 17:44:56.929262 & TRIP On \\
\hline 11 & &
\end{tabular}

\begin{tabular}{|l|l|l|l}
\hline 11 & May 14 2015 17:44:56.929262 & OPEN On \\
\hline 10 & May 14 2015 17:44:56.929262 & GEN BKR TRIP On \\
\hline
\end{tabular}

\begin{tabular}{|l|l|l|l}
110 & May 14 2015 17:44:56.929262 & GEN BKR TRIP On \\
\hline 10 &
\end{tabular}

\begin{tabular}{|l|llll}
\hline 9 & May 14 2015 17:44:56.929262 & AUX OV1 OP & \\
\hline 8 & May 14 2015 17:44:56.429638 & OSCILLOGRAPHY TRIG'D
\end{tabular}

7 May 14201517.44 .56 .429038 OSCILOG ON

ORD HARIM NTRL UV PKP

10.4 17:44:50:42933 $100 \%$ STATOR STG2 PKP

May $14201517: 44.56 .429638$ AUXOV1 PKP

14. 142015 17:41:23.4290405 AUX OV1 PKP Of

\begin{tabular}{|l|l|l|} 
May 14 2015 17:41:07.026142 & EVENTS CLEARED \\
\hline
\end{tabular}

5142A Actual Values: Records 
Figura 5.19 - Curto-circuito fase-terra no estator a $5 \%$ do centro estrela - carga pesada.

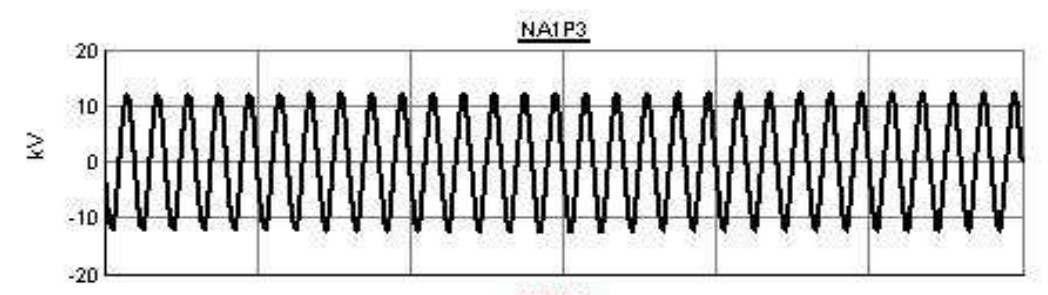

NA1P3
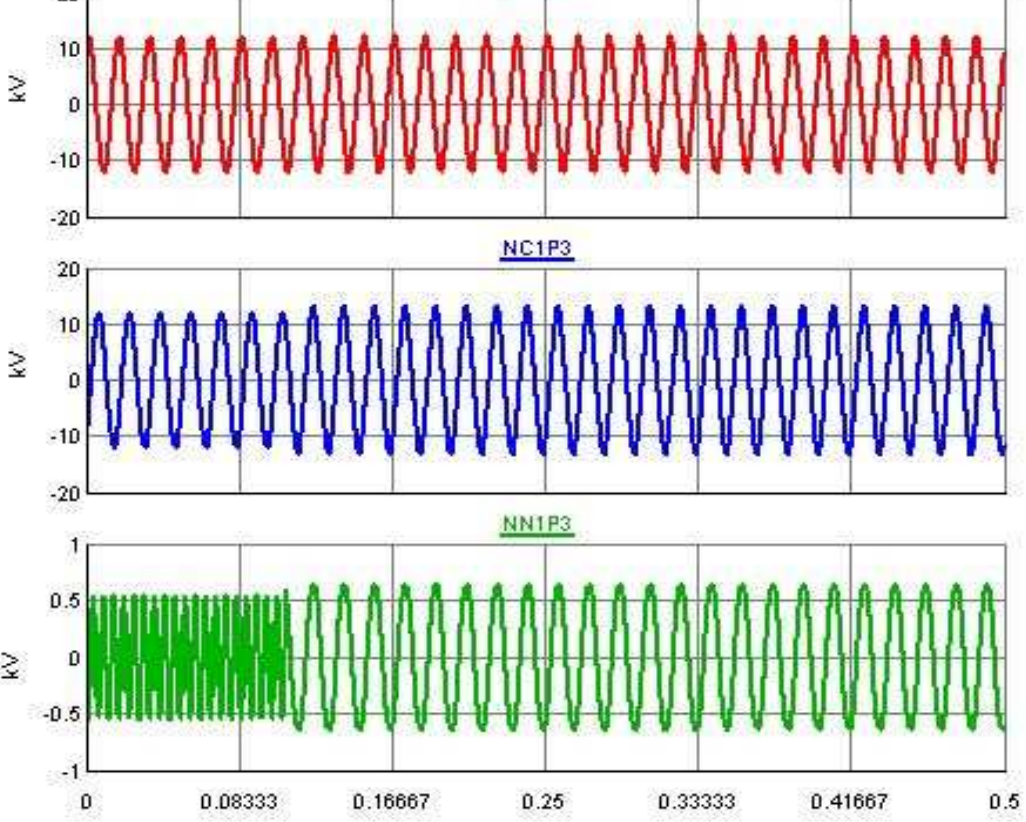

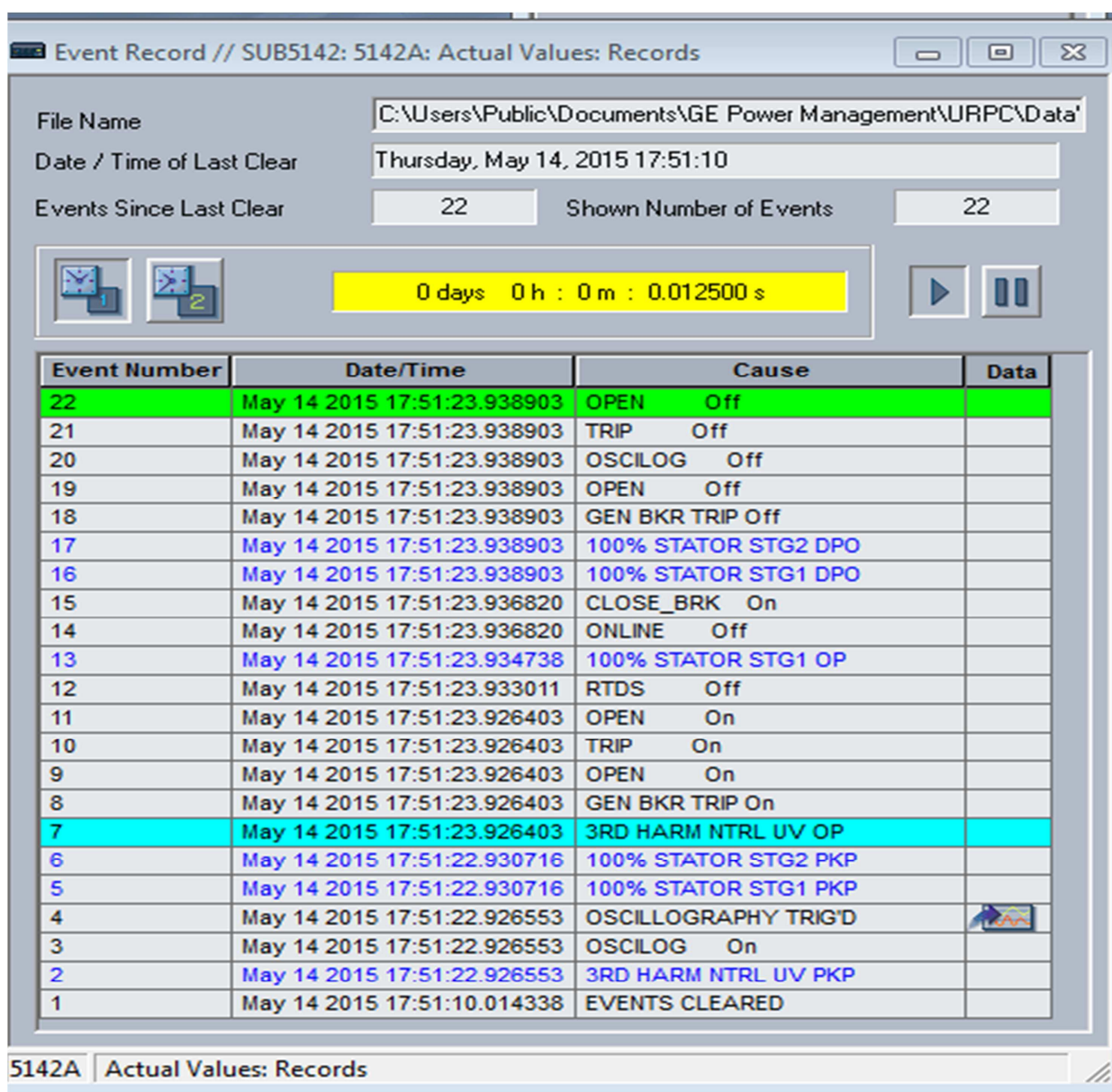

Fonte - Próprio autor. 
Figura 5.20 - Curto-circuito fase-terra no estator a $5 \%$ do centro estrela - carga pesada.

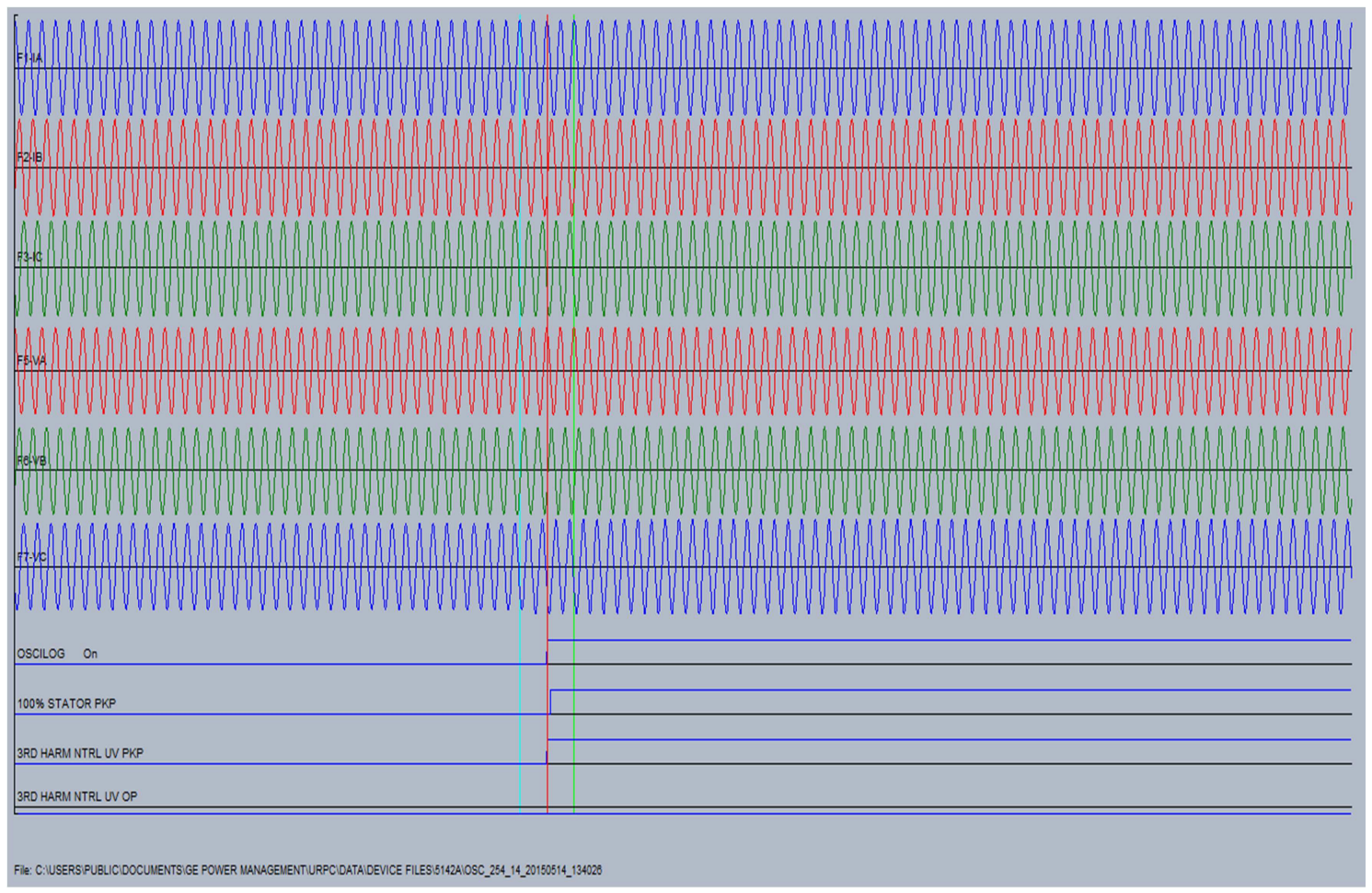

Fonte - Próprio autor

Figura. 5.21 - Curto-circuito fase-terra no estator a 5\% do centro estrela - carga leve.

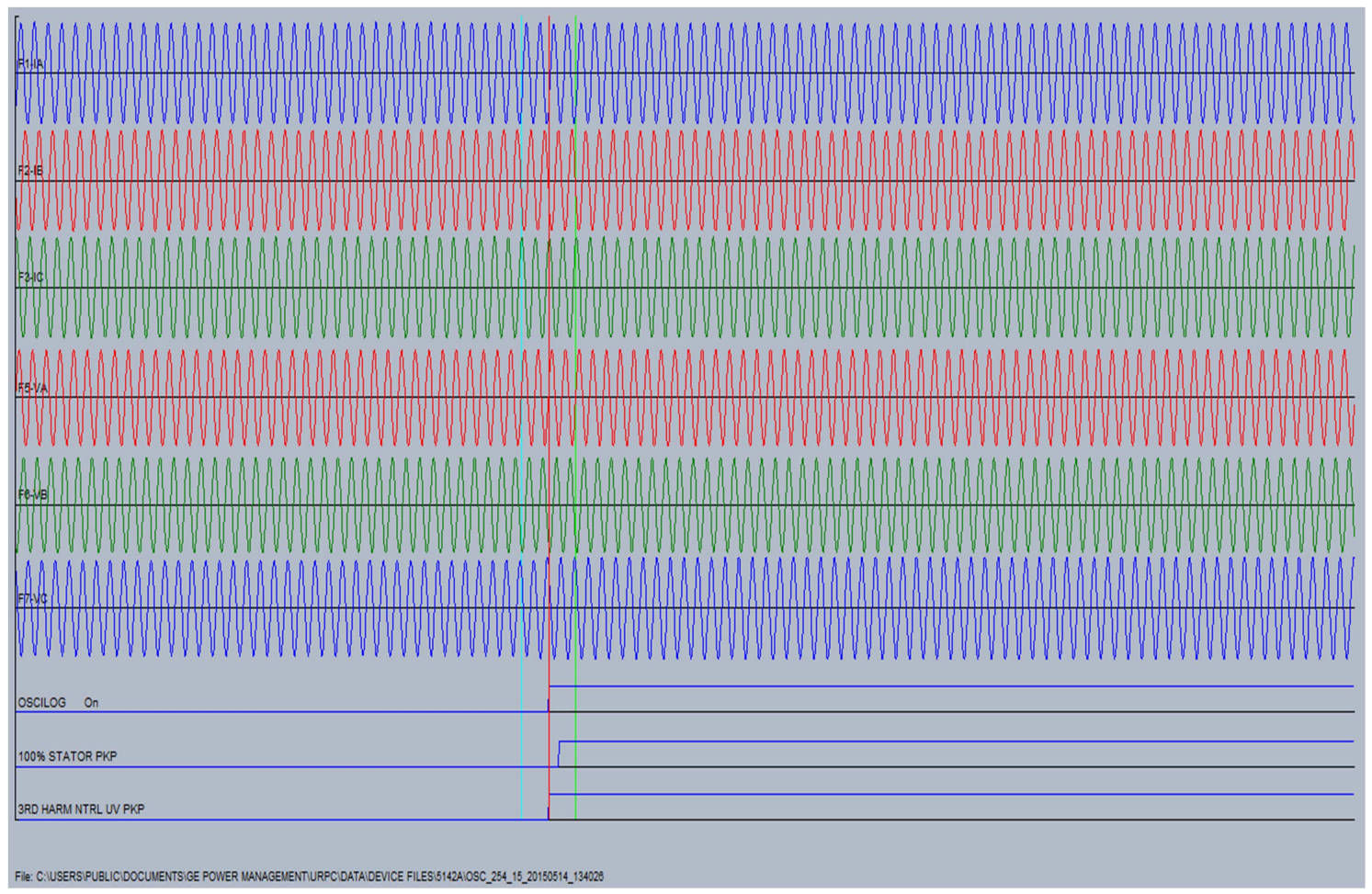

Fonte - Próprio autor. 
Figura 5.22 - Curto-circuito fase-terra no estator a $5 \%$ do centro estrela - carga leve.

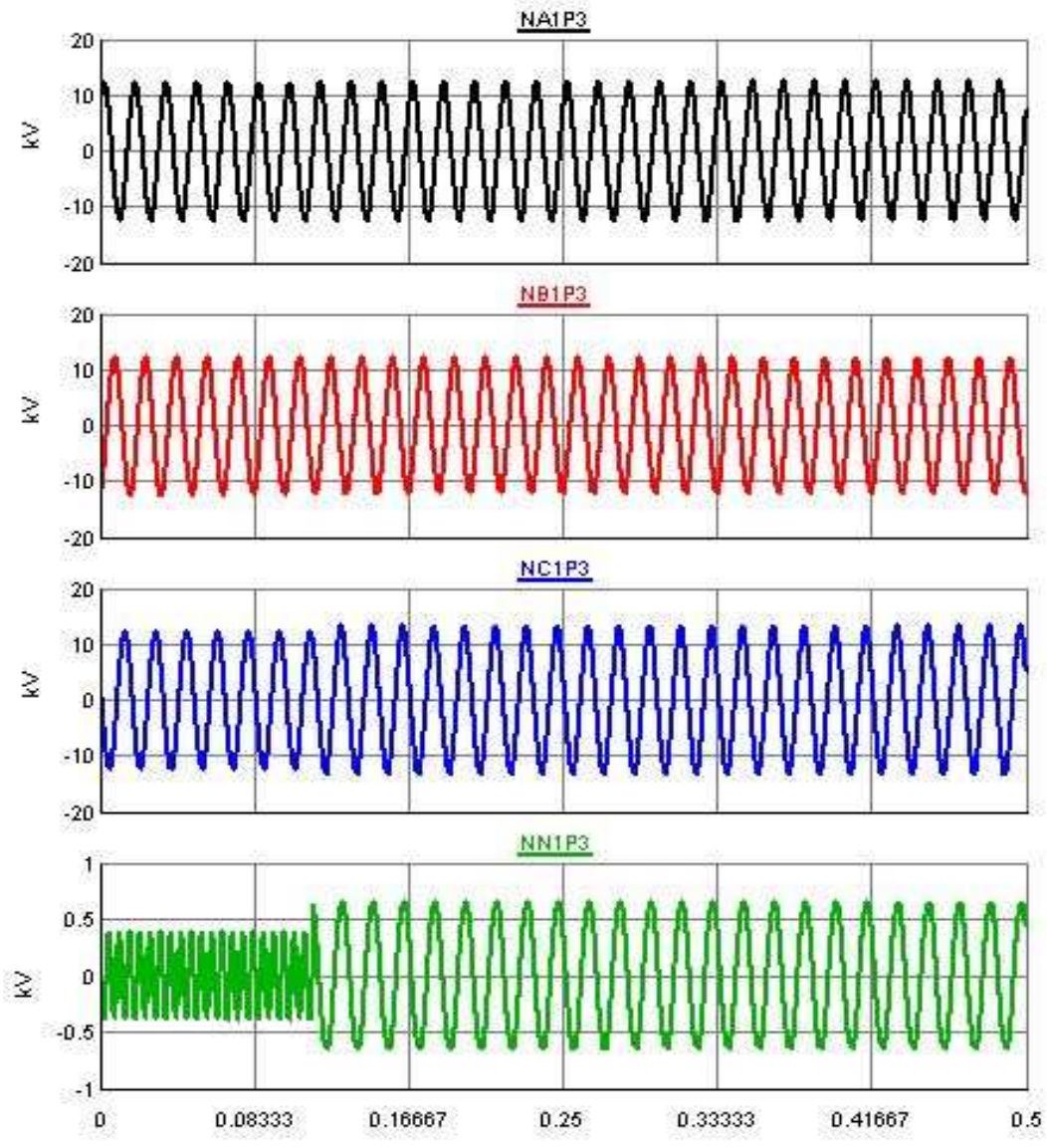

\begin{tabular}{|c|c|c|c|c|c|c|}
\hline Event Record/, & SUB514 & 2: 5142A: Actual Valu & Ies: Records & 口 & 回 & $\Sigma 3$ \\
\hline File Name & & C:VUsers $\backslash$ Public $\backslash D$ & Documents \GE Power Manac & entsu & RPCID & ata' \\
\hline Date / Time of Las & Clear & Thursday, May 14, & $201517: 57: 09$ & & & \\
\hline Events Since Last & Clear & 22 & Shown Number of Events & & 22 & \\
\hline 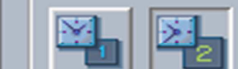 & & 0 days $0 \mathrm{~h}$ : & $0 \mathrm{~m}: 0.999843 \mathrm{~s}$ & $\nabla$ & वर & \\
\hline Event Number & & Date/Time & Cause & & Data & \\
\hline 22 & May 14 & $01517: 59: 41.831652$ & OPEN $\quad$ Off & & & \\
\hline 21 & May 14 & 015 17:59:41.831652 & TRIP $\quad$ Off & & & \\
\hline 20 & May 14 & 015 17:59:41.831652 & OSCILOG Off & & & \\
\hline 19 & May 14 & 015 17:59:41.831652 & OPEN $\quad$ Off & & & \\
\hline 18 & May 14 & 015 17:59:41.831652 & GEN BKR TRIP Off & & & \\
\hline 17 & May 14 & 015 17:59:41.831652 & $100 \%$ STATOR STG2 DPO & & & \\
\hline 16 & May 14 & 015 17:59:41.831652 & $100 \%$ STATOR STG 1 DPO & & & \\
\hline 15 & May 14 & 015 17:59:41.829581 & CLOSE_BRK On & & & \\
\hline 14 & May 14 & $01517: 59: 41.829581$ & ONLINE Off & & & \\
\hline 13 & May 14 & $.01517: 59: 41.825588$ & RTDS Off & & & \\
\hline 12 & May 14 & $01517: 59: 41.819150$ & OPEN & & & \\
\hline 11 & May 14 & $01517: 59: 41.819150$ & TRIP & & & \\
\hline 10 & May 14 & 015 17:59:41.819150 & OPEN $\quad$ On & & & \\
\hline 9 & May 14 & 015 17:59:41.819150 & GEN BKR TRIP On & & & \\
\hline 8 & May 14 & 015 17:59:41.819150 & 3RD HARIM NTRL UV OP & & & \\
\hline 7 & May 14 & .015 17:59:40.831800 & $100 \%$ STATOR STG2 PKP & & & \\
\hline 6 & May 14 & 015 17:59:40.831800 & $100 \%$ STATOR STG1 PKP & & & \\
\hline 5 & May 14 & 015 17:59:40.819307 & OSCILLOGRAPHY TRIG'D & & $\infty$ & \\
\hline 4 & May 14 & 015 17:59:40.819307 & OSCILOG On & & & \\
\hline 3 & May 14 & 015 17:59:40.819307 & 3RD HARIM NTRL UV PKP & & & \\
\hline 2 & May 14 & .015 17:57:16.307724 & CLOSE_BRK Off & & & \\
\hline 1 & May 14 & .015 17:57:09.299510 & EVENTS CLEARED & & & \\
\hline
\end{tabular}

Fonte - Própiao autor. 


\subsubsection{SIMULAÇÃO DE FALTAS NAS LINHAS DE 345 KV}

Para avaliar o desempenho das funções de proteção que fornecem cobertura de retaguarda para as linhas de transmissão, simulou-se uma falta dupla-fase $(A B)$ no final da linha de transmissão de circuito simples. Nesse ensaio, considerou-se uma resistência de arco de 0,5 Ohms, visando avaliar se o ajuste adotado fornecia adequada cobertura para a resistência de falta. Os resultados obtidos são mostrados na oscilografia e no registro de eventos das figuras 5.23 e 5.24, respectivamente. Pode-se observar que a zona 1 da função 21 detectou e isolou a falta com um delay de $1.0 \mathrm{seg}$, conforme esperado. Observa-se também a partida das funções de sequência negativa (desbalanço de corrente).

Figura 5.23 - Curto-circuito dupla-fase (AB) no final da linha de transmissão $-R_{\text {falta }}=0,5$ Ohms.

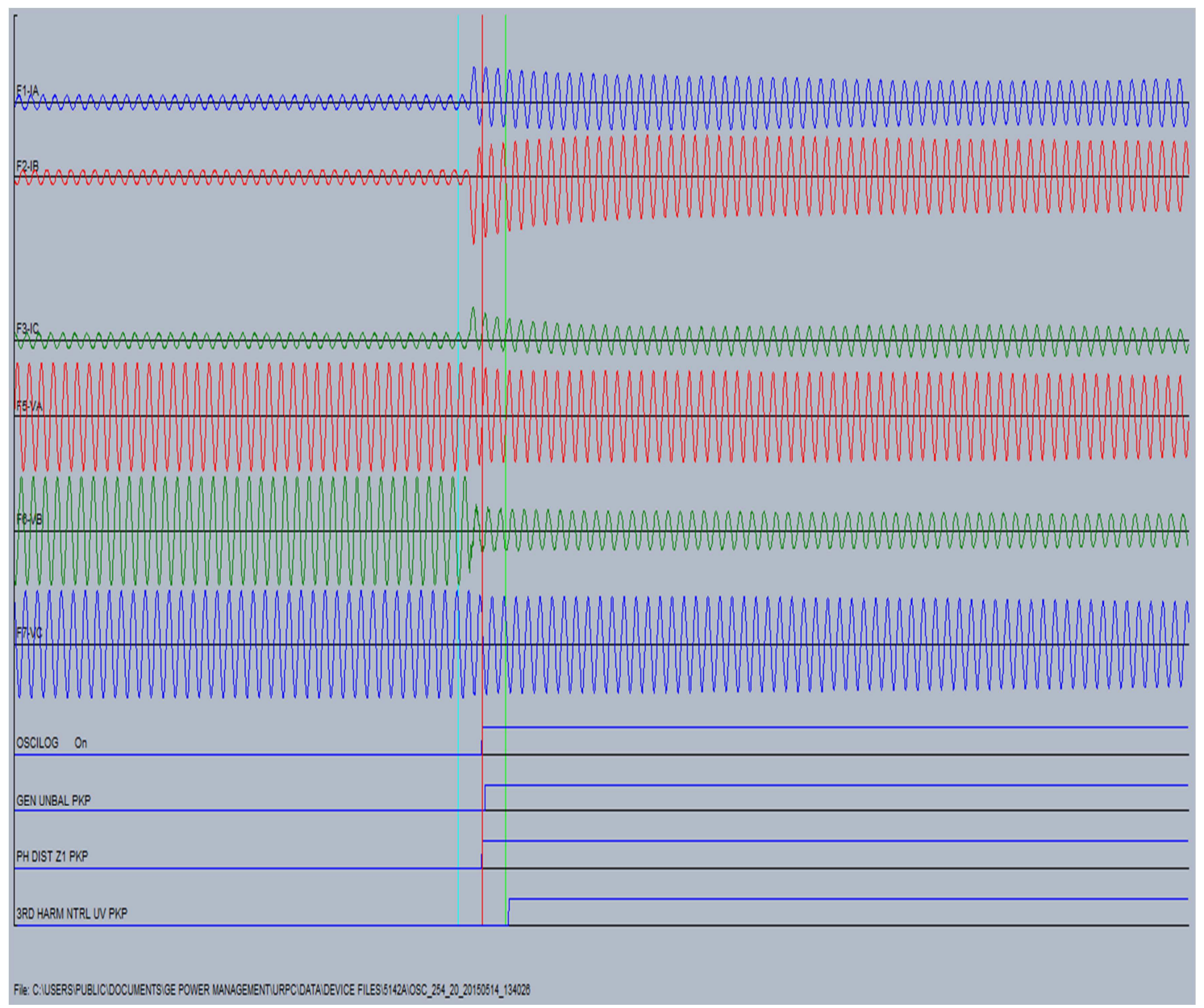

Fonte - Próprio autor. 
Figura 5.24 - Curto-circuito dupla-fase $(A B)$ no final da $L T\left(R_{\text {falta }}=0,5\right.$ Ohms).

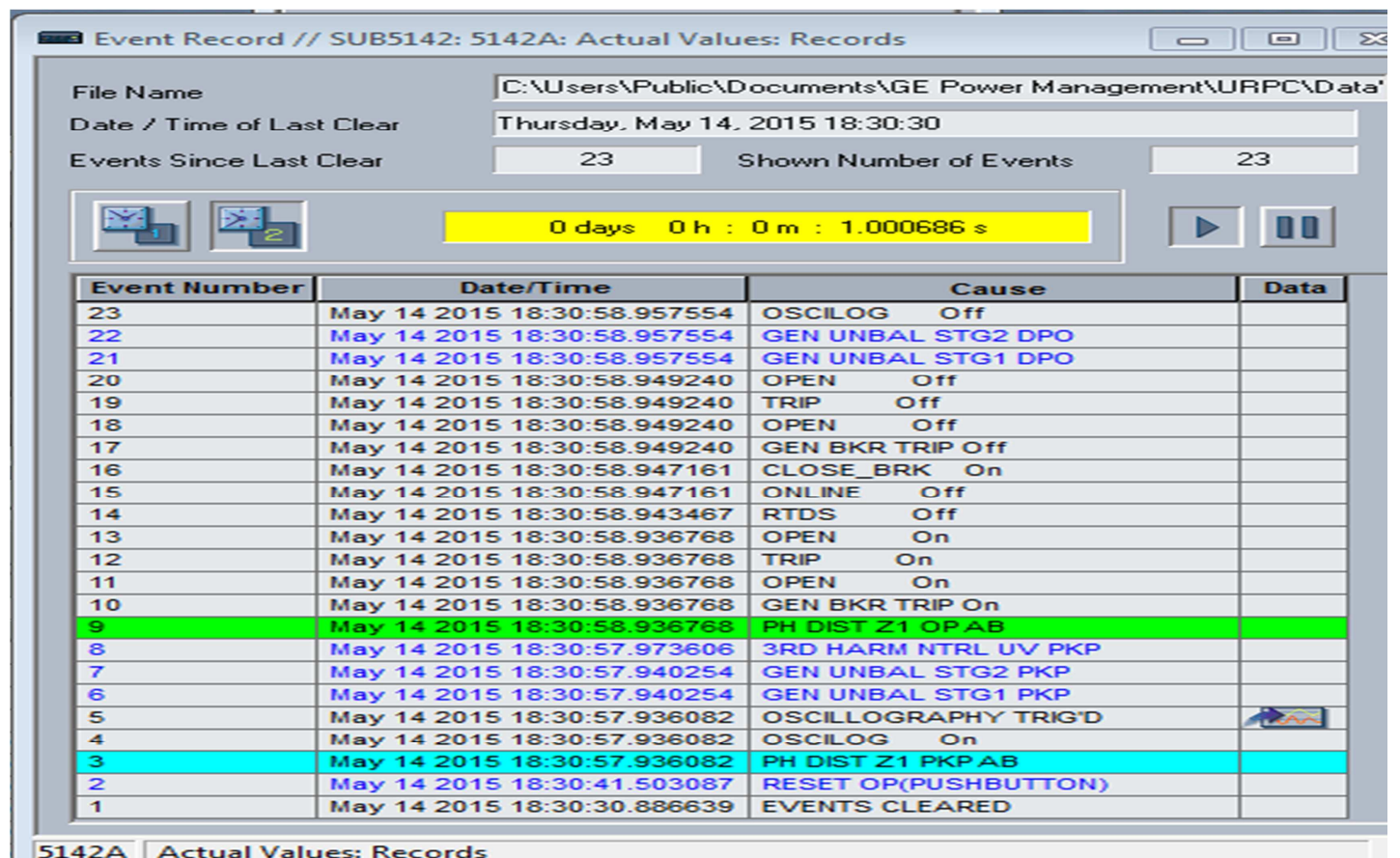

Fonte - Próprio autor.

\subsubsection{SIMULAÇÃO DE PERDA DE EXCITAÇÃO}

Este ensaio foi realizado abrindo-se subitamente o disjuntor de campo estando o gerador operando em regime permante. Da oscilografia mostrada na figura 5.25 observa-se o correto funcionamento da função 40 (perda de excitação).

Figura 5.25 - Perda de Excitação do Gerador

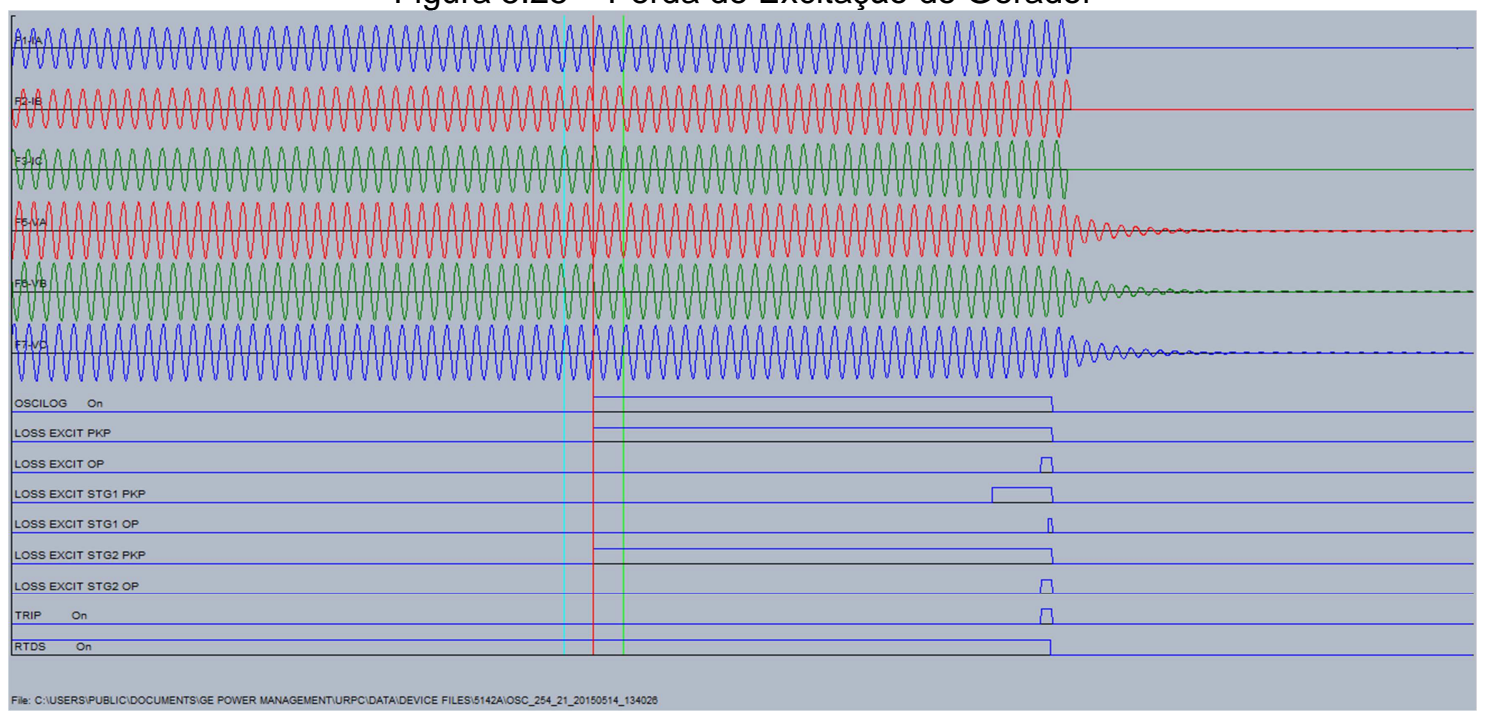

Fonte - Próprio autor. 


\subsubsection{SIMULAÇÃO DE MOTORIZAÇÃO DO GERADOR}

Este evento consistiu em alterar o torque mecânico fornecido pela turbina para um valor negativo. No ensaio realizado o torque foi alterado para $-10 \%$ do valor nominal ( $0.1 \mathrm{pu})$, o qual corresponde à potência de motorização fornecida para o gerador da rede exemplo. Na oscilografia da figura 5.26 observa-se a correta atuação da função 32.

Figura 5.26 - Motorização do Gerador.

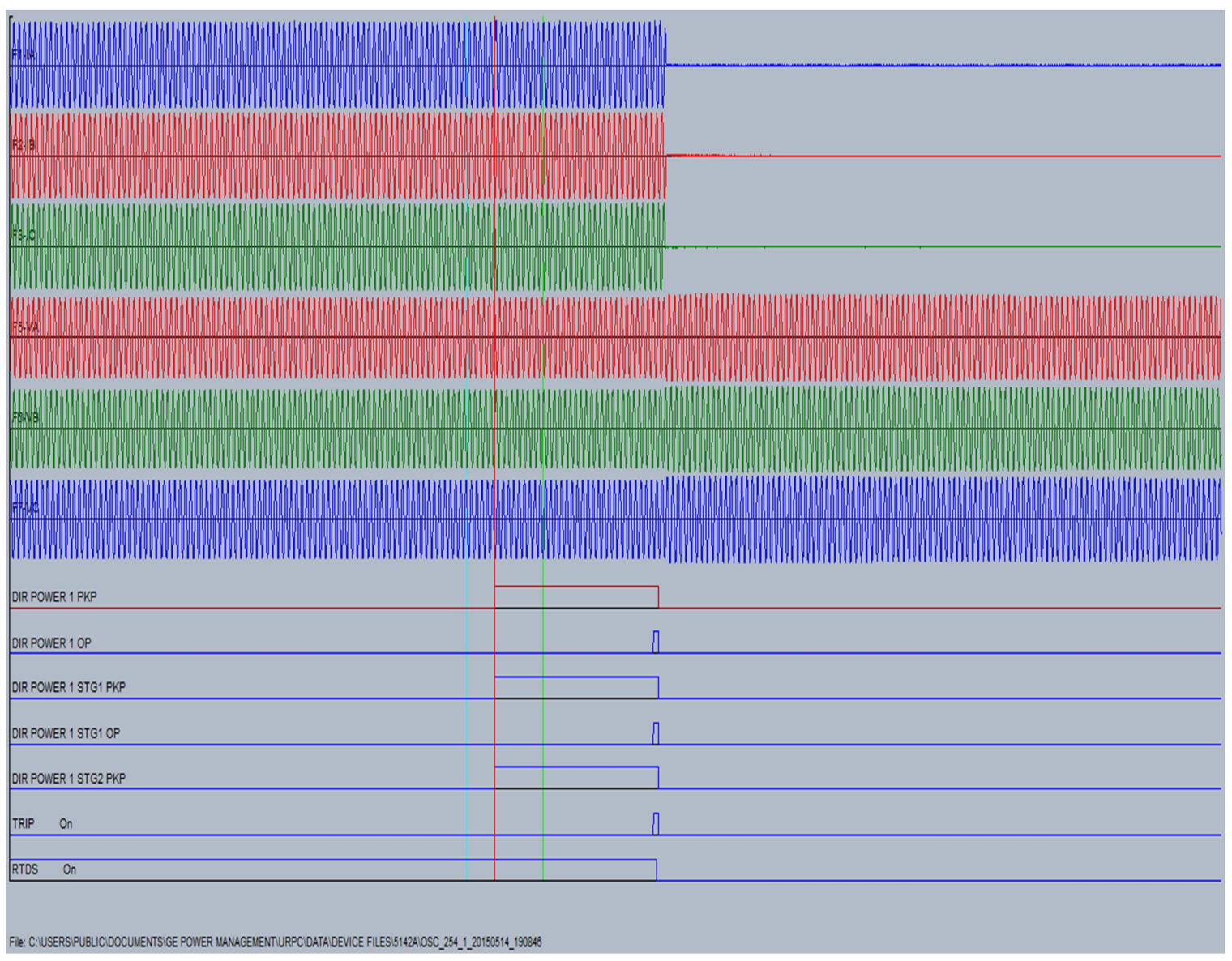

Fonte - Próprio autor. 


\section{CAPÍTULO 6}

\section{CONCLUSÕES E CONSIDERAÇÕES FINAIS}

Neste trabalho abordou-se os principais conceitos relacionados com o projeto de um sistema de proteção para geradores síncronos de grande porte. Inicialmente discutiu-se os diversos aspectos associados com a operação, com a modelagem e com os modos de falha dos geradores que, direta ou indiretamente, impactam a tarefa de proteção. Neste aspecto, particular atenção foi colocada nas formas de aterramento do gerador e nos critérios para dimensionamento do resistor de aterramento.

Em seguida discutiu-se as principais funções de proteção, disponíveis nos modernos IEDs, aplicáveis à proteção dos geradores. Enfase especial foi colocado nas funções voltadas para a proteção de $100 \%$ do enrolamento do estator. Abordou-se também os critérios para ajustes dos parâmetros dessas funções.

No capítulo 3 apresentou-se uma plataforma laboratorial, baseada no simulador de tempo real RTDS, para ensaio do sistema de proteção projetado. Com o uso desse recurso é possível, através de simulações do tipo HardwareIn-the-Loop (HIL), avaliar o desempenho do sistema de proteção frente a inúmeras situações de falta na rede elétrica. Dessa forma, qualquer deficiência ou erro no projeto do sistema de proteção pode ser prontamente detectado e corrigido, antes da instalação e comissionamento desse sistema em campo.

O modelo de gerador disponível na biblioteca do software (RSCAD) desse simulador permite simular faltas fase-terra internas, ao longo do enrolamento do estator. A principal limitação desse modelo, no entanto, reside na hipótese de fluxos puramente senoidais no entreferro do gerador, o que não permite representar as componentes harmônicas presentes nas tensões induzidas nos enrolamentos da máquina. 
Dessa forma, com o uso desse modelo de gerador é possível ensaiar as funções de proteção baseadas somente na componente de $60 \mathrm{~Hz}$ das tensões e correntes como, por exemplo, as funções $87 G$ e 59G. Já o desempenho das funções $27 \mathrm{TH}$ e $100 \%$ do estator não podem ser analisadas, dado que elas respondem às componentes de terceira harmônica.

O ideal seria que a biblioteca do RSCAD possuísse modelos de geradores baseados na teoria WMFA [12], a qual considera no cálculo das indutâncias a distribuição real dos enrolamentos e a forma do arco polar do rotor e ranhuras, permitindo, assim, determinar de forma precisa a distribuição não senoidal da força magneto-motriz no interior da máquina. A carga computacional imposta por esse modelo, no entanto, impede sua implementação em tempo real nas atuais versões de hardware do simulador.

Para superar a limitação apresentada pelo modelo de gerador disponível no RSCAD, discutiu-se no capitulo 4 a utilização de um circuito auxiliar visando inserir nos sinas de tensão, de forma artificial, as componentes de terceira harmônica. Os resultados apresentados por essa solução mostraram-se bastantes adequados e satisfatórios para o ensaio das funções $27 \mathrm{TH}$ e $100 \%$ do estator.

No capítulo 5 foi apresentado um estudo de caso utilizando-se os conceitos discutidos ao longo do trabalho. Para tanto, foi realizado o ajuste das principais funções de proteção para os geradores de uma rede exemplo. $O$ sistema de proteção projetado foi implantado no relé G60 da GE e ensaiado na plataforma descrita no capítulo 4.

Os resultados mostraram que a função $87 G$ fornece uma proteção segura e precisa para as faltas entre fases no estator. Já as faltas fase-terra, ocorrendo no trecho entre $95 \%$ a $90 \%$ a partir dos terminais, devido ao baixo valor da corrente de falta em geradores aterrados através de alta impedância, somente são adequadamente protegidas com o uso da função $59 \mathrm{G}$. No trecho entre os $10 \%$ a $5 \%$, próximo do centro estrela, essa função também não possui sensibilidade para detectar a falta. 
No passado, em virtude das baixissimas correntes produzidas por essa falta, considerava-se desnecessário sua detecção e a parada do gerador. A ocorrência de uma segunda falta fase-terra no mesmo enrolamento, no entanto, irá curto-circuitar o trecho entre os dois pontos defeituosos, podendo produzir a circulação de correntes elevadas e, até evoluir para um outro tipo, essa falta não será detectável pela função $87 \mathrm{G}$. Devido a isso, atualmente considera-se prudente que a primeira falta fase-terra seja prontamente detectada e medidas visando o reparo sejam tomadas. Para detectar as faltas não protegidas pela função $59 \mathrm{G}$ foram desenvolvidas as funções para proteção de $100 \%$ do estator para faltas fase-terra.

Especificamente para essas funções, neste trabalho, deu-se atenção especial às funções baseadas no monitoramento da componente de terceira harmônica (27TH e 100\% do estator), dado que são as de aplicação mais dificil e, com relativa frequência, são fontes de desligamentos indevidos de geradores. O uso da função $27 \mathrm{TH}$ pode ser inviável nas situações em que a percentagem de terceira harmônica nas tensões de fase apresenta uma variação muito elevada entre as diversas condições de carregamento do gerador. Nestes casos, deve-se utilizar a função 100\% do estator, a qual, devido ao princípio de funcionamento de seu algoritmo, apresenta um desempenho muito mais robusto frente a essa variação da terceira harmônica.

Mesmo com essas vantagens, o engenheiro de proteção pode encontrar alguma dificuldade na aplicação da função $100 \%$ do estator nos modernos geradores que podem apresentar uma percentagem de terceira harmônica muito reduzida. Nesses casos a tensão de $180 \mathrm{~Hz}$ pode não possuir magnitude suficiente para uma medição segura. A solução para essas situações seria utilizar a função de injeção de tensão subharmônica (64S) para detecção de faltas fase-terra próximas ao neutro. A desvantagem dessa solução é a necessidade de uso de hardware adicional. 


\section{REFERÊNCIAS BIBLIOGRÀFICAS}

[1] ELMORE W. A. Protective relaying theory and applications. Marcel Dekker, 2004.

[2] REIMERT D. Protective relaying for Power generation systems. Taylor \& Francis, 2006.

[3] HOROWITZ H. S, PHADKE G. A. Power system relaying. Wiley, 2008.

[4] PHADKE G. A, THORP S. J. Computer relaying for Power systems. Wiley, 2009

[5] ANDERSON M. P. Power system protection. IEEE PRESS, 1999.

[6] BOLDEA I. Synchronous generators. Taylor \& Francis, 2006.

[7] BLACKBURN L. J. Protective relaying principles and applications Taylor \& Francis, 2006.

[8] FILHO M. J, MAMEDE R. D. Proteção de sistemas elétricos de potência LTC, 2012

[9] KINDERMANN G. Proteção de sistemas elétricos de potência vol. 3 UFSCEEL, 2008

[10] IEEE, Guide for ac generator protection. IEEE Power engineering society, 2012.

[11] A. PACHECO. Tutorial IEEE protección de generadores síncronos.

[12] DEHKORDI A. B, et al. Protection testing of a $100 \%$ stator ground fault using a phase domain synchronous machine model in real time, Developments in Power System Protection. Managing the Change, on 10th Conference International IET .v. n, p.1,5, March 2010.

[13] ANDERSON M. P. Power system control and stability IEEE Press Power Engineering Series, 2003.

[14] AL-NUAIM, N. A. et al. A novel method for modeling dynamic air-gap eccentricity in synchronous machines based on modified winding function theory. Energy Conversion, On IEEE Transactions. v.13, n.2, p.156,162, Jun 1998.

[15] DEHKORDI A. B., Improved Models of Electric Machines for Real-Time Digital Simulator, Thesis University of Manitoba Winnipeg, 2010.

[16] LUO X, Y. et al. Multiple coupled circuit modeling of induction machines. IEEE Trans. Industry Applications. v. 31 n. 2, p. 311-318, Mar-Abr, 1995.

[17] SILVA ROGÉRIO C S. Proteção diferencial de geradores síncronos. Tese Universidade São Paulo - São Carlos, 2012.

[18] MOScoso. M, et al. Improvements to transformer differential protection - Design and test experience. Universities Power Engineering Conference (UPEC), 47th International .v. n. p.1,6, 4-7 Sept. 2012.

[19] NETI P. Stator fault analysis of synchronous machines, Ph. D. Thesis, University of Victoria. IEEE Trans Power System. v. 22, n. 3, p. 1221-1230, Aug, 2007.

[20] CHARLES J. M, et al. Coordination of generator protection with generator excitation control and generator capability. Pulp and Paper 
Industry Technical Conference. 54th Conference Annual Record .v. n. p.62,76, 22-27 June 2008

[21] MOZINA, C.J. 15 years of experience with $100 \%$ generator stator ground fault protection- What works, what doesn't and why. Protective Relay Engineers. for 62nd Conference Annual . v. n. p.92,106, March 2009.

[22] COURY V. D, OLESKOVICZ M, GIOVANINI R. Proteção digital de sistemas elétricos de potência; Dos relés eletromecânicos aos microprocessados inteligentes. USP/EESC, 2007.

[23] APPLICATIONS FOR SIPROTEC FOR PROTECTION RELAYS, Siemens Aktiengesellschaft, Power Transmission and Distribution energy Automation Division, Nuremberg Germany, January 2005.

[24] ROCKFELLER, G. D. Fault Protection with a digital computer, IEEE Transactions Power Applications Systems. v. PAS 88, p. 438 - 462, Apr. 1969.

[25] GILL, S. H. A Microprocessor based system for protecting bus bars. A Thesis (doctor philosophy). Department of electrical engineering, University of Saskatchewan, Saskatoon, Saskatchewan. Canada, Mar. 2000.

[26] CHEN, M. M. et al. Field Experience with a Digital System for Transmission Line Protection, Power Apparatus and Systems, on IEEE Transactions. v.PAS-98. n.5, pp.1796,1805, Sept. 1979.

[27] BULGARELLI R. Proteção térmica de motores de indução trifásicos industriales Tese Universidade de São Paulo, 2006.

[28] THE POWER ENGINEERING EDUCATION COMMITTEE, POWER SYSTEM RELAYING COMMITTEE. Tutorial IEEE de protección de generadores síncronos.

[29] ÁLVAREZ JUÁREZ M.A, Estudio de la protección diferencial de un generador síncrono, tesis México 2012.

[30] ZIEGLER, G. Numerical differential protection principles and applications. Siemens 2005.

[31] POPE, J. W. A Comparison of 100\% Stator Ground Fault Protection Schemes for Generator Stator Windings. Power Apparatus and Systems, on IEEE Transactions. v.PAS-103, n.4, p.832,840, April 1984.

[32] GRIFFIN C. H. ;POPE J. W. Generator Ground Fault Protection Using Overcurrent, Overvoltage, and Undervoltage Relays. Power Apparatus and 
Systems, on IEEE Transactions . v.PAS-101, n.12, p.4490,4501, Dec. 1982

[33] FULCZK M. Voltage 3rd harmonic in generator stator winding at changes in generator load conditions. Electric Machines and Drives Conference. IEMDC'03. IEEE International . v.3, n, p.1476,1482 v.3, 1-4 June 2003

[34] KUFEEL R. A Fully Digital Power System Simulator Operating in Real Time. Digital Power System Simulators, 1995, ICDS '95,on first Conference International. v. n., p.19, 5-7 April 1995

[35] DEHKORDI A.B. Permanent magnet synchronous machine model for real - time simulation, International conference on power systems transients. Canada, 2005.

[36] DEHKORDI A. B; GOLE A. M. A real time model for testing stator-ground fault protection schemes of synchronous machines. International conference on power systems. Canada, 2009.

[37] MAGUIRE T; GIESBRECHT J. Small time-step $(<2 \mu \mathrm{sec})$ VSC model for the real time digital simulator. International conference on Power system transients. Canada, 2005.

[38] IJB TREINAMENTOS. Proteção de geradores síncronos. Desenvolvimento profissional 2012.

[39] ABRAGE. Associção Brasileira das Grandes Empresas Geradoras de Energia Elétrica.

[40] MARQUES DE LIMA J. C. Aspectos de proteção e controle do gerador síncrono subexcitado. Tese Pontifícia Universidade Católica de Minas Gerais 2002.

[41] BLANQUEZ, F.R.; et al., Consideration of multi-phase criterion in the differential protection algorithm for high-impedance grounded synchronous generators, Environment and Electrical Engineering (EEEIC), on 2013 12th International Conference, vol., no., p.135,139, 5-8 May 2013

[42] SHI. Z. P, et al. The comparison and analysis for loss of excitation protection schemes in generator protection. Developments in Power Systems Protection. On 11th International Conference, vol., no., p.1,6, 23-26 April 2012

[43] BENMOUYAL G. Impacto do sistema de excitação dos geradores síncronos nos relés e sistemas de proteção. Schweitzer engineering laboratories, Inc.

[44] RTDS TECNOLOGIES Real time digital Simulator set: Power system user manual 2006.

[45] AMERICAM NATIONAL STANDARD FOR CYLINDRICAL SYNCHRONOUS GENERATOR, ANSI/IEEEC-5 0.13-2005.

[46] GUIMARÃES, CARLOS H. C.; RANGEL, RICARDO D. Diagramas operacionais de unidades geradoras, 2009.

[47] CASTRO, CARLOS A. J. Geradores síncronos. Campinas: 2005.

[48] MONTICELLI A, GARCIA A. Introdução a sistemas de energia elétrica2003.

[49] KRAUSE, P. C.; WASYNCZUK, O; SUDHOFF, S. D. Analysis of electric 
machinery McGraw-Hill Singapore, 1995.

[50] SUBRAMANIAM, P.; MALIK O. P. S. Digital simulation of a synchronous generator in direct-phase quantities. Proceedings of the Institution of Electrical Engineers. vol.118, no.1, p.153,160, January 1971

[51] MARTI, J. R; LOUIE, W. A. A phase-domain synchronous generator model including saturation effects. On Power Systems, IEEE Transactions .vol.12, no.1, p.222,229, Feb 1997

[52] REICHMEIDER, P. P. et al. Partitioning of synchronous machine winding for internal faults analysis. Energy, 2000.v.15,n.4,p.372-375,2000

[53] DEHKORDI, A. et al. Development and validation of a comprehensive synchronous machine model for real - time environment. In:IEEE Power energy society general meeting. 2009.p.1.ISSN 1944-9925.

[54] IEEE .Recommended Practice for Excitation System Models for Power System Stability Studies," IEEE Std 421.5-2005 (Revision of IEEE Std 421.51992) , vol., no., p.0_1,85, 2006.

[55] NETI, P.; NANDI, S. Stator Inter-turn Fault Detection of Synchronous Machines Using Field Current Signature Analysis. Industry Applications Conference. 41st IAS Annual Meeting. Conference Record of the 2006 IEEE . Industry Applications. vol.5, no., p.2360,2367, 8-12 Oct. 2006

[56] AL-NUAIM, N.A.; TOLIYAT, H.A. A novel method for modeling dynamic air-gap eccentricity in synchronous machines based on modified winding function theory. On Energy Conversion, IEEE Transactions, vol.13, no.2, p.156,162, Jun 1998

[57] GE INDUSTRIAL SYSTEMS, G60 Generator management relay, Ur series instruction manual, GE Multilin 2009.

[58] DEKORDI A. B., Testing A SEL-300G Generator Protection Relay using RTDS, RTDS Technologies INC, August, 2010.

[59] BIMBHRA P.S. Electrical machinery. Kharnna.India. 2013

[60] MOZINA, C.J., "Implementing NERC guidelines for coordinating generator and transmission protection. Protective Relay Engineers, 2012 65th Annual Conference . vol., no., pp.491,504, 2-5 April 2012

[61] MONARO R.M. Tese: Lógica fuzzy aplicada na melhoria da proteção digital de geradores síncronos. Escola de Engenharia de São Carlos - Brasil -2013. 